\title{
THE DEVELOPMENT OF A MINIATURE FLEXIBLE FLAPPING WING MECHANISM FOR USE IN A ROBOTIC AIR VEHICLE
}

\author{
A Thesis \\ Presented to \\ The Academic Faculty
}

by

Gautam Jadhav

\begin{abstract}
In Partial Fulfillment
Of the Requirements for the Degree

Master of Science in the

School of Mechanical Engineering
\end{abstract}

Georgia Institute of Technology

May 2007 


\section{THE DEVELOPMENT OF A MINIATURE FLEXIBLE FLAPPING WING MECHANISM FOR USE IN A ROBOTIC AIR VEHICLE}

Approved by:

Dr. Kevin C. Massey, Advisor Georgia Tech Research Institute Georgia Institute of Technology

Dr. Wayne J. Book, Advisor School of Mechanical Engineering Georgia Institute of Technology

Dr. David W. Rosen School of Mechanical Engineering Georgia Institute of Technology

Date Approved: March 8, 2007 


\section{ACKNOWLEDGEMENTS}

I wish to thank my thesis advisor, Dr. Kevin Massey for his guidance in this research. I am grateful for the lessons learned under him and the time he took to work with me.

I would like to thank my academic advisor, Dr. Wayne Book for his guidance in my academic endeavors.

I would like to thank Dr. David Rosen for being on my thesis reading committee and taking the time to read this thesis.

Lastly, I would also like to thank my mother and father for their support, without which I would not be here. 


\section{TABLE OF CONTENTS}

ACKNOWLEDGEMENTS

LIST OF TABLES Viii

LIST OF FIGURES $\quad$ ix

LIST OF SYMBOLS AND ABBREVIATIONS xiii

SUMMARY Xiv

CHAPTER 1: INTRODUCTION 1

CHAPTER 2: LITERATURE SURVEY 3

2.1 Lift Generation in Flapping Wing Flight 3

2.2 Thrust Generation in Flapping Wing Flight 5

2.3 Flexible Wings versus Rigid Wings 6

2.4 Current UAVs and Flapping Wing Mechanisms 7

2.5 Wing Geometries of Natural Flappers 12

2.6 Missing Links in Current Research $\quad 14$

CHAPTER 3: MECHANICAL DESIGN REQUIREMENTS 15

$\begin{array}{lll}3.1 & \text { Objective } & 15\end{array}$

3.2 Weight Requirements 15

3.3 Wingspan and Planform Requirements 15

3.4 Flapping Frequency and Speed Requirements 16

3.5 Summary of Requirements 17

$\begin{array}{ll}\text { CHAPTER 4: DESIGN PROCESS } & 18\end{array}$

$\begin{array}{lll}4.1 & \text { Mechanism } & 18\end{array}$ 
4.2 Materials and Dimensions Used 29

4.3 Mechanism Electronics 30

4.4 Weight Reduction Efforts 31

$\begin{array}{lll}4.5 & \text { Wings } & 33\end{array}$

4.5.1 Wing Fabrication Process 34

4.5.2 Wing Flexibility 36

CHAPTER 5: EXPERIMENTAL APPARATUS 43

$\begin{array}{lll}5.1 & \text { Force Balance } & 43\end{array}$

$\begin{array}{lll}5.2 & \text { Springs } & 47\end{array}$

$\begin{array}{lll}5.3 & \text { Wind Tunnel Modification } & 48\end{array}$

CHAPTER 6: TEST EQUIPMENT CALIBRATION 50

6.1 Calibration of Potentiometers 50

6.1.1 Measuring Spring Deflection: Position Transducers 50

$\begin{array}{lll}\text { 6.1.2 Wiring } & 51\end{array}$

6.1.3 Distance Calibration and LabView $\quad 51$

6.2 Calibration of Force Balance 53

6.2.1 Calibration of \pm X Direction (Thrust) 53

6.2.2 Calibration of \pm Y Direction (Lift) 54

6.3 Calibration of Motor and Encoder 56

6.3.1 Wiring of Motor 56

6.3.2 Wiring of the Optical Encoder 56

6.3.3 Encoder Calibration and LabView $\quad 57$

$\begin{array}{lll}6.4 & \text { Data Acquisition } & 58\end{array}$ 
6.5 Angle of Attack Calibration 58

CHAPTER 7: TESTING 60

$\begin{array}{lll}7.1 & \text { Testing Approach: Test Matrix } & 60\end{array}$

7.2 Encoder Position, Wing Tip and Root Position Correlation 62

7.3 Filtering of Force Balance Inertial Effects 64

7.4 Aerodynamic Forces Generated Without Flapping 66

CHAPTER 8: ANALYSIS OF RESULTS

$\begin{array}{lll}\text { 8.1 Wing } 1 \text { Phase Lag } & 69\end{array}$

$\begin{array}{lll}\text { 8.2 Wing } 2 \text { Phase Lag } & 73\end{array}$

$\begin{array}{lll}\text { 8.3 Wing Pitching Motions } & 76\end{array}$

$\begin{array}{lll}\text { 8.4 Analysis of } 1^{\text {st }} \text { Generation Wing } & 78\end{array}$

8.4.1 Results: Lift and Thrust Force vs. Time 78

8.4.2 Results: Lift and Thrust Force vs. Wing Position (Phase) 80

8.4.3 Lift and Thrust Data to High Speed Video Correlation 82

8.4.4 Wing 1 Velocity Analysis $\quad 89$

8.5 Analysis of $2^{\text {nd }}$ Generation Wings 92

8.5.1 Lift and Thrust Data to High Speed Video Correlation 92

$\begin{array}{ll}\text { 8.5.2 Wing 2 Velocity Analysis } & 102\end{array}$

8.6 Summary of Wing 1 and Wing 2 Performance 104

$\begin{array}{ll}\text { CHAPTER 9: UNCERTAINTY ANALYSIS } & 108\end{array}$

$\begin{array}{lll}9.1 & \text { Force Balance Uncertainty } & 108\end{array}$

$\begin{array}{lll}9.2 & \text { Lift and Thrust Uncertainty } & 109\end{array}$

CHAPTER 10: CONCLUDING REMARKS 114 
$\begin{array}{lll}10.1 & \text { Summary } & 114\end{array}$

$\begin{array}{ll}\text { 10.2 Contributions to Research Area } & 117\end{array}$

$\begin{array}{lll}10.3 & \text { Future Work } & 118\end{array}$

$\begin{array}{lr}\text { APPENDIX A: CALIBRATION DATA } & 120\end{array}$

$\begin{array}{ll}\text { APPENDIX B: PLOTS } & 122\end{array}$

$\begin{array}{lr}\text { REFERENCES } & 128\end{array}$ 


\section{LIST OF TABLES}

Table 3.1: Target Design Requirements

Table 4.1: Table of Mechanism Weights Before and After Weight Reduction Efforts

Table 4.2: Weights Applied to Structural Points of Wing 1

Table 4.3: Distributed Loading on Flexible Wing 40

Table 4.4 Weights Applied to Structural Points of Wing 2

Table 4.5: Stiffness Increases from Wing 1 to Wing 2 per Point 41

Table 5.1: Summary of Springs Used for Centering Mechanism in Test Apparatus 47

$\begin{array}{ll}\text { Table 7.1: Test Matrix for Wing } 1 & 60\end{array}$

Table 7.2: Test Matrix for Wing 2

Table 8.1: Summary of Experimental Results 104

Table 9.1: Error Analysis for Force Balance 108

Table A.1: Spring Constant Calibration Data 120

Table A2: Averaged Values of Spring Calibration Data 121 


\section{LIST OF FIGURES}

Figure 2.1: Unit Force vs. Time for Up and Down Strokes [4] 4

Figure 2.2: Average Lift vs. Frequency [3] 4

Figure 2.3: Lift and Thrust Generation vs. Phase [5] 5

Figure 2.4: Average Thrust vs. Frequency [3] 6

Figure 2.5: Flexible Wing UAV Developed at the University of Florida [9] 9

Figure 2.6: Mechanism Capable of Biaxial Rotation [14] 10

Figure 2.7: Microbat Transmission System and Fabricated UAV [15] 11

Figure 2.8: Drive Mechanism in Toronto Ornithopter [16] 11

Figure 2.9: High Speed Video of Bat Wing [20] 13

Figure 3.1: Planform of a Bat's Wing Showing Structural Members [22] 16

Figure 3.2: Flight Speed of Flyers vs. Mass [6] 17

Figure 4.1: Isometric View of Entire Flapping Mechanism (CAD Model) 18

Figure 4.2: Top View of Flapping Mechanism (CAD Model) 19

Figure 4.3: Left Side View of Flapping Mechanism (CAD Model) 20

Figure 4.4: Speed vs. Torque Curve for 2232 Micromo Motor [24] 23

Figure 4.5: Close-Up View (Top) of Drive Mechanism (CAD Model) 24

Figure 4.6: Close-Up of Flywheel and Crankshaft Connecting Pins (CAD Model) 25

Figure 4.7: Close-Up of Swivel Joints and Pitching Assembly (CAD Model) 27

Figure 4.8: Isometric View of Flapping Device 28

Figure 4.9: Top View of Flapping Device (Without Motor and Coupling) 28

Figure 4.10: Front View of Flapping Device 29 
Figure 4.11: Close-Up View of Swivel Joints After Weight Reduction Efforts

Figure 4.12: Encoder Hub Disk and Module Used

Figure 4.13: Isometric View of Mechanism After Weight Reduction Efforts

Figure 4.14: Top View of Mechanism After Weight Reduction Efforts

Figure 4.15: View of Wing Mold - One Half (CAD Model)

Figure 4.16: 7 Structural Points of Flexible Wing 1

Figure 4.17: Wing 1 Stiffness Curves

Figure 4.18: Wing 2 Stiffness Curves

Figure 5.1: Test Superstructure and Flapping Mechanism (CAD Model)

Figure 5.2: Close-Up of Linear Bearing Housing Assembly (CAD Model)

Figure 5.3: Close-Up of Mechanism on Center Shaft (CAD Model)

Figure 5.4: Actual View of Mechanism in Test Assembly

Figure 5.5: Actual View of Wind Tunnel After Modifications

Figure 6.1: View of Force Measurement for Drag and Thrust

Figure 6.2 : View of Measuring Spring Constant of Bottom Spring

Figure 6.3: Angle of Attack Calibration Tool

Figure 7.1: Encoder Position, Wing Root \& Tip Displacements vs. Time

Figure 7.2: Setup for Spring Dynamics Correction

Figure 7.3: Lift \& Drag Force vs. Time @ 5 m/s Without Flapping

Figure 7.4: Lift vs. Angle of Attack @ 5 m/s Without Flapping 68

Figure 8.1: High Speed Video Still Image of Wing 1 Beginning Upstroke 69

Figure 8.2: High Speed Video Still Image of Wing 1 on Downstroke 70

Figure 8.3: Wing 1 Root \& Tip Displacement with Curve Fits 
Figure 8.4: High Speed Video Still Image of Wing 2 Beginning Upstroke

Figure 8.5: High Speed Video Still Image of Wing 2 Beginning Downstroke 74

Figure 8.6: Wing 2 Root \& Tip Displacement with Curve Fits 75

Figure 8.7: Wing 1 Pitching Motions Produced During Flapping 77

Figure 8.8: Lift \& Thrust vs. Time @ 0 m/s, 3 Hz, \& $0^{\circ}$ AoA 79

Figure 8.9: Lift \& Thrust vs. Phase @ 0 m/s, 3 Hz, \& $0^{\circ}$ AoA 80

Figure 8.10: Wing 1 Position, Force \& Phase Correlation @ 0 m/s, 3 Hz, \& $0^{\circ}$ AoA 84

Figure 8.11: Wing 1 Position, Force \& Phase Correlation @ 5 m/s, 3 Hz, \& 7.5 AoA 86

Figure 8.12: Wing 1 Position, Force \& Phase Correlation @ 5 m/s, 4 Hz, \& 7.5 AoA 87

Figure 8.13: Wing 1 Position, Force \& Phase Correlation @ 5 m/s, 4 Hz, \& 7.5 AoA 88

Figure 8.14: High Speed Video Showing Stall @ 5 m/s, 4 Hz, 15ํAoA 89

Figure 8.15: Wing 2 Position, Force \& Phase Correlation @ 0 m/s, 3 Hz, \& $0^{\circ}$ AoA 93

Figure 8.16: Wing 2 Position, Force \& Phase Correlation @ 5 m/s, 3 Hz, \& 7.5 AoA 95

Figure 8.17: Relative AoAs for Wing1 and Wing 2, 4 inches Outboard from Root 96

Figure 8.18: Relative AoAs for Wing 1 and Wing 2, at the $3 / 4$ Span Point 98

Figure 8.19: Wing 2 Position, Force \& Phase Correlation @ 5 m/s, 4 Hz, \& 7.5 AoA 99

Figure 8.20: Aerodynamic Force Vectors vs. Wing Position in Flapping Cycle 100

Figure 8.21: Wing 2 Position, Force \& Phase Correlation @ 5 m/s, 4 Hz, \& 15 AoA 101

Figure 8.22: Lift \& Thrust vs. Phase @ 0 m/s, 3 Hz, \& $0^{\circ}$ AoA 106

Figure 8.23: Lift \& Thrust vs. Phase @ 5 m/s, 3 Hz, \& 7.5 AoA 106

Figure 8.24: Lift \& Thrust vs. Phase @ 5 m/s, 4 Hz, \& 7.5 AoA 107

Figure 8.25: Lift \& Thrust vs. Phase @ 5 m/s, 4 Hz, \& 15AoA

Figure 9.1: Uncertainty Curve for $5 \mathrm{~m} / \mathrm{s}, 4 \mathrm{~Hz}, 7.5^{\circ}$ AoA with Wing 2 
Figure 9.2: Repeatability $5 \mathrm{~m} / \mathrm{s}, 4 \mathrm{~Hz}, 7.5^{\circ}$ AoA with Wing 2

Figure 9.3: Uncertainty Curve for $0 \mathrm{~m} / \mathrm{s}, 3 \mathrm{~Hz}, 0^{\circ}$ AoA with Wing 1

Figure A.1: Spring Constant Data for Force Balance Calibration

Figure B.1: Wing 1 Root, Tip \& Encoder Position vs. Time @ 0 m/s, 2 Hz, 7.5 AoA 122

Figure B.2: Wing 1 Root, Tip \& Encoder Position vs. Time @ 5 m/s, 2 Hz, 7.5 AoA 122

Figure B.3: Wing 1 Root, Tip \& Encoder Position vs. Time @ 5 m/s, 3 Hz, $0^{\circ}$ AoA 123

Figure B.4: Wing 1 Root, Tip \& Encoder Position vs. Time @ 0 m/s, 3 Hz, 7.5 AoA 123

Figure B.5: Wing 1 Root, Tip \& Encoder Position vs. Time @ 5 m/s, 3 Hz, 7.5 AoA 124

Figure B.6: Wing 1 Root, Tip \& Encoder Position vs. Time @ 5 m/s, 4 Hz, $0^{\circ}$ AoA 124

Figure B.7: Wing 1 Root, Tip \& Encoder Position vs. Time @ 5 m/s, 4 Hz, 7.5 AoA 125

Figure B.8: Wing 1 Root, Tip \& Encoder Position vs. Time @ 5 m/s, 4 Hz, 15 AoA 125

Figure B.9: Lift \& Thrust Force vs. Phase at $0 \& 5 \mathrm{~m} / \mathrm{s}, 2 \mathrm{~Hz}, \& 7.5^{\circ}$ AoA

Figure B.10: Lift \& Thrust vs. Phase at $0 \mathrm{~m} / \mathrm{s}, 3 \mathrm{~Hz}, \& 0^{\circ} \& 7.5^{\circ} \mathrm{AoA}$

Figure B.11: Lift \& Thrust vs. Phase at $5 \mathrm{~m} / \mathrm{s}, 3 \mathrm{~Hz}, \& 0^{\circ} \& 7.5^{\circ}$ AoA

Figure B.12: Lift \& Thrust vs. Phase at $5 \mathrm{~m} / \mathrm{s}, 4 \mathrm{~Hz}, \& 0^{\circ}, 7.5^{\circ} \& 15^{\circ} \mathrm{AoA}$ 


\section{LIST OF SYMBOLS AND ABBREVIATIONS}

$\begin{array}{ll}\mathrm{F}_{\mathrm{L}} & \text { Lift Coefficient } \\ \mathrm{F}_{\mathrm{D}} & \text { Drag Force } \\ \mathrm{C}_{\mathrm{L}} & \text { Lift Coefficient } \\ \mathrm{C}_{\mathrm{D}} & \text { Drag Coefficient } \\ \mathrm{C}_{\mathrm{T}} & \text { Thrust Coefficient } \\ \omega & \text { Wing Angular Velocity } \\ \mathrm{c} & \text { Root Cord Length } \\ \mathrm{k}_{\mathrm{FL}} & \text { Reduced Flapping Frequency } \\ \theta & \text { Pitch } \\ \text { AoA } & \text { Angle of Attack }\end{array}$




\section{SUMMARY}

In this study a mechanism which produced flapping and pitching motions was designed and fabricated. These motions were produced by using a single electric motor and by exploiting flexible structures. The aerodynamic forces generated by flexible membrane wings were measured using a two degree of freedom force balance. This force balance measured the aerodynamic forces of lift and thrust. Two sets of wings with varying flexibility were made. Lift and thrust measurements were acquired as the mechanism flapped the wings in a total of thirteen cases. These thirteen cases consisted of zero velocity free stream conditions as well as forward flight conditions of five meters per second. In addition, flapping frequency was varied from two Hertz to four Hertz, while angle of attack offsets varied from zero degrees to fifteen degrees. The four most interesting conditions for both sets of wings were explored in more detail. For each of these conditions, high-speed video of the flapping wing was taken. The images from the video were also correlated with cycle averaged aerodynamic forces produced by the mechanism. Several observations were made regarding the behavior of flexible flapping wings that should aid in the design of future flexible flapping wing vehicles. 


\section{CHAPTER 1: INTRODUCTION}

Over the past twenty-five years, interest in small-unmanned aerial vehicles (UAVs) has greatly increased. Small UAVs range in size from the micro range, having a wingspan of a few inches and weighing 80 grams, to the miniature range where they can have spans up to 20 feet across and weigh up to 25 kilograms. Most of the UAVs in production and use today are fixed wing airplanes. This means they employ traditional methods of lift and thrust: a propeller for thrust and rigidly attached wings relying heavily on the free stream velocity for lift. These vehicles are capable of performing wide range of missions, having both military and civilian applications. These include surveillance, communication relay links, decoys, and detection of biological, chemical and radiological materials. However, there is another realm of UAVs that is just beginning to be explored, those which utilize flapping wings. These types of vehicles are also known as ornithopters.

The motivation for the development of an ornithopter is based on the argument that flapping wing flight, at small scale, is more efficient than traditional fixed wing and rotary flight [1]. Flapping wing flight more closely mimics natural flight and has potential for being lower in weight and having greater endurance. In addition, strategic and stealth applications for flapping wing vehicles are evident as well, as they mimic natural flyers and could perch. Thus, flapping wing air vehicles may provide a significant advantage over their fixed-wing counterparts [1].

Recent approaches involve analyzing bird, bat and insect flight [1]. This has led to an increased understanding of the mechanisms that biological 'machines' which use 
flapping to provide lift and thrust, but this knowledge has not readily transferred to a machine analog. In analyzing natural flyers, the issue of wing flexibility has emerged, with many insect and bird wings being complex elastic structures. It has been shown in certain studies that the flexible nature of membrane type wings can actually increase aerodynamic stability by damping unsteady forces and storing elastic energy [2]. While some vehicles and mechanisms that utilize flapping wing flight have been demonstrated [3], few have been successful. Furthermore, very little has been done to understand the role of wing flexibility, and thus there is much more to be learned in this field.

The objective of this research was to design, construct, and test a small, low inertia device capable of producing flapping and pitching that utilize flexible wings to produce both lift and thrust. This device needed to provide plunging motions (pure flapping) in addition to pitching motions and was to be powered by a DC micro-motor. The device built in this stage was not designed to be a complete flapping wing robot capable of sustained flight. Rather it was a mechatronic device which could provide a suitable platform for measuring the forces of lift, drag and thrust. Cost was an issue due to budget restrictions, so it was desired to build the flapping wing mechanism with as many low-cost off the shelf materials as possible. 


\section{CHAPTER 2: LITERATURE SURVEY}

It was mankind's fascination with bird flight which originally spawned the discipline of aerodynamics [2]. In the earliest stages of developing flying vehicles, it was discovered that separating the mechanisms for lift and thrust was the easiest and quickest way to become airborne, thereby freeing the earliest engineers from the fruitless attempts at mimicking animal flight [3]. In the recent years an interest to imitating nature in the development of UAVs has become more popular. Flapping wings have been thought to be more efficient, maneuverable, agile and stealthier than fixed wings. Flapping is also an interesting challenge in mankind's quest to constantly imitate nature.

\subsection{Lift Generation in Flapping Wing Flight}

To begin to understand flapping wing flight, it is necessary to observe when lift is generated during a flapping cycle. A typical cycle in the flight of a flapping wing vehicle consists of a downstroke and an upstroke (Figure 2.1). Lift generation on the various strokes of a flat rigid plate have been studied by Hong et al. [4]. Assuming the wing starts from a maximum height position, at the start of the downstroke, the lift starts to increase. Next is the actual downstroke, where the aerodynamic force peaks. Third is the end of the downstroke, when the lift force starts to decrease. Next is the actual upstroke where aerodynamic forces create negative lift as the wing travels upwards. At the end of the upstroke where negative lift is generated again due to changing wind velocity distributions along the wing's surface [4]. 


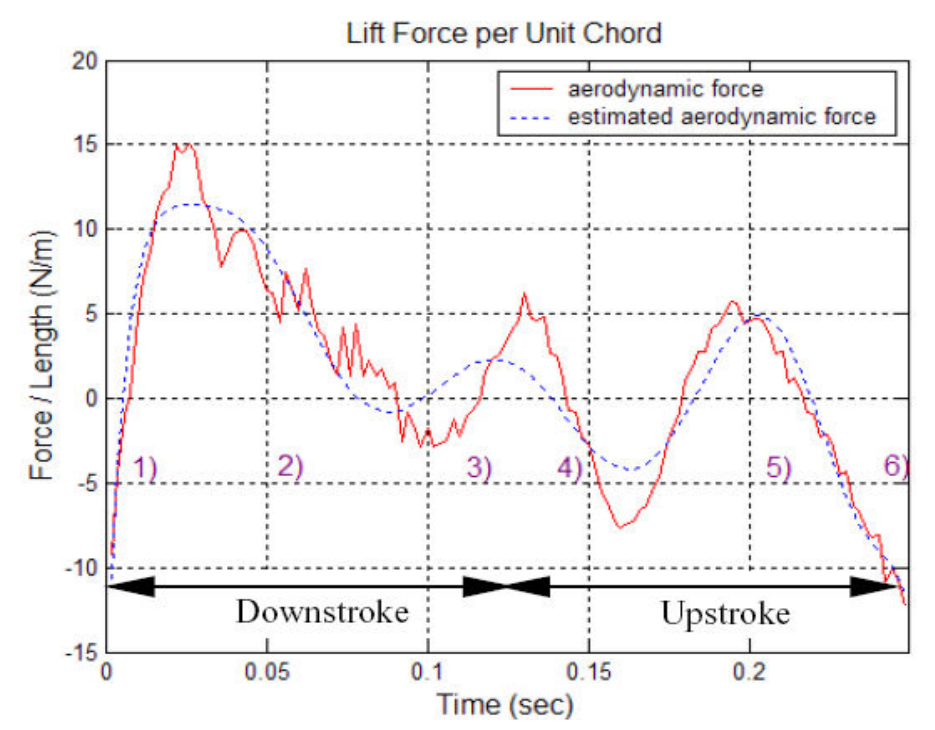

Figure 2.1: Unit Force vs. Time for Up and Down Strokes [4]

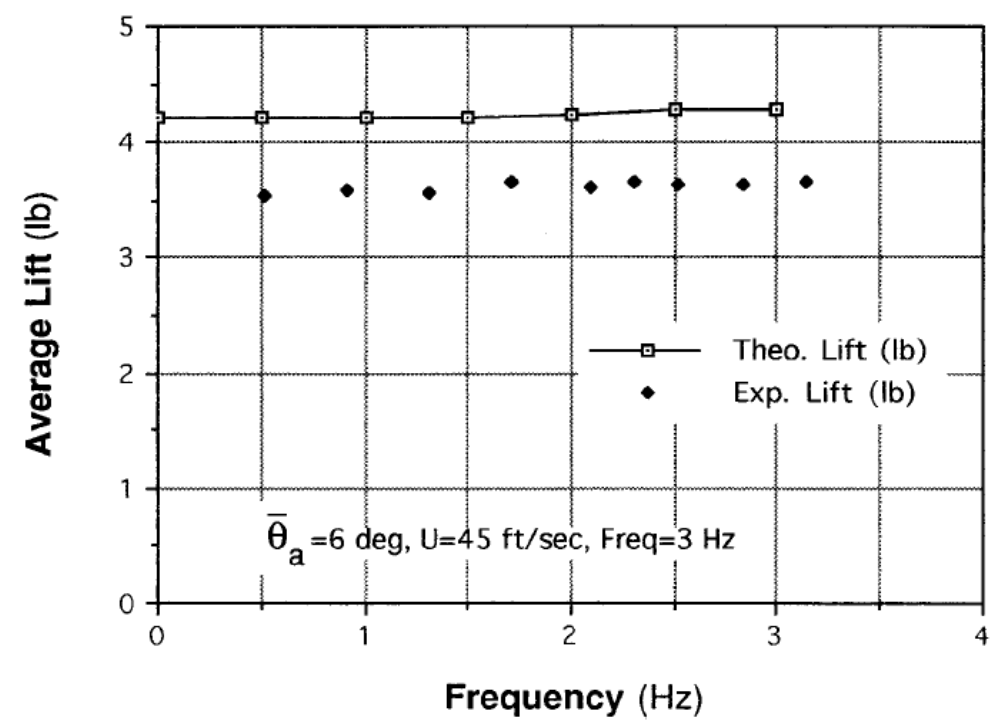

Figure 2.2: Average Lift vs. Frequency [3]

It has been shown that the generation of lift is a fairly weak function of flapping frequency (Figure 2.2) by DeLaurier et al. [3]. There is very little change in average lift values as frequency increases. As the flapping frequency is increased, the amount of lift generated increases slightly. With the above information, the lift force and the dynamics 
can be characterized qualitatively, yielding a better understanding under what frequencies to expect the maximum/minimum lift, and maximum/minimum acceleration during one full stroke. This information was also useful in understanding when during a flapping cycle lift generation could be expected

\subsection{Thrust Generation in Flapping Wing Flight}

In natural flyers, it has been shown that insects take advantage of unsteady aerodynamic phenomena to generate thrusts [1]. The generation of thrust can be broken into 4 parts [4]: First, on the downstroke the wing translates with a fixed collective pitch angle, next near the end of the downstroke, the wing turns so that the blade angle of attack is positive on the upstroke, third is the actual upstroke when the angle of attack is still positive. Fourth is the end of the upstroke/beginning of the downstroke when the wing's angle of attack changes from positive to negative.

Figure 2.3 shows the lift and thrust generation with respect to the phase of a flapping airfoil [5]. The wing starts at a point, labeled as $18^{\circ}$, and then proceeds to complete one full flap (traveling $360^{\circ}$ ) and returning to its starting position. From Figure 2.3, it can be seen that thrust is almost always being generated, but positive lift forces occur primarily on the down stroke.

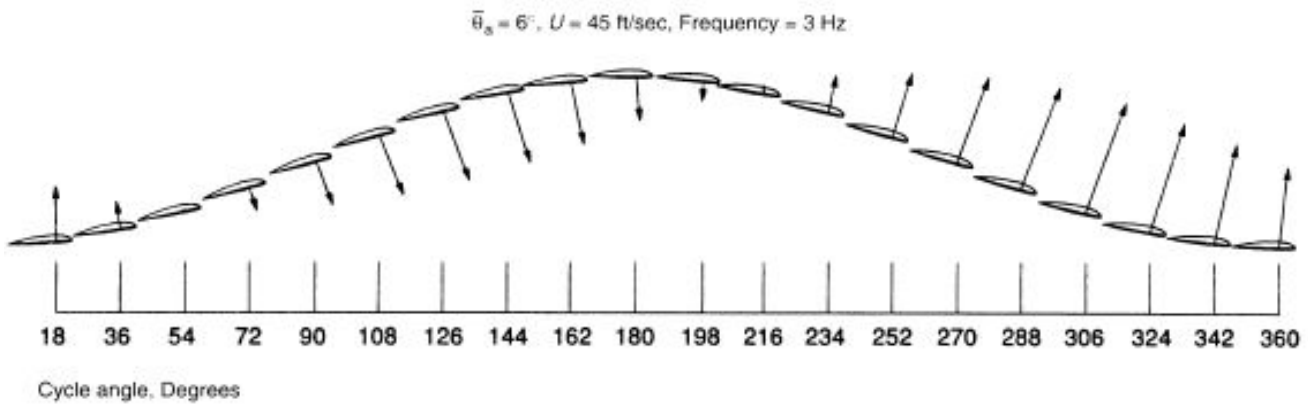

Figure 2.3: Lift and Thrust Generation vs. Phase [5] 
The generation of thrust is also a direct function of flapping frequency [3].

Delaurier et al. have shown that as the flapping frequency increases, so does the average thrust generated. These results can be seen in the following graph:

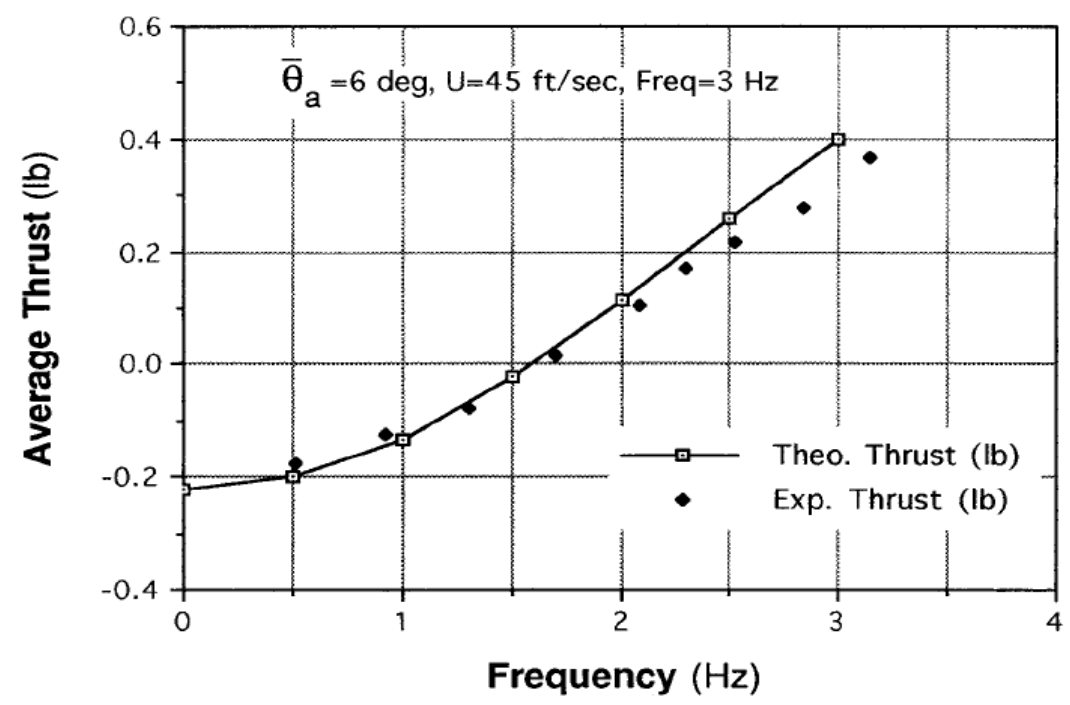

Figure 2.4: Average Thrust vs. Frequency [3]

The above information was useful in understanding the effects of flapping frequency on thrust generation as when to expect thrust forces during a typical flap.

\subsection{Flexible Wings versus Rigid Wings}

Since flapping wing UAVs fly typically at low Reynolds numbers, gusting and disturbances in the flow are more problematic. It has been shown that flapping wing based UAVs have certain advantages compared to their fixed wing counterparts: ability to hover, react more efficiently to gusts, have lower weight, and generate lift without excessive size and weight [8]. Flexible wings have also been shown to be more advantageous than rigid wings, with having higher stall angles by performing adaptive 
washout, and providing smoother flight [8]. In addition, every natural flyer has flexible wings, and noting that nature converges towards the most efficient solution, it can be believed that flexible wings are more advantageous than their rigid counterparts.

It is possible to replace the rigid surface of a wing with a more flexible membrane, while still retaining the stiff structural members. This type of practice has been used for centuries in ship sails, with a stiff mast providing the support while the sail is a membrane material. It has been found that the main advantage of flexible wings is that they facilitate shape adaptation, essentially adapting to the airflow to provide a smoother flight [9]. It has been shown by Ifju et al. a wing changes shape as a function of angle of attack and wind speed [8]. This adaptive washout is produced through extension of the membrane and twisting of the structural members, resulting in angle of attack changes along the span of the wing in response to the oncoming flow [9]. The shape change causes a slightly decreased efficiency in lift, but because of gusting phenomena, the overall lift is maintained. However, as the air speed decreases, the wing recovers to its original position [9]. When there is a decrease in relative airspeed, the angle of attack of the wing increases, and the wing becomes more efficient, resulting in near constant lift. This enables a UAV with flexible wings to fly with exceptional smoothness, even in gusty conditions.

\subsection{Current UAVs and Flapping Wing Mechanisms}

Since this thesis was concerned with designing a flapping wing mechanism, it was useful to see what mechanisms already exist and typical designs (if any) are commonly used. It was found that certain mechanisms were capable of flapping at higher 
frequencies than others. The type of pitch motions varies between the mechanisms as well; some can dynamically change pitch, while others have fixed pitch envelopes. Some of the information learned from mechanisms designed by others was incorporated in Chapter 4, which explains the design process of the mechanism for this thesis.

There are numerous small fixed wing UAVs in use today for a variety of applications. Three of the more common fixed wing UAVs are the Dragon Eye [10], Mite 2 [11], and Black Widow [12]. All three of these UAVs use traditional methods of obtaining flight. They have flaps and rudders for directional controls and a propeller is the main source of thrust. The propellers in these UAVs are powered by small battery powered electric motors, and are capable for flying up to 60 minutes at speeds of up to 40 miles per hour depending on their size. There are also some UAVs which use miniature jet engines to provide thrust.

Work has also been done on fixed-flexible wing UAVs. Ifju et al. [9] have designed a series of flexible, fixed-wing UAVs (Figure 2.5) in an effort to determine the role of wing flexibility in flight. Their basic structure and wingspan is similar to a small aerial vehicle such as the Mite, and employs the use of a propeller to produce thrust. The difference is that this mechanism has flexible wings. The wings are thin, un-cambered and have been shown to be more efficient than those with significant thickness. 


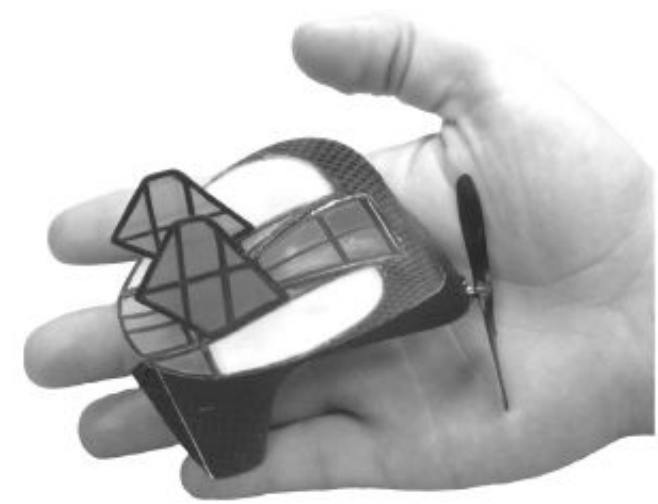

Figure 2.5: Flexible Wing UAV Developed at the University of Florida [9]

Various flapping wing mechanisms have been developed to measure aerodynamic forces. Some have been capable of sustained flight [13], [14], [15] and [16]. Considerable efforts have been done to understand the nature of flapping rigid plates in water [13]. This mechanism developed by Isaac et al., produced both dynamically changing pitching and flapping motions. The main flapping was driven by a motor which drove a flywheel with a connecting rod. The connecting rod was connected to the wing through the use of a fixed pivot joint. Pitching motions were done through the use of a servomotor. This motor was attached below the fixed pivot point so the entire motor assembly was flapped as well, with the servomotor directly driving the pitch change of the wing. This is one of the very few mechanisms which can produce controllable changing pitching and plunging motions on the fly. The flapping frequencies used are low, and the mechanism is flapped in water. Producing a mechanism which can produce higher flapping frequencies and dynamically controllable pitching motions on the fly is a significant challenge.

Mcintosh et al. [14] have been successful in creating a mechanism which is capable of flapping two rigid wings while being able to change the pitching angle. This 
mechanism has a distinct feature: both the pitching and flapping mechanisms are created through the use of a single actuator. The motion created by this mechanism is similar to many insects, wherein the wing is rotated at the top and bottom of each flap. Flapping frequencies of 1.2 to $1.9 \mathrm{~Hz}$ could be generated. The drive mechanism is again a connecting rod and gear assembly to produce the main plunging motions. Pitching motion is generated through the use of various bending and torsion springs and a pin and follower assembly. The mechanism varies its pitch during the flap. It is not controllable on the fly, meaning the mechanism must be stopped and reconfigured to produce a different set of pitching potions. An image of this mechanism can be seen in Figure 2.6.

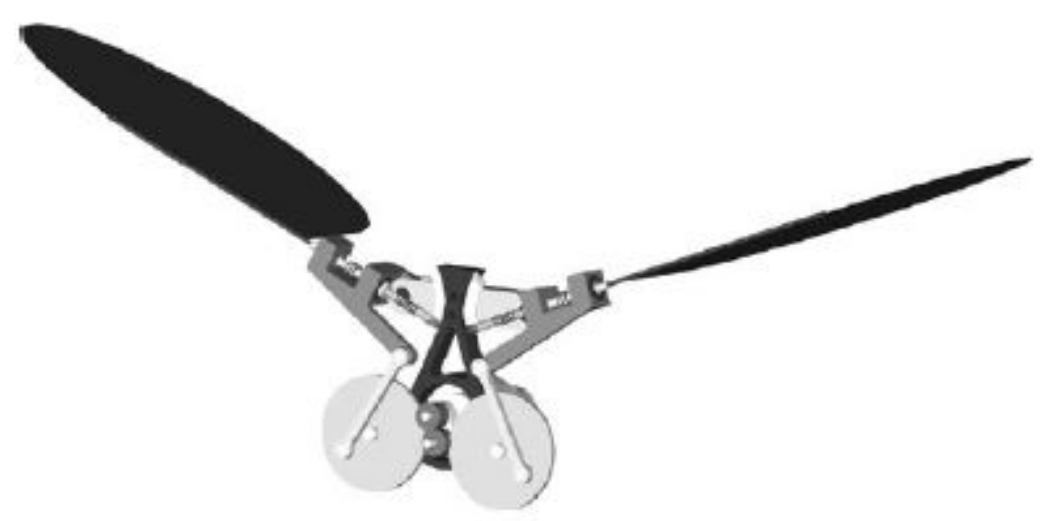

Figure 2.6: Mechanism Capable of Biaxial Rotation [14]

The Microbat developed by Pornsin-Sirirak et al. [6] is a micro aerial vehicle (MAV) with MEMS based membrane wings. These wings were made of titanium-alloy (Ti6Al-4V) for the wing's frame, and parylene $\mathrm{C}$ for the skin. The study mainly focused on insect wings. A drive mechanism converting rotary motion to the flapping motion of the wings was designed [15]. Figure 2.7 below shows a picture of the drive mechanism used as well as a picture of the completed mechanism. 


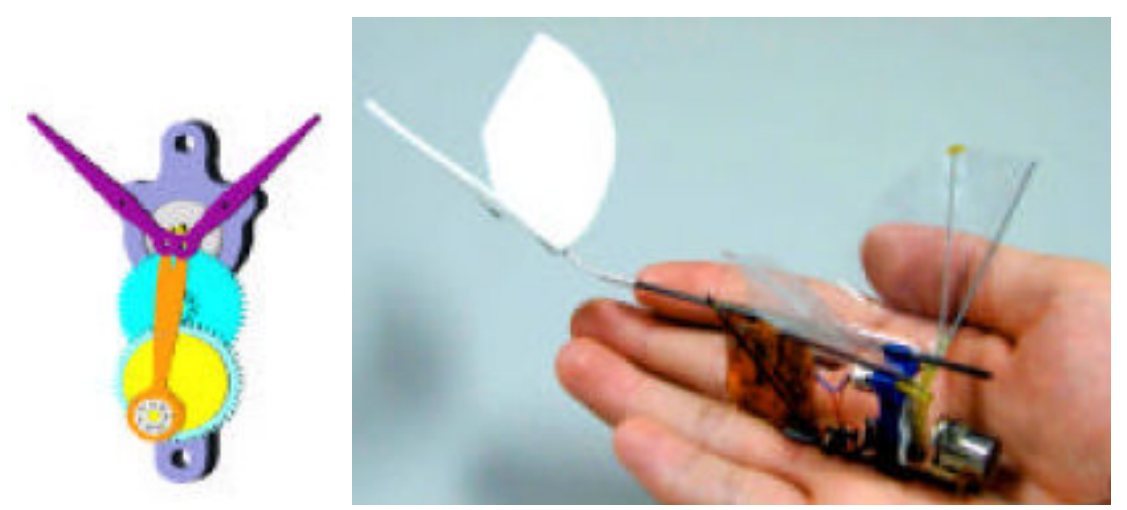

Figure 2.7: Microbat Transmission System and Fabricated UAV [15]

This design consists of a small DC motor with a 22:1 gearing reduction ratio turning a geared flywheel which in turn drives a scotch yoke crankshaft in the vertical motion. The crankshaft is restricted in motion so it can only move in the vertical direction. This mechanism is capable of flapping at $42 \mathrm{~Hz}$ when no wings are attached, and at $30 \mathrm{~Hz}$ with wings [15].

The largest successful flapping wing UAV designed is by DeLaurier et al. [3]. This mechanism, like many of the others, converts rotational motion to translational motions. A picture of this mechanism can be seen in Figure 2.8.

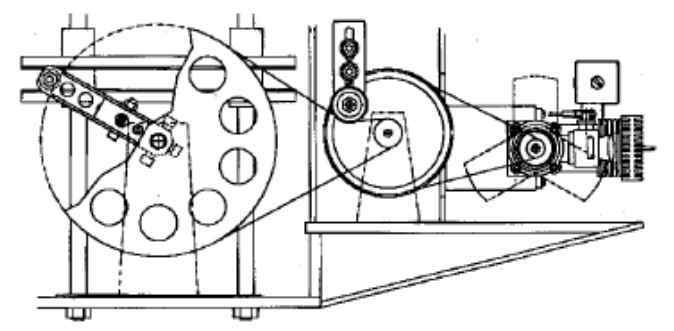

Figure 2.8: Drive Mechanism in Toronto Ornithopter [16]

The principle plunging motions are created by a motor. Through a series of flywheels connected together by drive belts, a slider mechanism is driven in an up and 
down motion. The slider assembly is connected to two parallel posts which move up and down. The two posts raise and lower a center section of wing. This section is in turn connected to the left and right wing in a hinge like connection. The wings are held in place through a type of pivot joint and when the center panel is raised and lowered through the use of the slider assembly, the left and right wing are caused to plunge because of the pivot joint. Frequencies from $3 \mathrm{~Hz}-5 \mathrm{~Hz}$ have been generated by this mechanism [16]. This flapping wing mechanism has been successful in actual sustained flight and is perhaps the most successful flapping wing mechanism to date.

\subsection{Wing Geometries of Natural Flappers}

Part of this research involved designing a flexible wing to be used in the flapping experiments, and therefore was helpful to observe the various types of wings natural flyers have developed. Based on the information found on wing geometries of natural flyers, a decision could be made as to which one to imitate in this thesis. Birds, insects and bats were studied. Once a particular natural flyer was selected, the wings could be studied in more detail, and a simplified version could be constructed for testing purposes.

Avian wings were the first kinds of wings studied in the quest to design flight vehicles [17]. In designing wings for fixed wing aerial vehicles engineers used relatively thin airfoils, as those found in birds. Studies conducted on a seagull wing have shown that the wing has two regions of different flexibilities. The wing consists of a stiffer section closer to the root, and has higher flexibility closer to the tip [17], [18]. The ornithopter developed by DeLaurier employs this avian model in the wing design [5]. 
Insects and bats both have membrane wings. The wings of an insect are very thin and various veins make up the members for structural rigidity [19]. Their wings are predominantly oval in shape and extremely flexible. It was found that insect wings would be extremely difficult to reproduce. Bat's wings on the other hand are slightly different. They have approximately 5 main structural members known as battens, though their flapping motion is different from both birds and insects [20]. Research has been done by Tian et al. on the kinematics of bat flight. Figure 2.9 below shows images of the motion a bat wing produces in addition to showing the locations of the structural members.

Although the flapping motions produced by the bat were not reproduced in this thesis, the planform and locations of the structure was. The bat wings were chosen over insect and bird wings because they met two important criteria: they were membrane wings, and were relatively easy to reproduce. The basic form and location of the members was copied, with complex curved features being simplified by being made linear wherever possible. This is further discussed in Section 4.5.
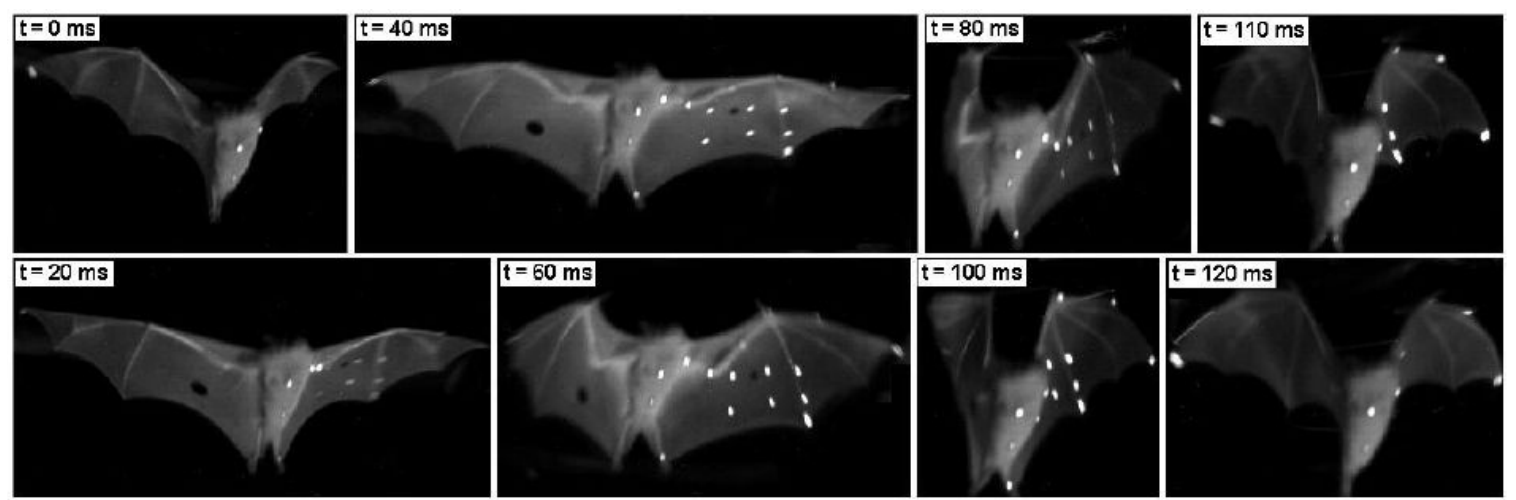

Figure 2.9: High Speed Video of Bat Wing [20] 


\subsection{Missing Links in Current Research}

Research efforts have been done in hopes of understanding why flapping wing flight is beneficial and more efficient. It has been shown that natural flyers are capable of performing a broader range of missions than their fixed wing counterparts. In addition, studies on flexible wings have proved that they are more resistant to stalling at higher angles of attack and produce the same amount of lift as rigid wings, all the while providing smoother flight and better gust stability using adaptive washout.

Various flapping mechanisms have been constructed which flap wings, flexible and rigid, at different frequencies. Additional mechanisms have also been built where rigid wings are flapped where there is dynamic pitch and amplitude control. These experiments have been conducted in water, and the flapping frequencies are very low, allowing the motors which control both degrees of freedom to work together more easily. Currently, the only mechanisms which alter pitch do so in direct drive forms, meaning the rates of pitch change and deflection of the pitch angles are constant for a given frequency.

To the author's knowledge, at this time, there is no mechanism which flaps thin membrane wings and is able to determine the aerodynamic forces generated at different frequencies. There is also no clear understanding on how the flexibility of membrane wings affects lift, drag and thrust in flapping flight. To explore these open concerns and questions, this research aims to develop inexpensive hardware that produces pitch and flapping motions that could lead to future UAV applications. 


\section{CHAPTER 3: MECHANICAL DESIGN REQUIREMENTS}

\subsection{Objective}

The objective of this research was to design a flapping wing mechanism which could produce both flapping and pitching motions. In designing this mechanism, the most important factors were weight, wing design, flapping frequency and flow velocity. Cost was also a major issue, and it was desirable to keep it to a minimum. This meant using commercially available off the shelf parts wherever possible.

\subsection{Weight Requirements}

Due to the fact that this mechanism was to simulate a flapping wing aerial robot, it was necessary to be as light weight as possible. Each component and sub-assembly was weighed and an effort was made to choose light-weight materials. The mechanism was built to emulate a larger bird in size, such as a crow. The crow was chosen as a weight and size (wingspan) target. It was found that the weight of a crow is approximately 1.5 to 1.75 pounds [21], thus it was desirable that all of the parts combined did not weigh more than this. Parts such as motors, bearings and joints constitute a significant amount of weight, so it was necessary to choose materials which had very low cost-to-weight ratios.

\subsection{Wingspan and Planform Requirements}

Larger birds and bats have wing semi-spans of approximately 16 inches [21].

Since the mechanism had a target weight to that of a crow and a large bat, it was also 
desirable to have the same wing span as a large bat or crow. Since the wing was supposed to be a membrane wing, the largest natural flapper which employed this characteristic is a bat, and therefore the wings were designed to be like those of a bat. This involved having structural members, or battens, in the same places a real bat does as well as using a thin membrane. Structurally, the wing needed to be stiff at the leading edge, while having a very flexible membrane.

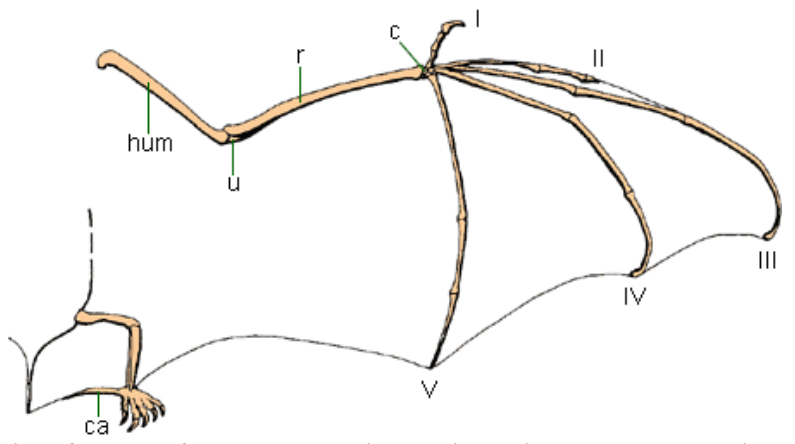

Figure 3.1: Planform of a Bat's Wing Showing Structural Members [22]

\subsection{Flapping Frequency and Speed Requirements}

Analysis of bird and insect flapping motions show that sustained forward flight can be produced by different flapping motions, and that the motion appropriate for one vehicle or one wing might not be the best for another wing or vehicle. Crows have a flapping frequency of approximately $4 \mathrm{~Hz}$ or wing-beats per second [21]. This meant that the target flapping frequency for the flapping mechanism had to be at least $4 \mathrm{~Hz}$, with the possibility at flapping at a higher frequency being desirable. It was decided to flap the mechanism at 2, 3 and $4 \mathrm{~Hz}$, at various free stream velocities. $10 \mathrm{~Hz}$ was arbitrarily chosen as an upper bound in frequency when selecting a motor. Realistically, 
large natural flappers do not flap at frequencies as high as $10 \mathrm{~Hz}$, but it was thought it might be interesting to observe how the mechanism behaved at higher frequencies.

According to Figure 3.2, it can be seen that the cruising speed of natural flappers which have a mass of approximately $1.5 \mathrm{lbs}$ to $1.75 \mathrm{lbs}$ is approximately 10 to $13 \mathrm{~m} / \mathrm{s}$. However, the flapper must also experience speeds below this, so a target speed of $5 \mathrm{~m} / \mathrm{s}$ was chosen. This enabled testing at speeds of 0,5 and $10 \mathrm{~m} / \mathrm{s}$ to more fully understand the nature of flapping. Therefore, it was necessary that the wind tunnel facilities be able to reach speeds as low as $5 \mathrm{~m} / \mathrm{s}$.

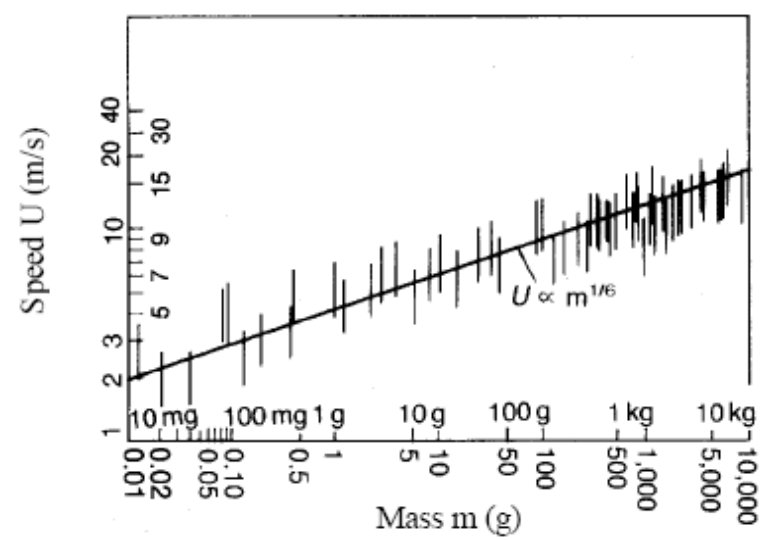

Figure 3.2: Flight Speed of Flyers vs. Mass [6]

\subsection{Summary of Requirements}

Table 3.1 lists the desired design requirements for the flapping mechanism.

Table 3.1: Target Design Requirements

\begin{tabular}{|l|c|}
\hline Desired Weight: & $\leq 1.75 \mathrm{lbs}$ \\
\hline Desired Wing Semi-Span: & $16 \mathrm{in}$. \\
\hline Desired Flapping Frequency: & $0 \geq f \leq 4 \mathrm{~Hz}$ \\
\hline Air Velocities: & $0,5,10 \mathrm{~m} / \mathrm{s}$ \\
\hline
\end{tabular}




\section{CHAPTER 4: DESIGN PROCESS}

\subsection{Mechanism}

A complete set of CAD models were developed to ensure an accurate fit between parts. The software used to generate CAD models was SolidWorks 2005. An isometric conceptual view of the flapping mechanism can be seen in Figure 4.1. This figure also depicts the relative scale between the flapping mechanism and the wings

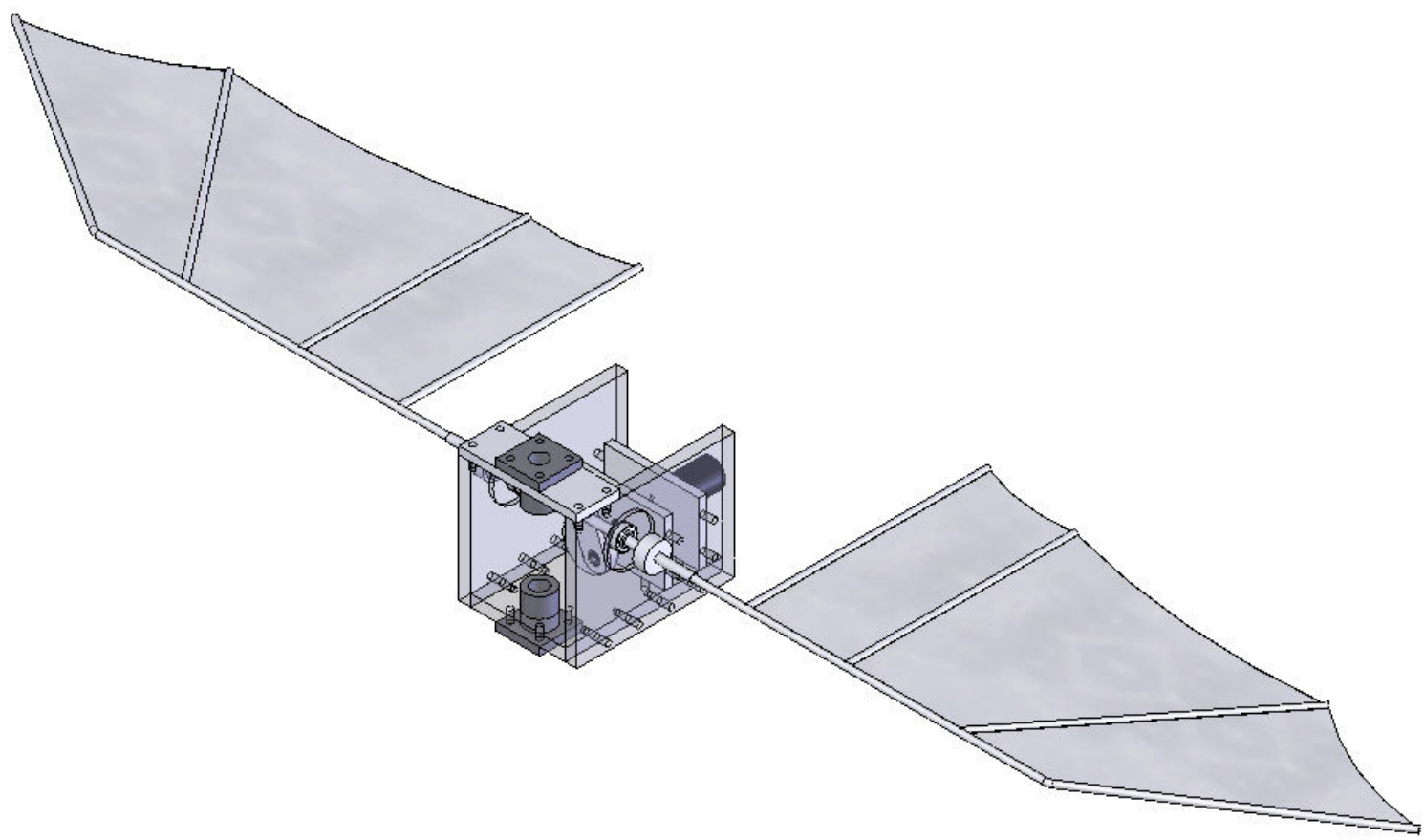

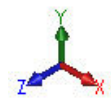

Figure 4.1: Isometric View of Entire Flapping Mechanism (CAD Model) 
Top and left side views can be seen in Figure 4.2, and Figure 4.3. A DC Micro motor/gearhead assembly was face-mounted to a motor mounting plate (Figure 4.2, Figure 4.3).

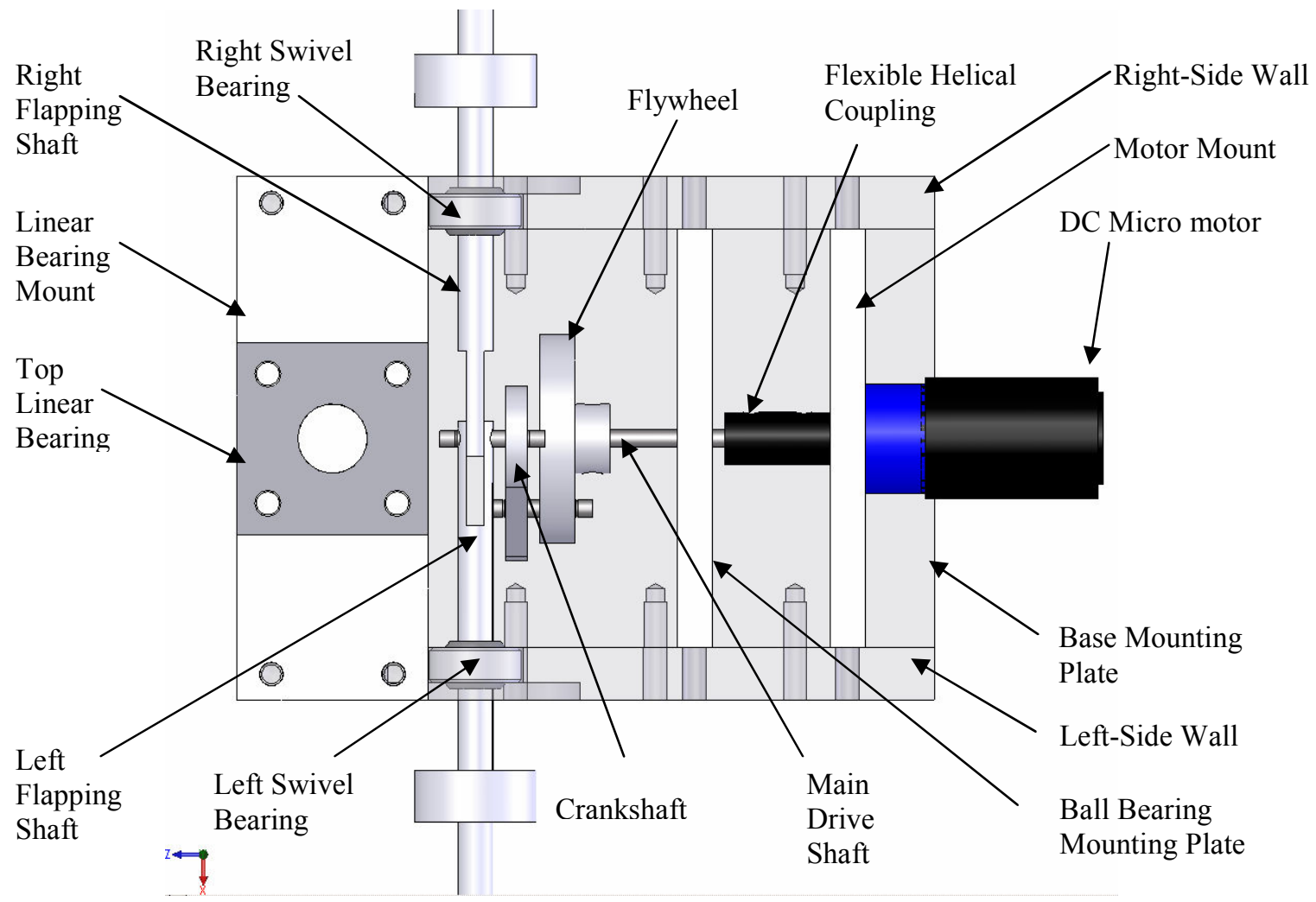

Figure 4.2: Top View of Flapping Mechanism (CAD Model)

The output shaft of the motor was connected to a helical beam coupling, which was connected to a main drive shaft. A helical beam coupling was chosen to ensure the elimination of any shaft misalignment. The coupling chosen was capable of correcting for up to $1.5^{\circ}$ of shaft misalignment. The drive shaft passed through a ball bearing for additional support. This ball bearing was press-fit and housed within the ball bearing mount. The far end of the main drive shaft was connected to a flywheel through the use 
of a set screw. A setscrew was used because it was very low profile and flush with the surface of the flywheel when fully tightened; more importantly it was very low mass.

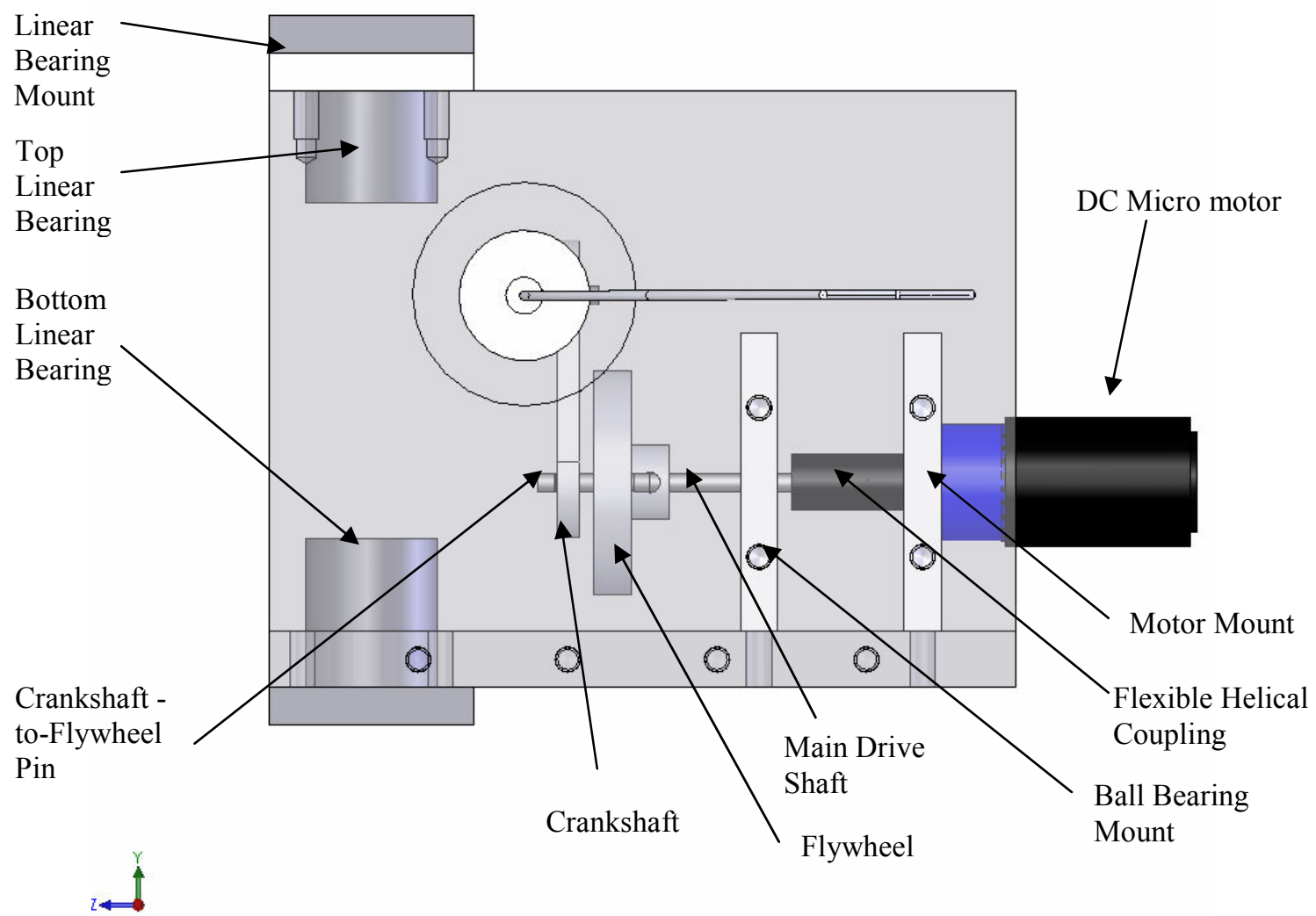

Figure 4.3: Left Side View of Flapping Mechanism (CAD Model)

The flywheel was used to enhance the inertia of the system. Equation 4.1 was used to estimate the torque due to the system's increased inertia.

$\tau=I \alpha$ Equation 4.1

First it was necessary to calculate the moment of inertia of the flywheel, I. This was given by Equation 4.2. 
$I=\frac{1}{2} m r^{2}$

Equation 4.2

In this equation, the mass was taken to be $0.02 \mathrm{~kg}$, the radius $r$ was $0.0191 \mathrm{~m}$, and therefore, the calculated value of $I$ was $3.6 \times 10^{-6} \mathrm{kgm}^{2}$. From the specification sheets of the motor, the maximum angular acceleration $\alpha$, of the motor was $120 \times 10^{3} \mathrm{rad} / \mathrm{s}^{2}$. Using a 14:1 planetary gearhead, this was reduced to $8.57 \times 10^{3} \mathrm{rad} / \mathrm{s}^{2}$. Substituting the values into Equation 4.1, the increased torque was calculated to be $2.38 \times 10^{-3} \mathrm{Nm}$.

Equation 4.3 was used in determining if the motor had enough torque to flap the wings. In Equation 4.3, $\tau$ is the motor torque, $r$ is the torque arm, and $F$ is the force the motor needs to be able to lift. The radius was measured to be 5.25 inches $(0.1334 \mathrm{~m})$, which was the distance from the center of the crankshaft to the pivot point at the swivel bearings. The weight of the wing was measured to be $0.02 \mathrm{~kg}$.

$\tau=r \times F$

Equation 4.3

$\tau=0.1334 \mathrm{~m} \times 9.8 \mathrm{~m} / \mathrm{s}^{2} \cdot 0.02 \mathrm{~kg}=26.1 \mathrm{mNm}$

Equation 4.4

From Equation 4.4, it can be seen that the minimum torque required to lift the wing from the bottom position of the flap, to the highest point in the flapping motion is $26.1 \mathrm{mNm}$. Since there are two wings, the required torque is $52.2 \mathrm{mNm}$. Since the motor selected only has a specified torque of $10 \mathrm{mNm}$, a gear head was needed to increase the torque. The highest frequency expected in the flapping motions was approximately 10 $\mathrm{Hz}$, so it was not necessary to flap faster than that.

To achieve both of these requirements, a planetary gear head was chosen. A planetary gear head was chosen over a spur gear head because they produce higher torque in a 
limited space, whereas spur gear heads typically consume less power but are larger and heavier. To achieve speeds of $10 \mathrm{~Hz}$, or $600 \mathrm{RPM}$, Equation 4.5 was used. In this equation, $\omega$ is the desired speed, $\omega_{N L}$ is the no load speed of the motor and $R_{G}$ is the reduction of the gear head. Equation 4.6 solves for the desired reduction. It can be seen that the reduction ratio needs to be approximately 13.33:1.

$$
\begin{aligned}
& \omega=\frac{\omega_{N L}}{R_{G}} \\
& R_{G}=\frac{8000 \mathrm{rpm}}{600 \mathrm{rpm}}=13.33
\end{aligned}
$$

A coreless DC micro motor (model number 2232) was purchased from Faulhaber Micromo Electronics. The speed versus torque curve can be seen in Figure 4.4 [24]. It was a 12 volt DC coreless micromotor, with a maximum rpm of 8000 and a current rating of 2.7 amps. Coreless motors are lighter than traditional DC motors and as such are more commonly used in aerospace applications. The closest gear head available which fits the 2232 motor was a 14:1 reduction. This yielded a new speed of $571 \mathrm{RPM}$, or $9.5 \mathrm{~Hz}$. To calculate the torque increase due to this gear head, Equation 4.7 was used. In this equation $\tau_{\mathrm{New}}$ is the torque at the output shaft of the gear head, $\tau_{\text {Orig }}$ is the original torque at the motor shaft, and $\varepsilon$ is the efficiency of the motor.

$$
\tau_{\text {New }}=\tau_{\text {Orig }} \cdot R_{G} \cdot \varepsilon_{G}=10 \mathrm{mNm} \cdot 14 \cdot 0.9=126 \mathrm{mNm}
$$


Thus, using a gear head reduction ratio of 14:1, the motor speed was reduced to 9.5 $\mathrm{Hz}$, and the torque was increased to approximately $128.4 \mathrm{mNm}$ including the effects of the flywheel. This was enough torque to successfully flap the wings.

This is a very rough estimate, since there is drag faced by the wing surface as it moves up and down. This additional force should be accounted for. However at the time of motor selection, there was no information about the types of forces generated when flapping flexible wings. It would be necessary to take into account the flexure of the membrane and the resulting drag force at that frequency. Most of these were unknown at this time, and these are the questions this thesis is attempting to answer.

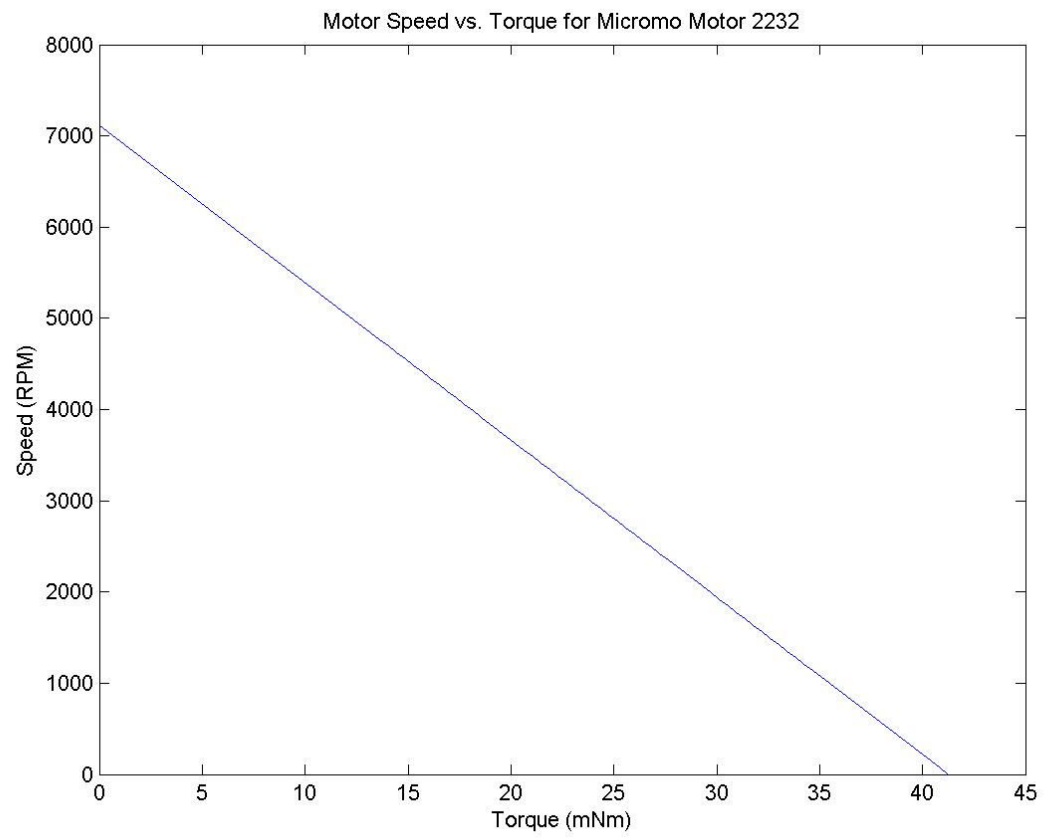

Figure 4.4: Speed vs. Torque Curve for 2232 Micromo Motor [24] 
The model 2232 motor was purchased because it offered a very good tradeoff between weight and power. It weighs only 62 grams, while being able to provide 10 $\mathrm{mNm}$ of torque at $8000 \mathrm{rpm}$.

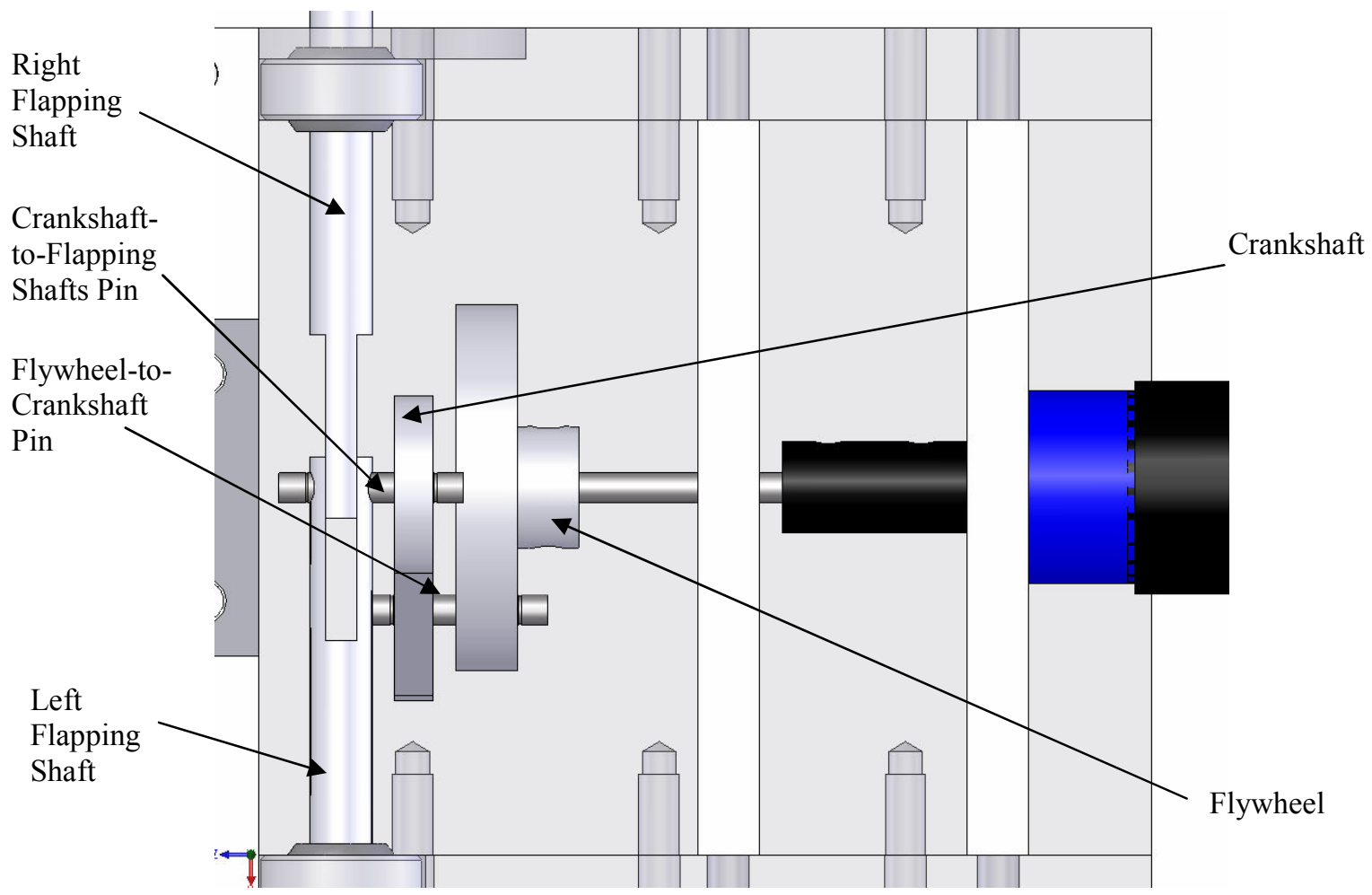

Figure 4.5: Close-Up View (Top) of Drive Mechanism (CAD Model)

The flywheel has an Oilite ${ }^{\circledR}$ bushing press-fit into it (Figure 4.6), through this passes the "flywheel to crankshaft connecting pin". The pin is held into place by the use of an external retaining ring. An Oilite ${ }^{\circledR}$ bushing was used because it was lower cost and lower weight alternative to a standard roller bearing, which would have been used, had rotation speeds been high. These bearings are oil impregnated and lubricate the shaft to lower the coefficient of friction between the shaft and the bearing inner race as the shaft 
rotates. The other end of the pin is press-fit into a ball bearing (Figure 4.6), which itself is press-fit into a hole in the crankshaft.

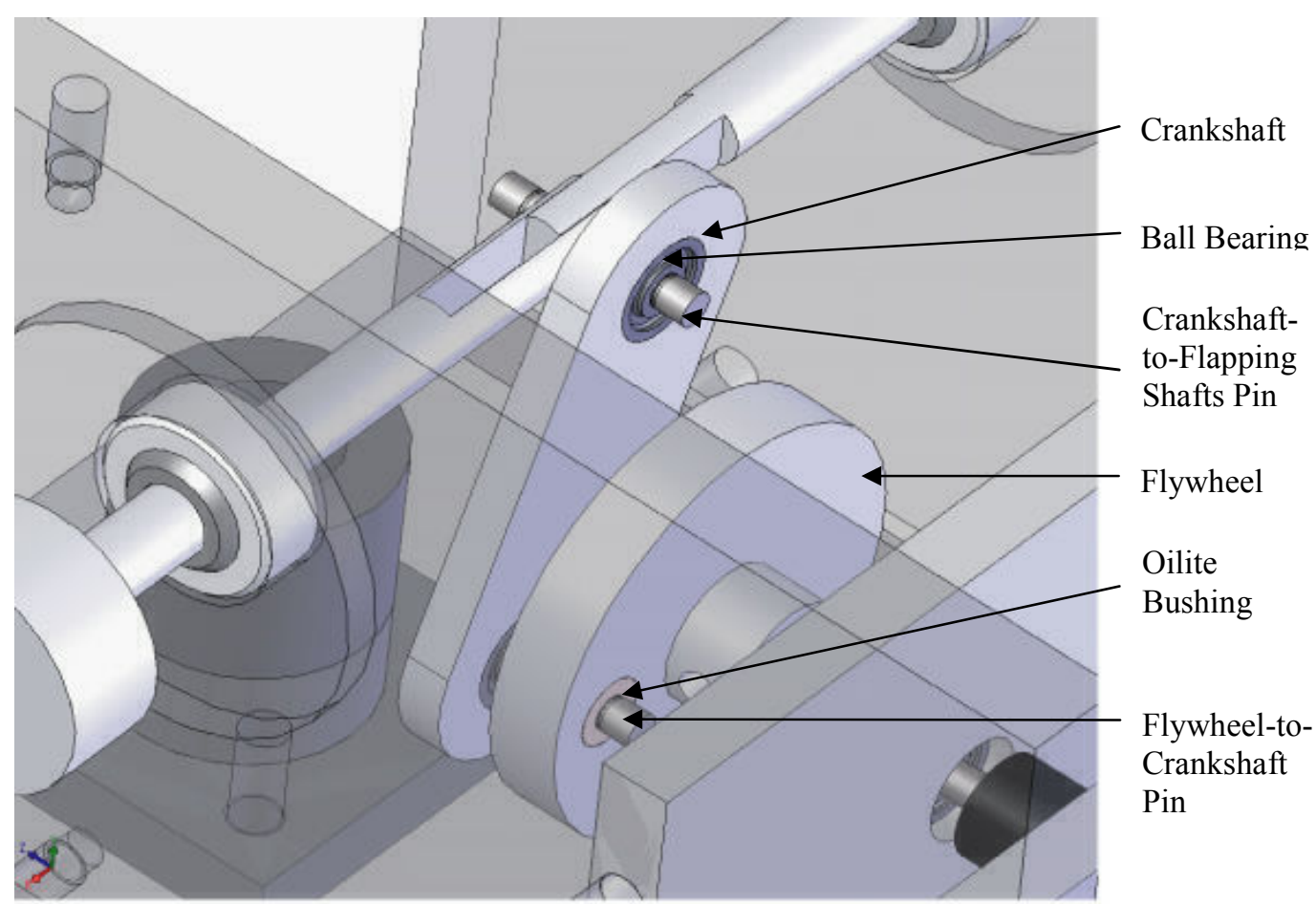

Figure 4.6: Close-Up of Flywheel and Crankshaft Connecting Pins (CAD Model)

The top end of the crankshaft has another ball bearing press-fit into it (Figure 4.6). Through this ball bearing passes the "crankshaft-to-flapping shafts pin, again pressfit into the second ball bearing. The two flapping shafts (left and right), have male and female connection joints which allow them to mesh within themselves. Each side has a hole, through which the "crankshaft-to-flapping shafts pin" passes. The far end of this pin is held in place through the use of a shaft collar. Originally, retaining rings were used for this connection, but the loads produced by the flapping wings caused the retaining rings to squeeze loose. The external retaining rings for $1 / 8$ inch diameter shafts were 
originally used because of their almost negligible weight $(0.001 \mathrm{mg})$. The retaining rings were replaced by the above mentioned shaft collars after the first test.

Through these series of connections, as the motor rotates, so does the crankshaft. This in turn causes the flywheel to rotate. As the flywheel turns, the ball bearings allow the crankshaft to move up and down, essentially converting rotary motion to linear motion. In order to get this linear up and down motion to convert into a plunging, flapping motion, swivel joints are used. These swivel joints are press-fit into each wall Figure 4.7. As the crankshaft moves up and down, one end of each flapping shaft is forced to translate up or down. The flapping shaft passes through the side wall, and thus the swivel bearing. This enables the shaft to pivot about the side wall and perform plunging motions. To keep the crankshaft to stay true in the center of the mechanism and not travel side to side, two springs were compressed-fit between the side walls and the roller bearing housing.

To allow for pitching motions, two approaches were taken. First, a ball bearing/housing assembly was used (Figure 4.7). The inner race of the bearing was press fit over the far end of each flapping shaft. The outer race was press fit into a housing (Figure 4.7), the far end of which connected to a wing shaft via the use of a shaft coupling (not shown). This enabled the wings to rotate freely. An actual image of this can be seen in Figure 4.7. 


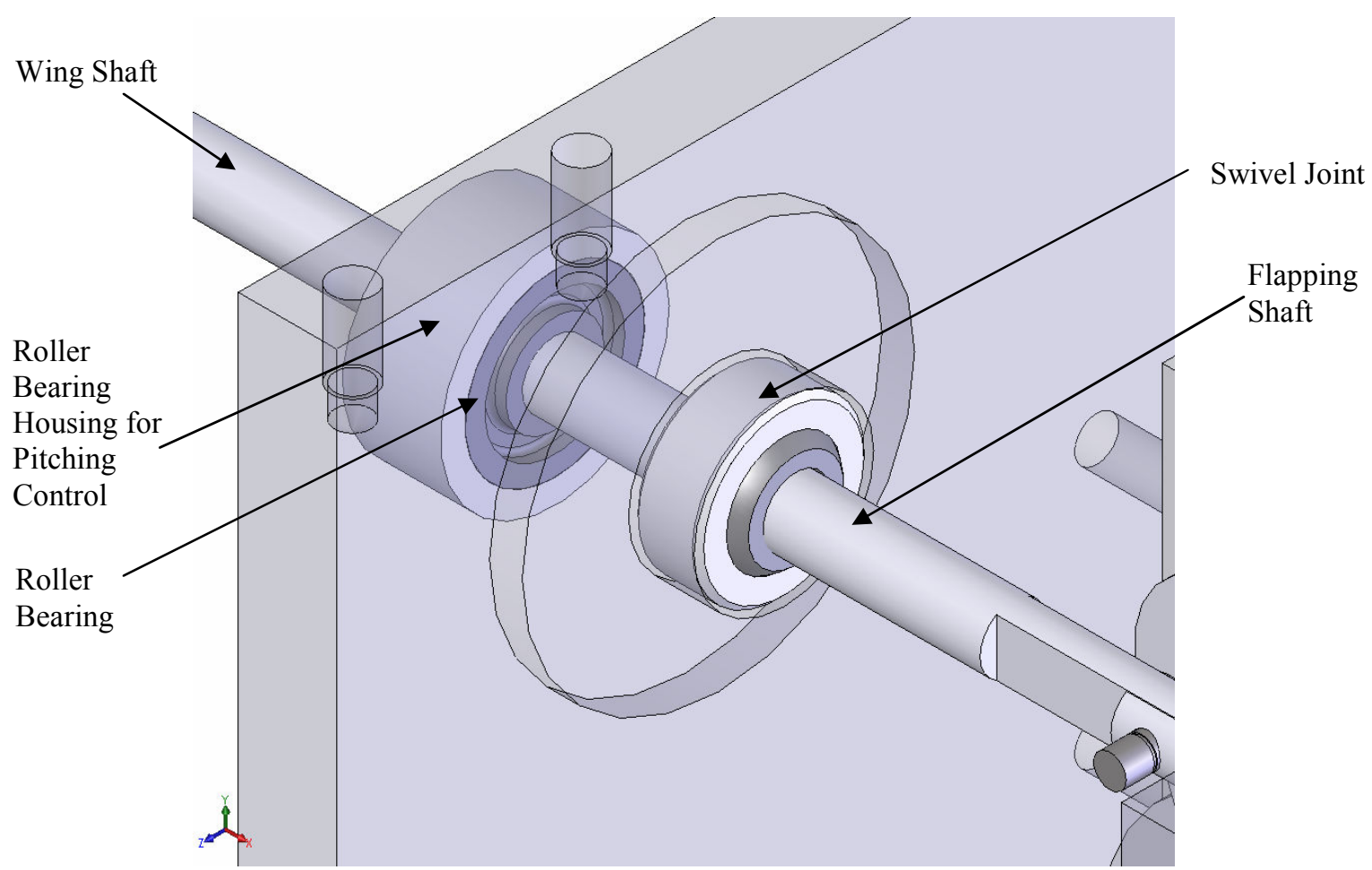

Figure 4.7: Close-Up of Swivel Joints and Pitching Assembly (CAD Model)

The second approach for producing pitching motions involved natural properties of the wing materials. To do this, additional wing shafts were fabricated which did not utilize the roller bearing and roller bearing housing. These shafts were designed for pure wing plunging, with no pitch control. The pitch control for this direction was taken into account when fabricating the wings, with natural material frequency modes providing the necessary pitch when the wings were flexed. Chapter 4.5 further discusses the flexible wings with natural pitching exhibited through the wing structural material's stiffness. Real-life images of the flapping mechanism can be seen in Figure 4.8 through Figure 4.11. 


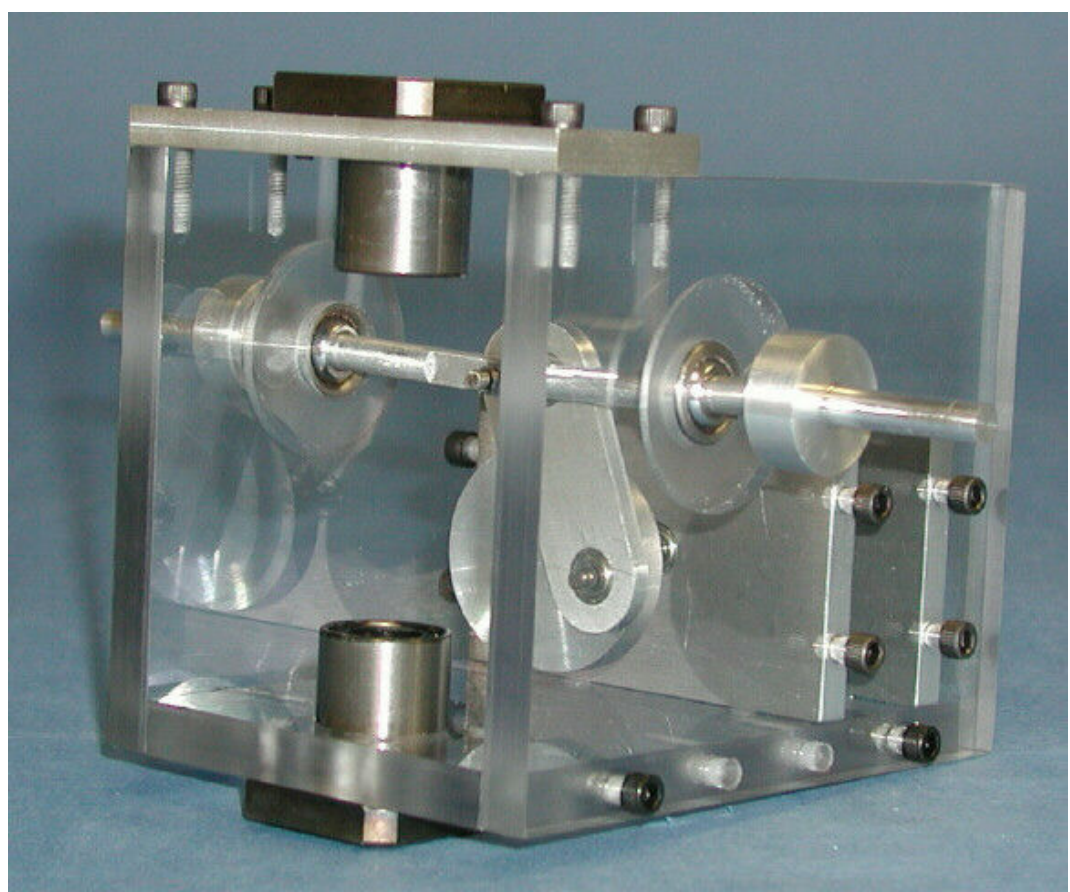

Figure 4.8: Isometric View of Flapping Device

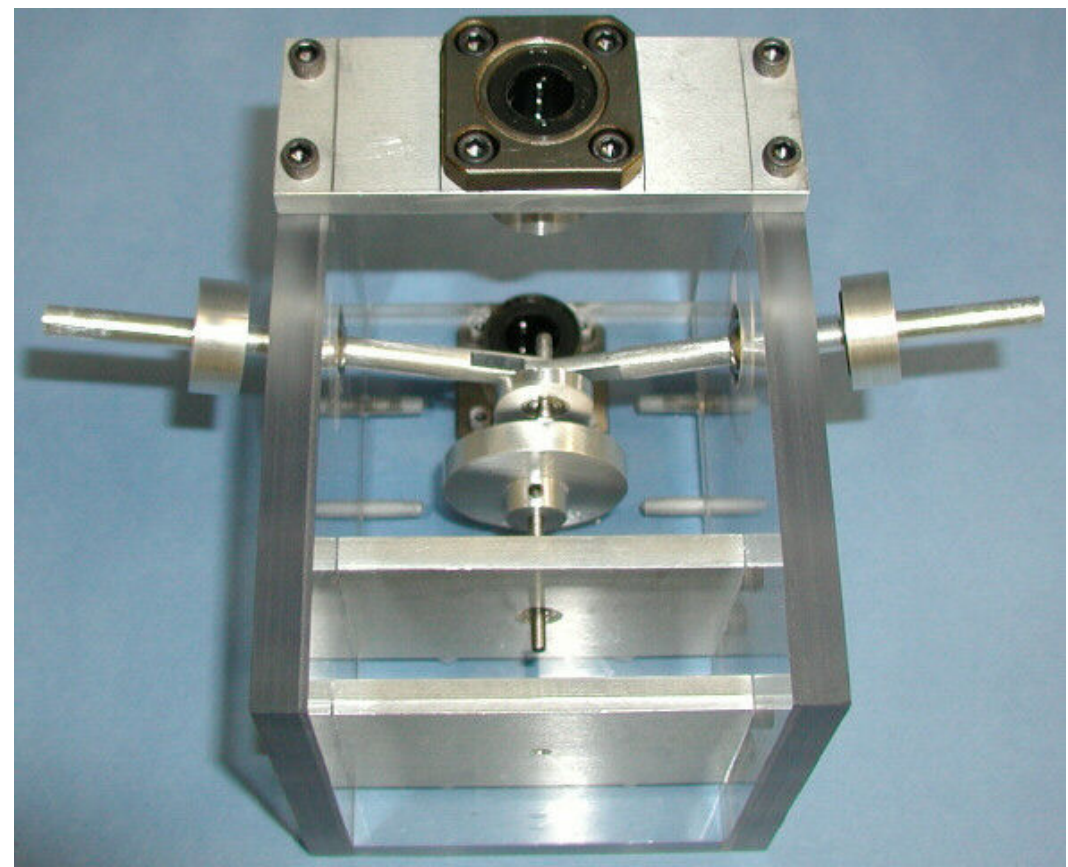

Figure 4.9: Top View of Flapping Device (Without Motor and Coupling) 


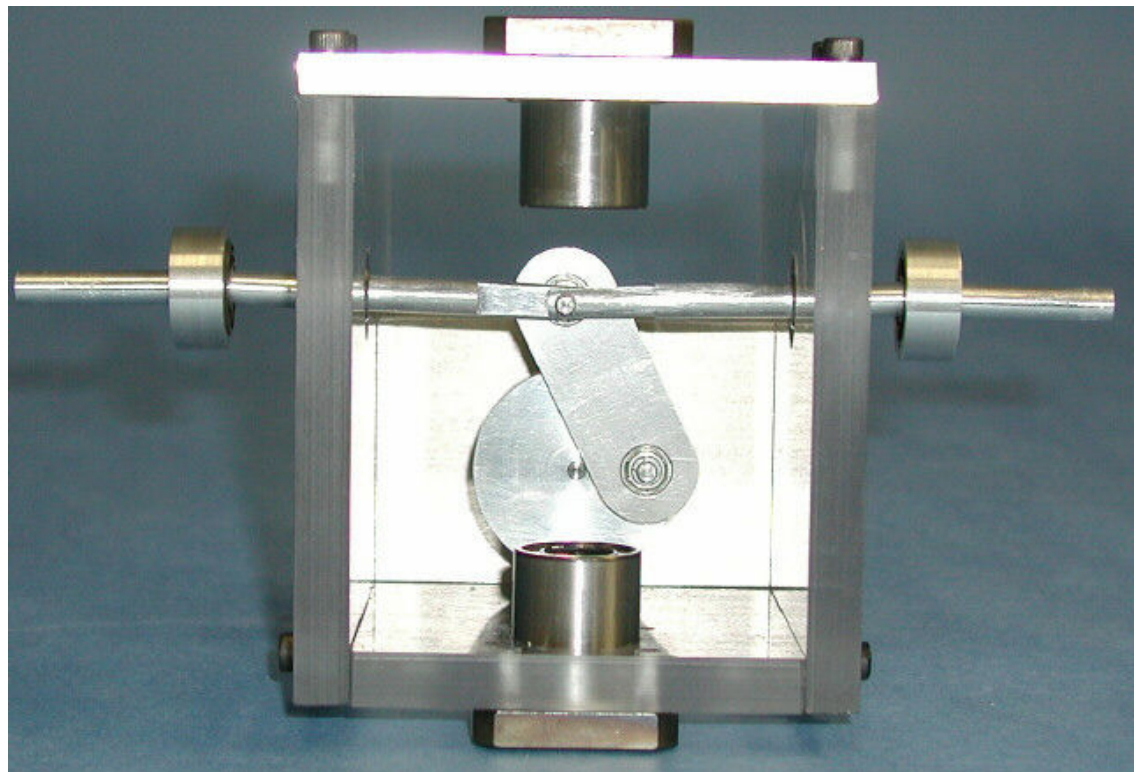

Figure 4.10: Front View of Flapping Device

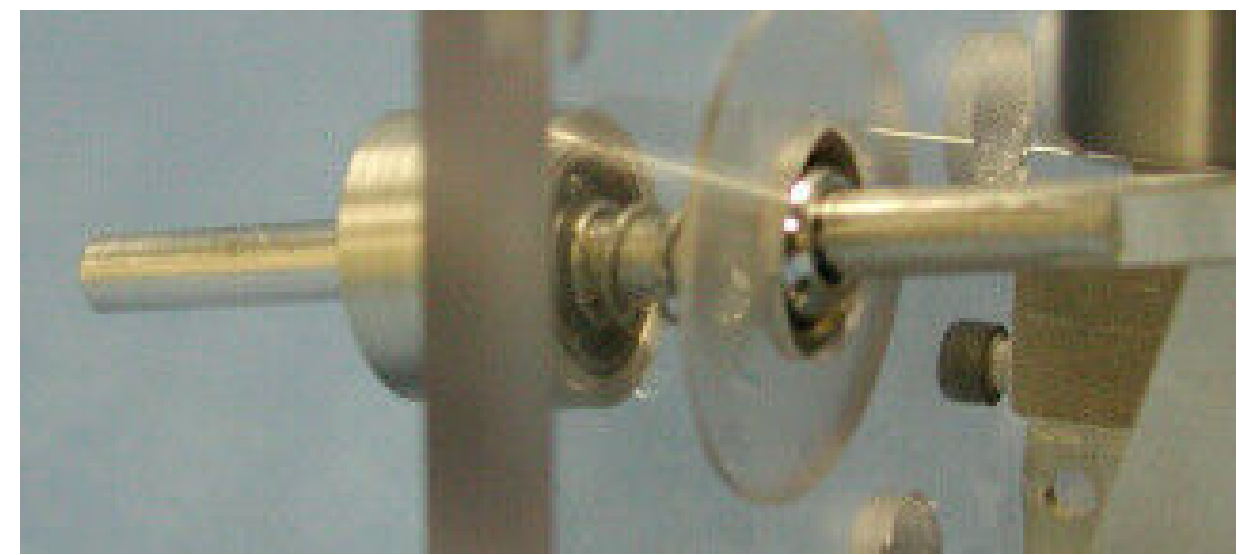

Figure 4.11: Close-Up View of Swivel Joints After Weight Reduction Efforts

\subsection{Materials and Dimensions Used}

In order to standardize the assembly process, all major tapped holes were size \#832. The base plate, left and right side walls were made of $3 / 8$ inch polycarbonate. The base plate was 5 inches long and 3 inches wide. The left and right walls were each 5 inches long and 4 inches wide. It was found that these were the minimum dimensions 
which would provide enough room for the mechanism drive-train. All of the bearing mounts (for both linear and ball) as well as the motor mount were machined from Aluminum 7075-T6. This alloy was chosen because it is a very light weight aluminum alloy with excellent machineability characteristics. It is also widely used in aerospace applications. The flapping shafts, flywheel, crankshaft and the roller bearing housings

for pitching were all also machined from the same alloy. The flapping shafts were 2.75 inches long made of 0.25 inch diameter aluminum, and the crankshaft was 2.098 inches long.

The drive shafts as well as the two pins were all made of $1 / 8$ inch titanium. Titanium was chosen because it is stronger than aluminum and lighter than steel. These parts felt the brunt of the loads in this mechanism and thus, it was necessary to ensure adequate strength.

The linear bearings, ball bearings and swivel joints were all steel with press-fit actions used wherever possible. When necessary, the press-fit application was augmented with the use of Loctite epoxy for an extra firm hold. All materials were purchased from McMaster-Carr.

\subsection{Mechanism Electronics}

In order to get an accurate reading of the flapping frequency, an optical encoder was used (Figure 4.12). The optical encoder wheel was purchased from US Digital. The optical encoder was chosen with a hub assembly to facilitate mounting on a shaft. It was designed for a 0.125 inch shaft and held in place with a set-screw. This encoder wheel was mounted on the 0.125 inch titanium drive shaft. The encoder wheel chosen has a 
resolution of 500, meaning there are 500 holes at an optical radius of 0.433 inches. In order to properly read the counts on the encoder wheel, an optical encoder module was used. This module had a two channel quadrature output with index pulsing. The encoder module has an emitter-detector feature. The module emits a light, and as the encoder wheel spins, one of the windows passes over the emitter allowing the light to be detected by the detector. This constitutes one count.
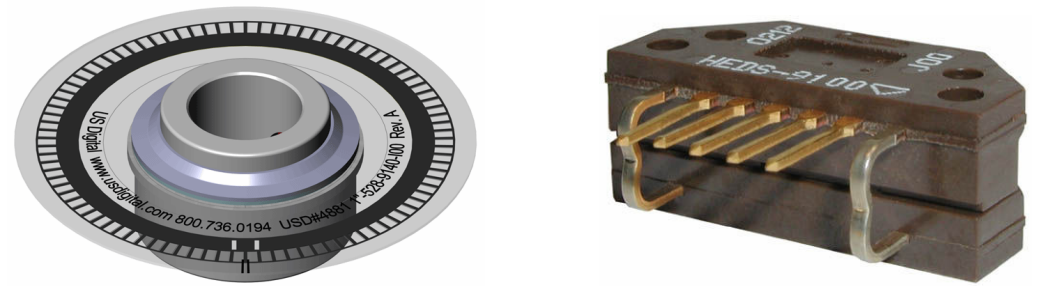

Figure 4.12: Encoder Hub Disk and Module Used

\subsection{Weight Reduction Efforts}

As stated earlier, light weight materials were chosen for the design. These included using aerospace grade aluminum alloys, polycarbonates and titanium wherever possible. In an effort to further reduce weight, parts a post processing step which involved removing material by hand was performed. This involved removing material wherever possible. Figure 4.13 displays an isometric view of the entire mechanism after weight reduction efforts were completed.

Two sections of the linear bearing mount were machined down from 0.25 inches to 0.125 inches, and 24, 0.25 inch holes were drilled through it (Figure 4.14). The left and right side walls, as well as the base plate had 0.5 inch holes drilled through them, for a total of 12 holes per side. The linear bearing mount also had 0.25 inch holes drilled 
through it; in addition 2 sections of the 0.25 inch thick material was reduced to 0.125 inches. All machining was done on a 3-axis Bridgeport milling machine.

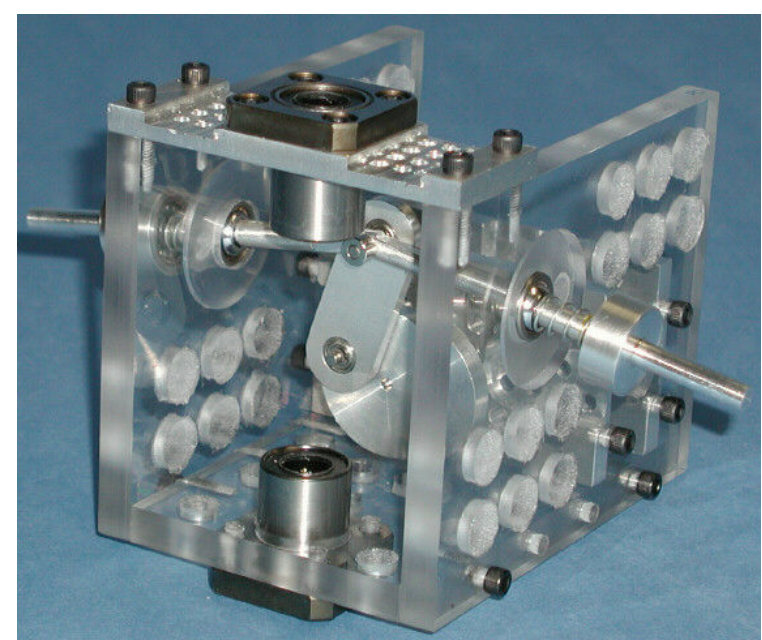

Figure 4.13: Isometric View of Mechanism After Weight Reduction Efforts

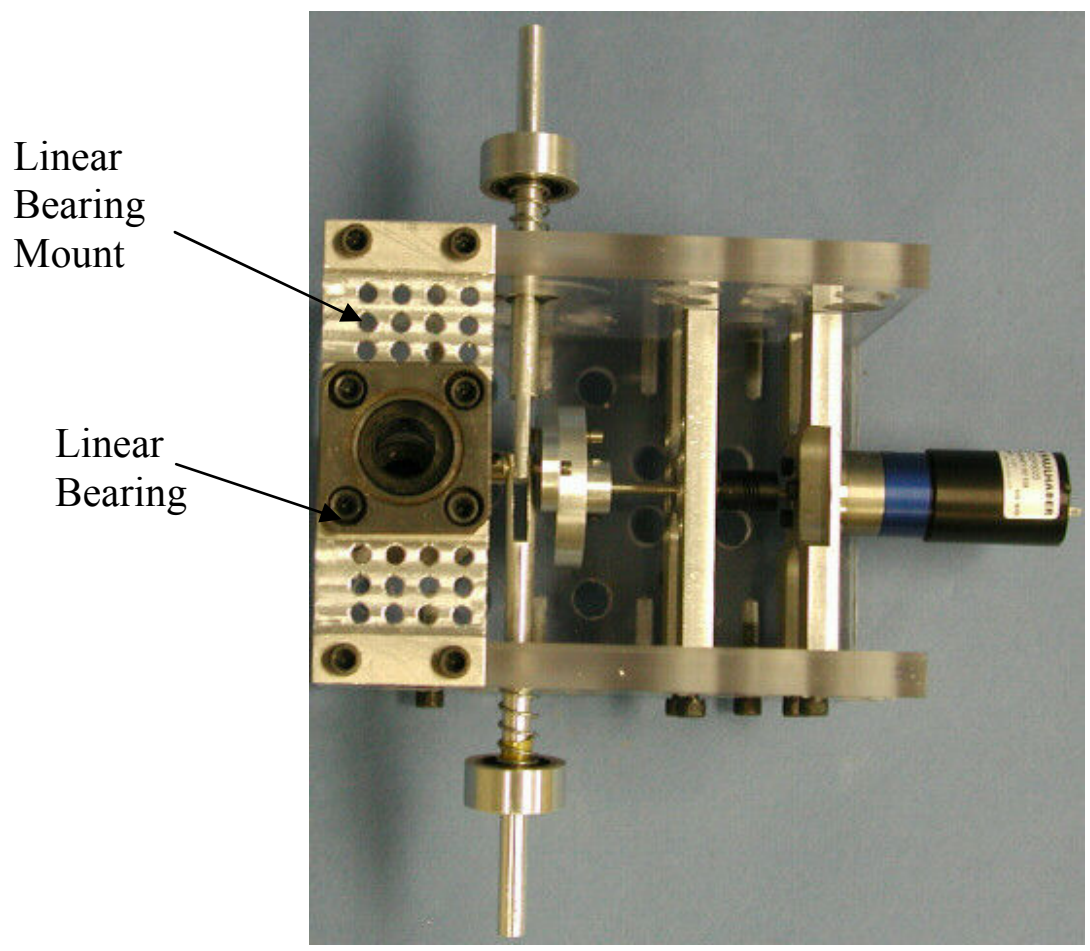

Figure 4.14: Top View of Mechanism After Weight Reduction Efforts 
Table 4.1: Table of Mechanism Weights Before and After Weight Reduction Efforts

\begin{tabular}{|l|l|l|}
\hline \multicolumn{1}{|c|}{ Part/Assembly } & \multicolumn{1}{|l|}{ Original Weight: g (lb) } & $\begin{array}{l}\text { Weight After Weight } \\
\text { Reduction: } \mathrm{g}(\mathrm{lb})\end{array}$ \\
\hline Motor + Gearhead & $128(0.28)$ & $128(0.28)$ \\
\hline Left side wall (w/ swivel joint) & $146(0.32)$ & $120(0.26)$ \\
\hline Right side wall (w/ swivel joint) & $146(0.32)$ & $120(0.26)$ \\
\hline Base plate (w/ linear bearing) & $176(0.38)$ & $160(0.35)$ \\
\hline Motor mount & $66(0.14)$ & $66(0.14)$ \\
\hline Ball bearing mount (w/ ball bearing) & $68(0.15)$ & $46(0.10)$ \\
\hline Flywheel/crankshaft/connecting pins & $45(0.10)$ & $45(0.10)$ \\
\hline Ball bearing housing (w/ bearings) $\mathrm{x} 2$ & $14 \times 2(0.03 \times 2)$ & $14 \times 2(0.03 \times 2)$ \\
\hline Top linear bearing mount (w/ bearing) & $128(0.28)$ & $90(0.20)$ \\
\hline Weight of wings & $16 \times 2(0.035 \times 2)$ & $16 \times 2(0.035 \times 2)$ \\
\hline & & \\
\hline Total Weight & $963(2.12)$ & $839(1.82)$ \\
\hline
\end{tabular}

Table 4.1 displays the weight of the mechanism parts and sub-assemblies before and after weight reduction. Target design requirements from Table 3.1 call for the mechanism to weigh approximately $1.75 \mathrm{lbs}$, and the weights after weight reduction fall very close to the target range. An effort was made to use the lightest available materials. However, due to budget restrictions only materials available on hand were used, such as aluminum and polycarbonate. It would definitely be possible to achieve a weight less than $1.75 \mathrm{lbs}$, but this would increase cost which was a major factor in this experiment.

\subsection{Wings}

One of the most important aspects of this effort was wing design and development. This research called for flexible membrane bat wings. As discussed in Section 3.3 and Table 3.1, the wings each needed to have a semi-span of 16 inches. Since the mechanism was designed to emulate a natural flapper the size and weight of a crow, a crow's 
wingspan was chosen, while the structural members and supports of a bat's wings were copied (Figure 3.1).

\subsubsection{Wing Fabrication Process}

Two families of wings with varying stiffness were used. The first wing was classified as "flexible", while the second was relatively more rigid or "semi-rigid". Tests were performed on the "flexible" wing, labeled as Wing 1. Eventually, high speed video imagery was taken to observe its behavior. After the behavior was studied, a second "semi-rigid" wing was made.

The wings were made from three materials: fiberglass, carbon fiber and epoxy. The skin of the wing was made from two layers of fiberglass, each 0.0025 inches thick (post-cured). The structural members consisted of carbon fiber braided sleeves filled with fiberglass unidirectional strands. The manufacturing process of the wings was very straight forward. A right side and left side mold was fabricated from 0.25 inch thick aluminum 6061 (Figure 4.15). These molds were mirror images of each other. Aluminum was used because it would not bend or warp over time and is very durable. Each mold was $9 \times 18$ inches to allow for a wing of appropriate size. Both sides of the mold had channeled grooves. These grooves were in the same location where the structural members should be. There was a main spar groove which ran from the wingtip to the root. Three additional grooves were cut from each of the other tips, and joining the spar groove at various locations.

The fabrication process for the first set of wings is as follows: one carbon fiber sleeve was placed in the main spar groove from the tip to the root of the wing. Successive sleeves were placed from each of the other three tips all the way to the wing's 
root. This divided the wing into four sections. The layering of the carbon fiber strands in this manner meant that the sections of the spar closer to the wing's root had more layers and strength than those sections closer to the wingtip. Four strands made up the structural member fit into an aluminum shaft coupling which was attached to the main flapping shafts. The carbon fiber and fiberglass were saturated with epoxy. Both molds were placed in a vacuum bag for curing. The vacuum bag provided pressure to compact the laminate providing good consolidation and inter-laminar bonds while also providing a vacuum to draw out volatiles and trapped air, resulting in a low void content wing. The vacuum bag also helps to improve resin flow while the laminate cures.

This second stiffer wing was made by using larger diameter carbon fiber sleeves (0.3 inches instead of 0.1 inches) as structural members from the wing's root to the wingtip. 0.1 inch sleeves, filled with fiberglass unidirectional, were still used for the other structural members, only the leading edge was strengthened. This 0.3 inch diameter sleeve ran from the wing's root to the tip and was filled with both fiberglass as well as the carbon fiber sleeves which provided strength to the other structural points. So essentially this 0.3 inch sleeve was bundled and filled with 0.1 inch diameter unidirectional filled carbon fiber sleeves, as well as additional fiberglass leading out to the wingtip. One of the completed wings can be seen in Figure 4.16.

The radii on the joint corners of the mold were approximately 0.1875 inches. The larger diameter carbon fiber sleeves had a more difficult time staying in place during the curing process as they rounded these corners. For this reason the corner radii were increased to 0.375 inches for the semi-rigid wings. 


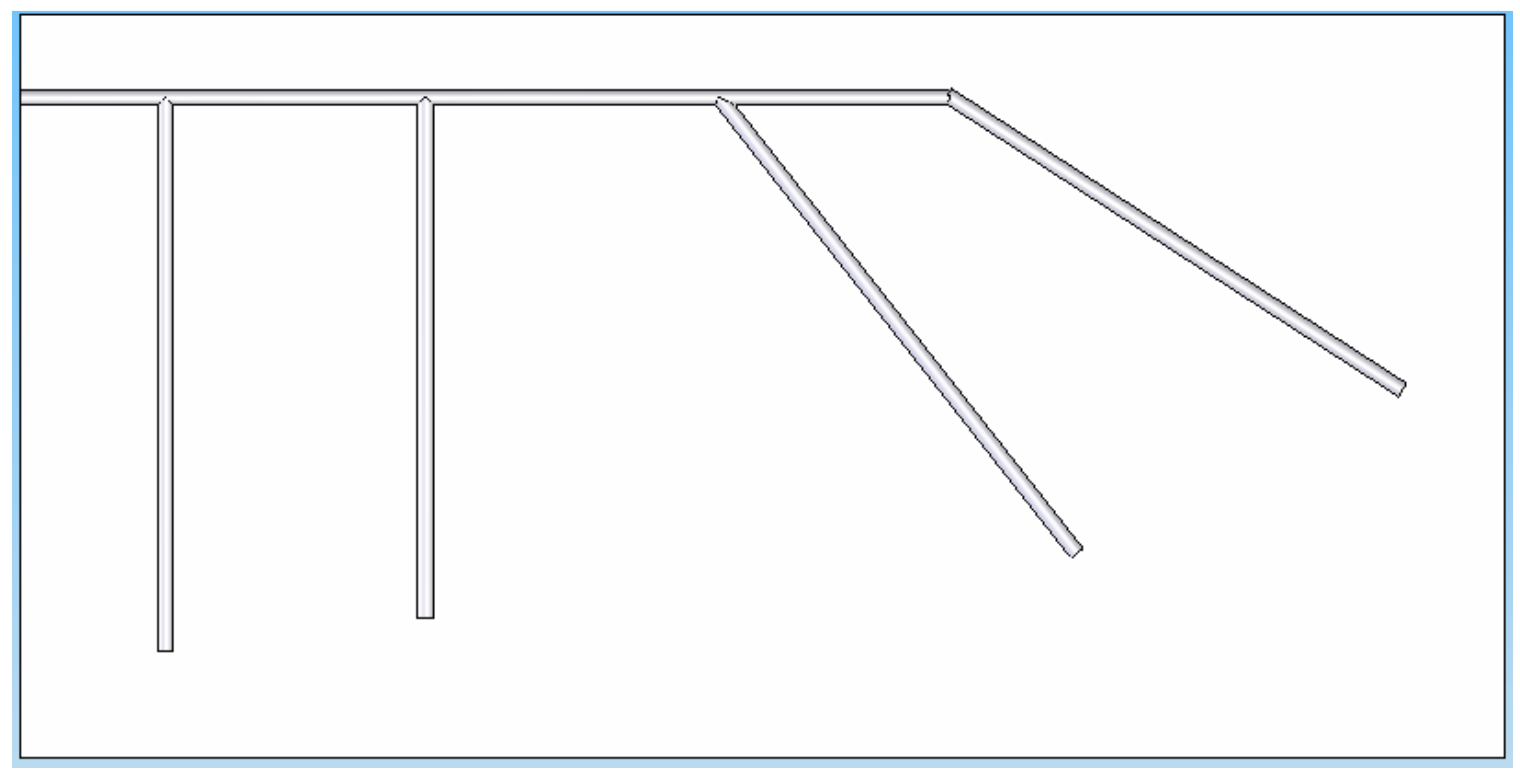

Figure 4.15: View of Wing Mold - One Half (CAD Model)

\subsubsection{Wing Flexibility}

After each set of wings were built, it was useful to determine how much the wings would deform, or flex, under an applied load. This would allow for a quantization of the wing's flexibility characteristics. This testing was performed in two parts. First, various loads from 0 to 50 grams were applied to each of the major 7 intersection and connection points on the structural skeleton, with the resulting deformation being measured. The second test involved making sure the wing could handle a load of $1 \mathrm{lb}$ without failing. 1 pound was selected as a target because the entire apparatus weighed approximately 1.75 lbs, with two wings distributing the load between them at about $1 \mathrm{lb}$ each.

To perform the first test, the wing was clamped at the root to a table edge with its membrane parallel to the horizontal surface. The wing was categorized into 7 structural points, with each point being assigned a number from 1 to 7 . Figure 4.16 below shows 
the locations of the 7 points. The black lines are the unidirectional filled carbon fiber sleeves. The white is the fiberglass membrane.

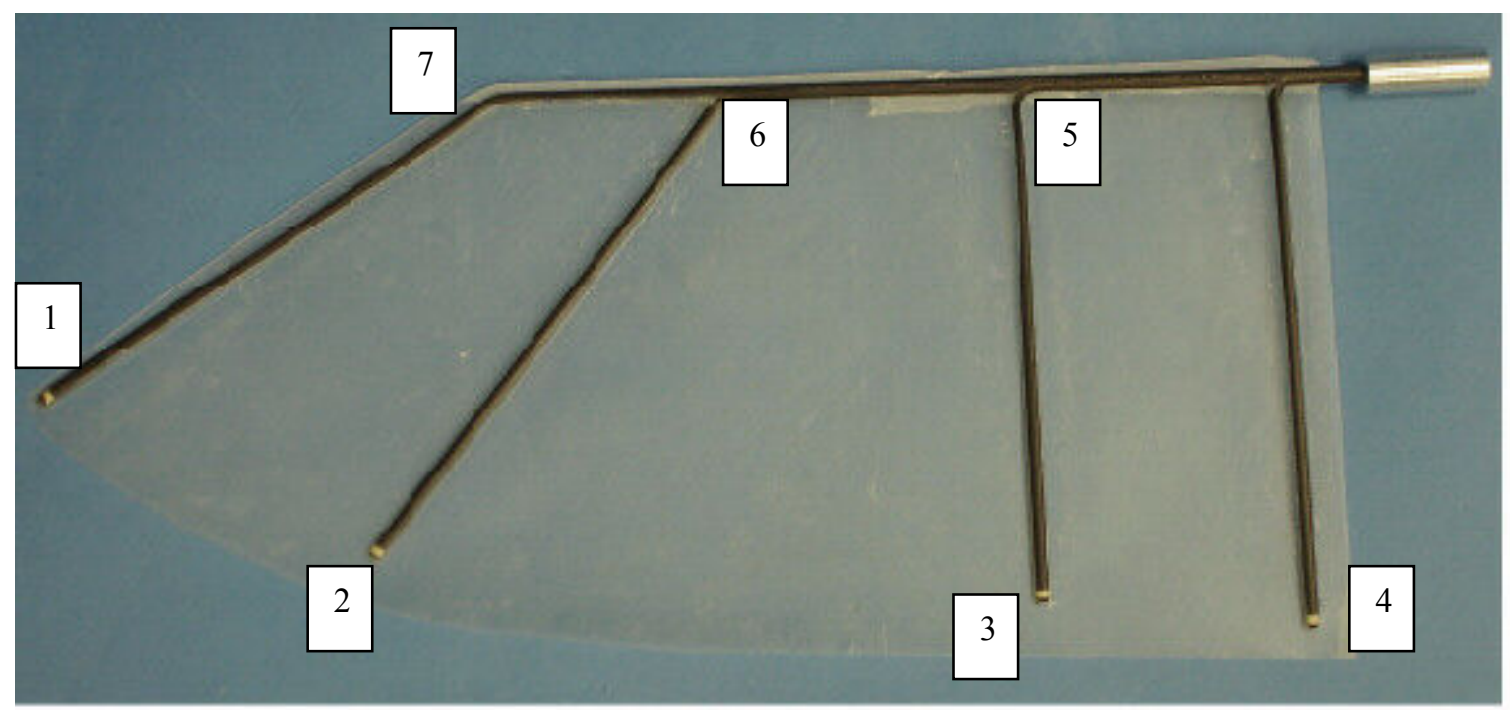

Figure 4.16: 7 Structural Points of Flexible Wing 1

At each of the 7 locations, individual weights were placed, ranging from 3 grams to 50 grams. A laser distance measurement tool was placed on the ground under the wing, which was clamped to the edge of the table. The laser was first aimed at the underside of point 1 (Figure 4.16), and the initial position was recorded. Next, a 3 gram weight was added to the top of point 1 ; this caused the wing to deform slightly. The laser measurer was then used to record the new position, which was the amount of deflection. This result was subtracted from the initial measurement yielding a true value of deflection. Then additional weights were added to point 1 , with the deflection of each being measured. This process was done for each of the 7 structural points of the wing. Table 4.2 lists the weights used and the amount of deflection at each point. 
Table 4.2: Weights Applied to Structural Points of Wing 1

\begin{tabular}{c|ccccccc} 
Weight (Ib) & $\begin{array}{c}\text { Point 1 } \\
\text { Deflection } \\
\text { (in) }\end{array}$ & $\begin{array}{c}\text { Point 2 } \\
\text { Deflection } \\
\text { (in) }\end{array}$ & $\begin{array}{c}\text { Point 3 } \\
\text { Deflection } \\
\text { (in) }\end{array}$ & $\begin{array}{c}\text { Point 4 } \\
\text { Deflection } \\
\text { (in) }\end{array}$ & $\begin{array}{c}\text { Point 5 } \\
\text { Deflection } \\
\text { (in) }\end{array}$ & $\begin{array}{c}\text { Point 6 } \\
\text { Deflection } \\
\text { (in) }\end{array}$ & $\begin{array}{c}\text { Point 7 } \\
\text { Deflection } \\
\text { (in) }\end{array}$ \\
\hline 0.0066 & 0.228 & 0.144 & 0.06 & 0.036 & 0.024 & 0.024 & 0.072 \\
0.011 & 0.396 & 0.276 & 0.096 & 0.06 & 0.048 & 0.048 & 0.132 \\
0.022 & 0.804 & 0.456 & 0.168 & 0.132 & 0.06 & 0.084 & 0.216 \\
0.044 & 1.5 & 0.888 & 0.264 & 0.204 & 0.096 & 0.132 & 0.336 \\
0.066 & 2.22 & 1.284 & 0.432 & 0.288 & 0.132 & 0.18 & 0.492 \\
0.088 & 3.33 & 1.908 & 0.54 & 0.408 & 0.144 & 0.276 & 0.648 \\
0.11 & 5.244 & 2.508 & 0.684 & 0.492 & 0.156 & 0.324 & 0.84
\end{tabular}

Applying the weights in steady increments allowed for the observation of the wing flexibility. From the above table, it can be seen that majority of the deflection occurs towards the tip of the wing. This is as one would expect since in natural flyers, the area nearest the wingtip deforms the most. In natural flyers, most of the lift is generated farther away from the root of the wing. This is due to the high amount of deflection the wingtips see from a rest horizontal position. Figure 4.17 below shows a plot of the applied loads at each point and the resulting deflections. 


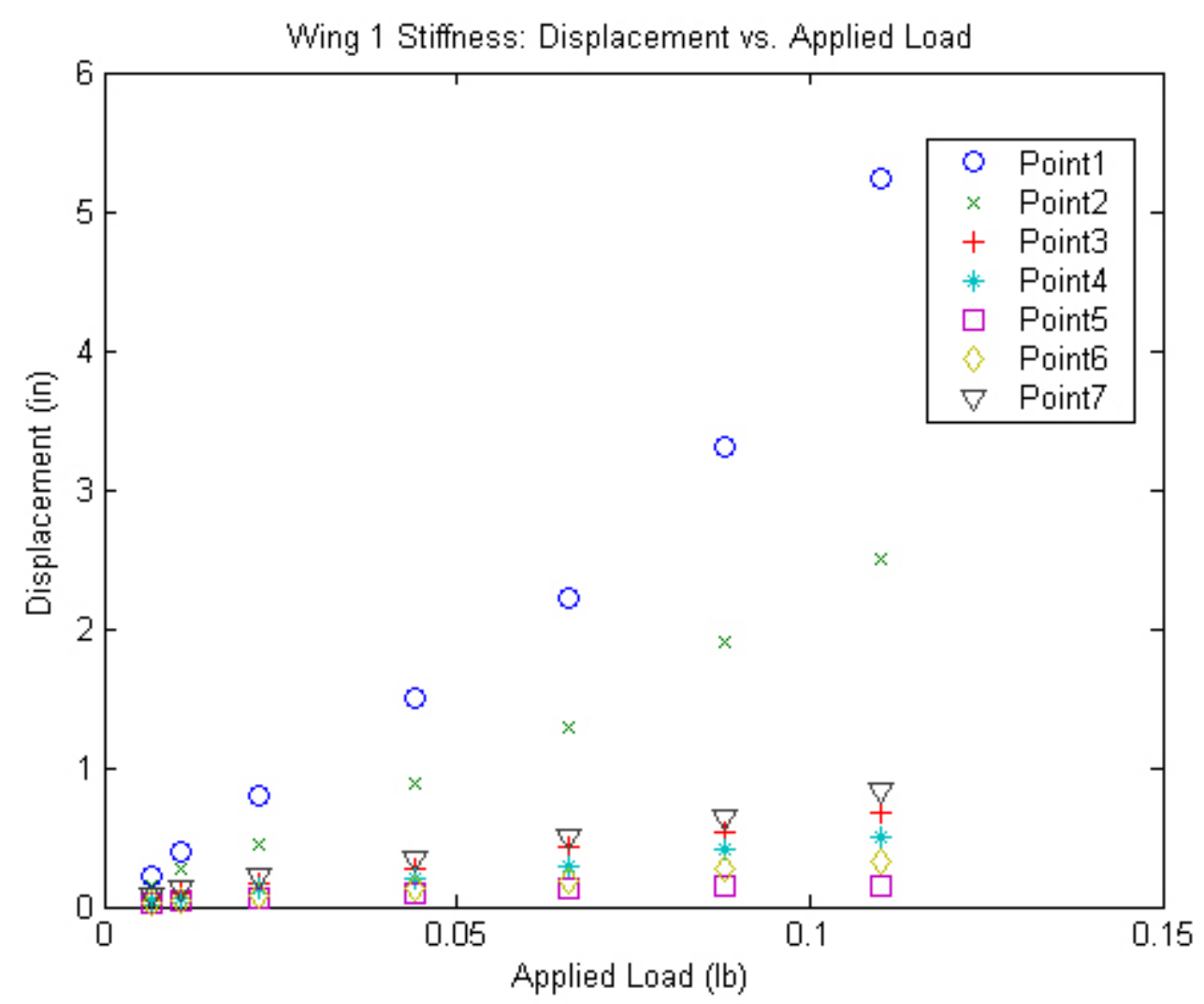

Figure 4.17: Wing 1 Stiffness Curves

The second step was to ensure that the wings were capable of supporting the load of the mechanism without failing. The entire mechanism weighed approximately $2 \mathrm{lbs}$, and since there were two wings, each needed to be capable of lifting $1 \mathrm{lb}$. To test this, a similar test procedure was developed as with the previous wing deflection experiment. This time however, each of the 7 structural connection points was loaded at the same time with $1 \mathrm{lb}$ of weight. This was done in 3 trials. In each trial, the load was distributed among those 7 points. Table 4.3 displays each of the 3 trials and the loads applied at each position. After all of the weights were applied on the wing, the laser measurement tool described above was used at each point to calculate the resulting deflection. This value 
was subtracted from a preliminary initial position value to give a true deflection amount for the applied weight.

Table 4.3: Distributed Loading on Flexible Wing Trial 1 Trial 2 Trial 3

\begin{tabular}{|c|cc|cc|c|c|}
\hline Position & Weight (Ib) & $\begin{array}{c}\text { Deflection } \\
\text { (in) }\end{array}$ & $\begin{array}{c}\text { Weight } \\
\text { (lb) }\end{array}$ & $\begin{array}{c}\text { Deflection } \\
\text { (in) }\end{array}$ & $\begin{array}{c}\text { Weight } \\
\text { (lb) }\end{array}$ & $\begin{array}{c}\text { Deflection } \\
\text { (in) }\end{array}$ \\
\hline 1 & 0.044 & 0.791 & 0 & 0.618 & 0 & 0.625 \\
2 & 0.11 & 0.811 & 0.066 & 0.711 & 0.044 & 0.703 \\
3 & 0 & 2.508 & 0.11 & 2.748 & 0.066 & 2.604 \\
4 & 0.22 & 1.524 & 0.11 & 0.336 & 0.22 & 2.112 \\
5 & 0.44 & 0.564 & 0.44 & 0.612 & 0.44 & 0.564 \\
6 & 0.11 & 1.896 & 0.22 & 1.788 & 0.11 & 1.752 \\
7 & 0.066 & 2.988 & 0.044 & 2.604 & 0.11 & 2.796 \\
\hline
\end{tabular}

From the above table, it can be seen that even though the positions of the loads were changed, the amount of deflection is quite consistent for the amount of weight added. Since the wing did not fail during these experiments, it is safe to assume that it is capable of carrying a load of $1 \mathrm{lb}$.

The same experiment was carried out for the second and stiffer Wing 2. Since the wing was stiffer larger weights were used (Table 4.4).

Table 4.4 Weights Applied to Structural Points of Wing 2

\begin{tabular}{c|ccccccc} 
Weight (Ib) & $\begin{array}{c}\text { Point 1 } \\
\text { Deflection } \\
\text { (in) }\end{array}$ & $\begin{array}{c}\text { Point 2 } \\
\text { Deflection } \\
\text { (in) }\end{array}$ & $\begin{array}{c}\text { Point 3 } \\
\text { Deflection } \\
\text { (in) }\end{array}$ & $\begin{array}{c}\text { Point 4 } \\
\text { Deflection } \\
\text { (in) }\end{array}$ & $\begin{array}{c}\text { Point 5 } \\
\text { Deflection } \\
\text { (in) }\end{array}$ & $\begin{array}{c}\text { Point 6 } \\
\text { Deflection } \\
\text { (in) }\end{array}$ & $\begin{array}{c}\text { Point 7 } \\
\text { Deflection } \\
\text { (in) }\end{array}$ \\
\hline 0.11 & 0.384 & 0.3 & 0.108 & 0.168 & 0.036 & 0.12 & 0.168 \\
0.22 & 0.72 & 0.516 & 0.18 & 0.204 & 0.06 & 0.18 & 0.288 \\
0.33 & 1.14 & 0.864 & 0.288 & 0.264 & 0.072 & 0.24 & 0.384 \\
0.44 & 1.764 & 1.308 & 0.468 & 0.348 & 0.072 & 0.312 & 0.492 \\
0.55 & 2.34 & 1.596 & 0.636 & 0.444 & 0.096 & 0.408 & 0.588 \\
0.66 & 2.808 & 1.824 & 0.756 & 0.564 & 0.096 & 0.468 & 0.72 \\
0.77 & 3.072 & 2.064 & 0.936 & 0.624 & 0.12 & 0.504 & 0.828 \\
0.88 & 3.828 & 2.412 & 0.996 & 0.696 & 0.144 & 0.552 & 0.936 \\
0.99 & 3.852 & 2.724 & 1.044 & 0.792 & 0.168 & 0.6 & 1.02 \\
1.1 & 4.248 & 3.036 & 1.164 & 0.9 & 0.216 & 0.672 & 1.14
\end{tabular}


Figure 4.18 below shows a plot of the applied loads at each point and the resulting deflections.

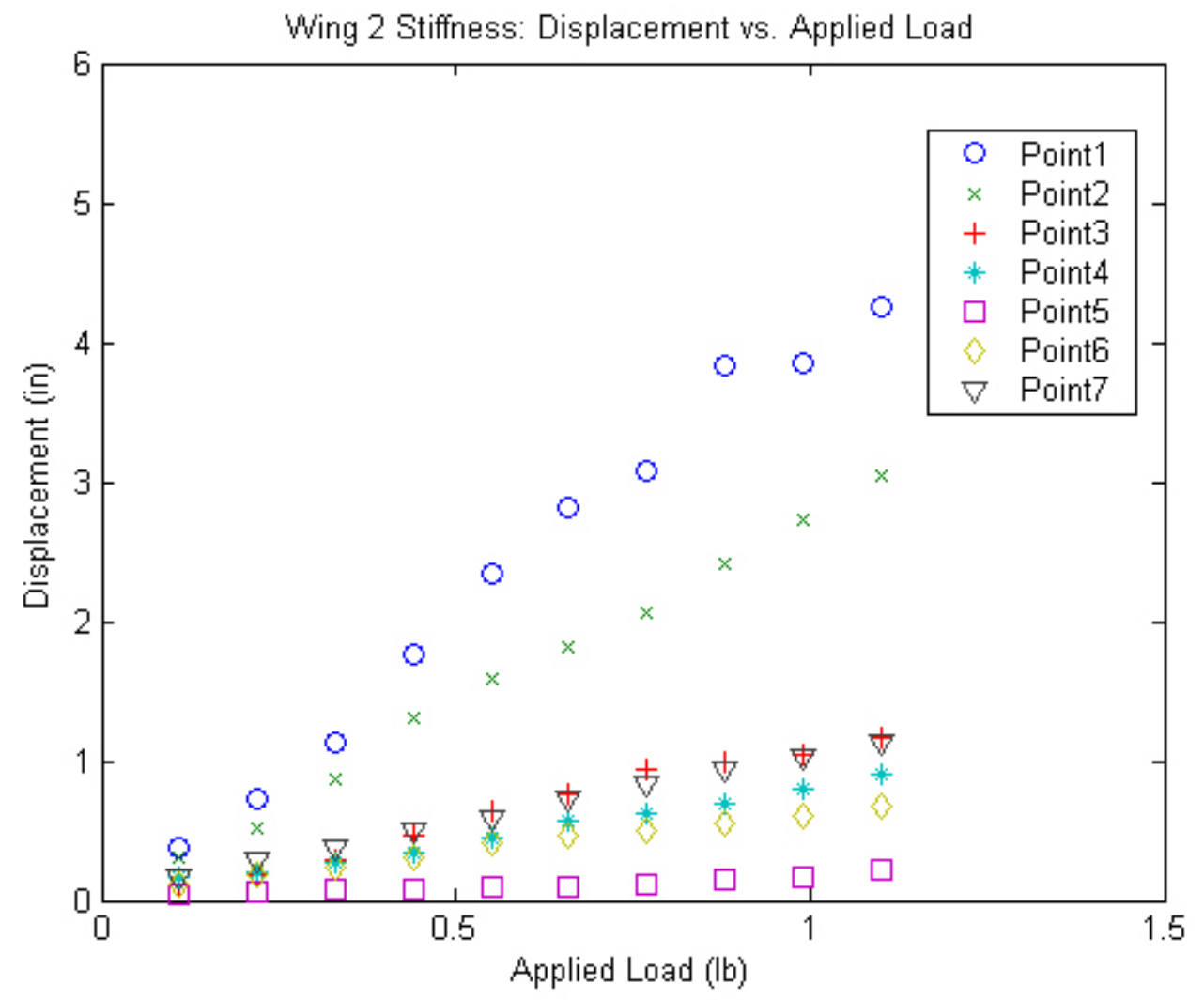

Figure 4.18: Wing 2 Stiffness Curves

Table 4.5 below shows the increase in stiffness of each point from Wing 1 to

Wing 2. It can be seen that there is a dramatic increase in stiffness for each point.

Table 4.5: Stiffness Increases from Wing 1 to Wing 2 per Point

\begin{tabular}{|l|c|c|c|c|c|c|c|}
\hline Point: & 1 & 2 & 3 & 4 & 5 & 6 & 7 \\
\hline Wing 1 Stiffness (Ib/in): & 0.0978 & 0.0487 & 0.0131 & 0.0096 & 0.0028 & 0.0063 & 0.0156 \\
\hline Wing 2 Stiffness (Ib/in): & 4.1064 & 2.7722 & 1.1359 & 0.7610 & 0.1587 & 0.5567 & 0.9792 \\
\hline Increase in Stiffness \%: & 41.9852 & 56.8824 & 86.8670 & 79.6400 & 57.2393 & 88.8723 & 62.7998 \\
\hline
\end{tabular}


The point which saw the greatest increase in stiffness was Point 6, followed closely by points 3 and 4 . When the first wing was cantilevered, and had weights applied to it, Point 6 was the point where the wing always buckled. This gain in stiffness at this point was very beneficial and dramatically increased the structural stability of the wing. 


\section{CHAPTER 5: EXPERIMENTAL APPARATUS}

\subsection{Force Balance}

A testing apparatus was constructed to measure lift and thrust forces generated by the flapping mechanism. The test bed was essentially a set of springs coupled with linear ball bearings and linear air bearings. A testing superstructure frame built out of 1 inch aluminum structural tubing was constructed to route wires and mount mechanism electronics. A conceptual view can be seen in Figure 5.1.

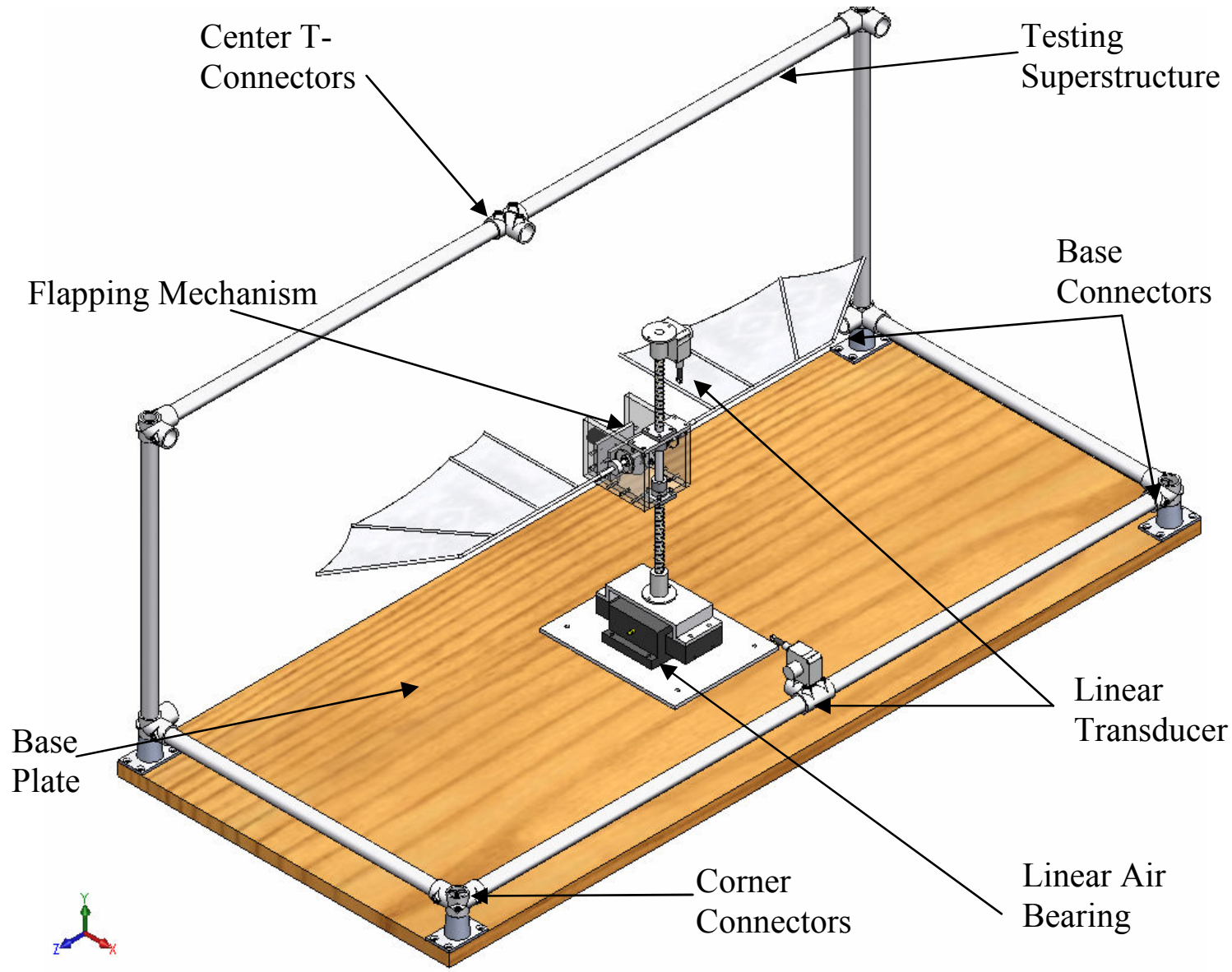

Figure 5.1: Test Superstructure and Flapping Mechanism (CAD Model) 
The basic premise of this testing superstructure was to use springs, linear position transducers, and bearings in parallel to measure distance and thrust. The mechanism was constrained by bearings so that it was only capable of motion in the $\mathrm{X}$ and $\mathrm{Y}$ directions (Figure 5.1). Motion in the $+\mathrm{X}$ direction represented thrust, while motion in the $-\mathrm{X}$ direction represented drag. Similarly, motion in the $+Y$ direction represented lift. Figure 5.2 below shows a close-up view of the mechanism's ability to translate $\pm \mathrm{Y}$.

In order to move in the $\mathrm{X}$ direction, a linear air bearing was used. Originally, linear ball bearings were used in conjunction with a rail assembly on which they rode. However, this idea was not used because the static friction inherent in the ball bearings was too high, and there were also binding issues. The air bearing was supplied with 90 psi, and yielded an almost frictionless cushion of air for the mechanism to move on. Connected to the air bearing was an aluminum bracket (Figure 5.3). The mechanism itself was mounted directly to this bracket via the use of an aluminum rod.

When the measuring end of the linear transducers was connected to the mechanism, the 7 ounces of force their internal spring had was enough to move the mechanism all the way to one end. This was due to the recoiling force required to keep the measurement cable in constant tension. To constrain the mechanism at the center point of the air bearing, a spring was used. One end of the spring was attached to the sliding part of the air bearing, while the other was attached to a fixed point on the testing apparatus. This distance where the fixed-end of the spring was attached was hand calibrated until the mechanism naturally stayed in the center point of the air bearing, using the spring force as well as the linear transducer's recoil force. 
The mechanism rode up and down in the $\pm \mathrm{Y}$ direction on this rod through the use of 2 linear ball bearings (Figure 4.2). As shown in Figure 4.2, these bearings were mounted directly to the flapping mechanism. The mechanism was suspended on the center of the rod through the use of springs (Figure 5.2). Since springs were placed in parallel to the bearings' direction of translation, the mechanism created motions in the $\pm X$ and $\pm Y$ directions. The distance the mechanism moved was measured with the position transducers. These transducers, in turn with known spring constants of the springs, yielded force measurements.

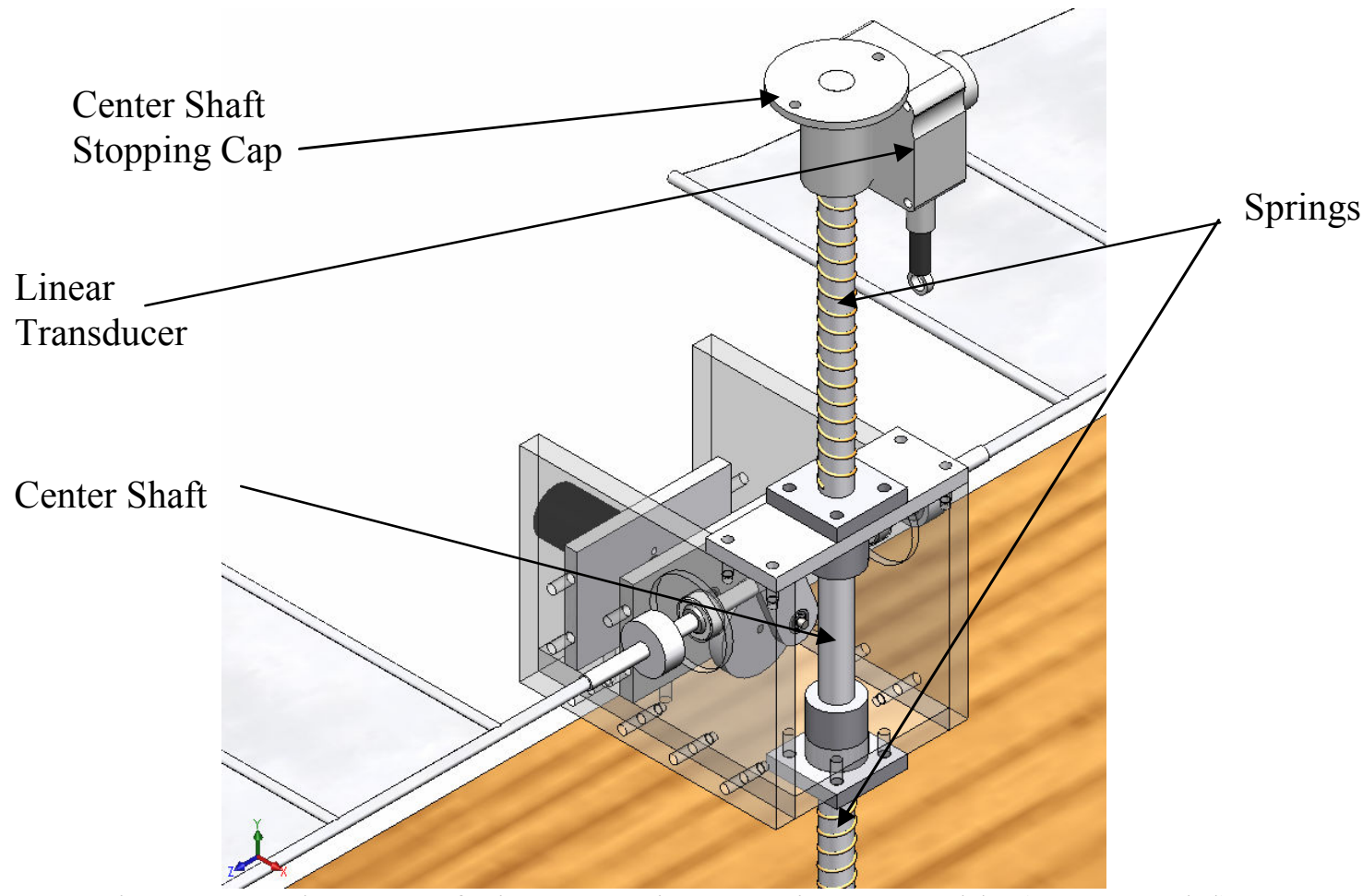

Figure 5.2: Close-Up of Linear Bearing Housing Assembly (CAD Model) 


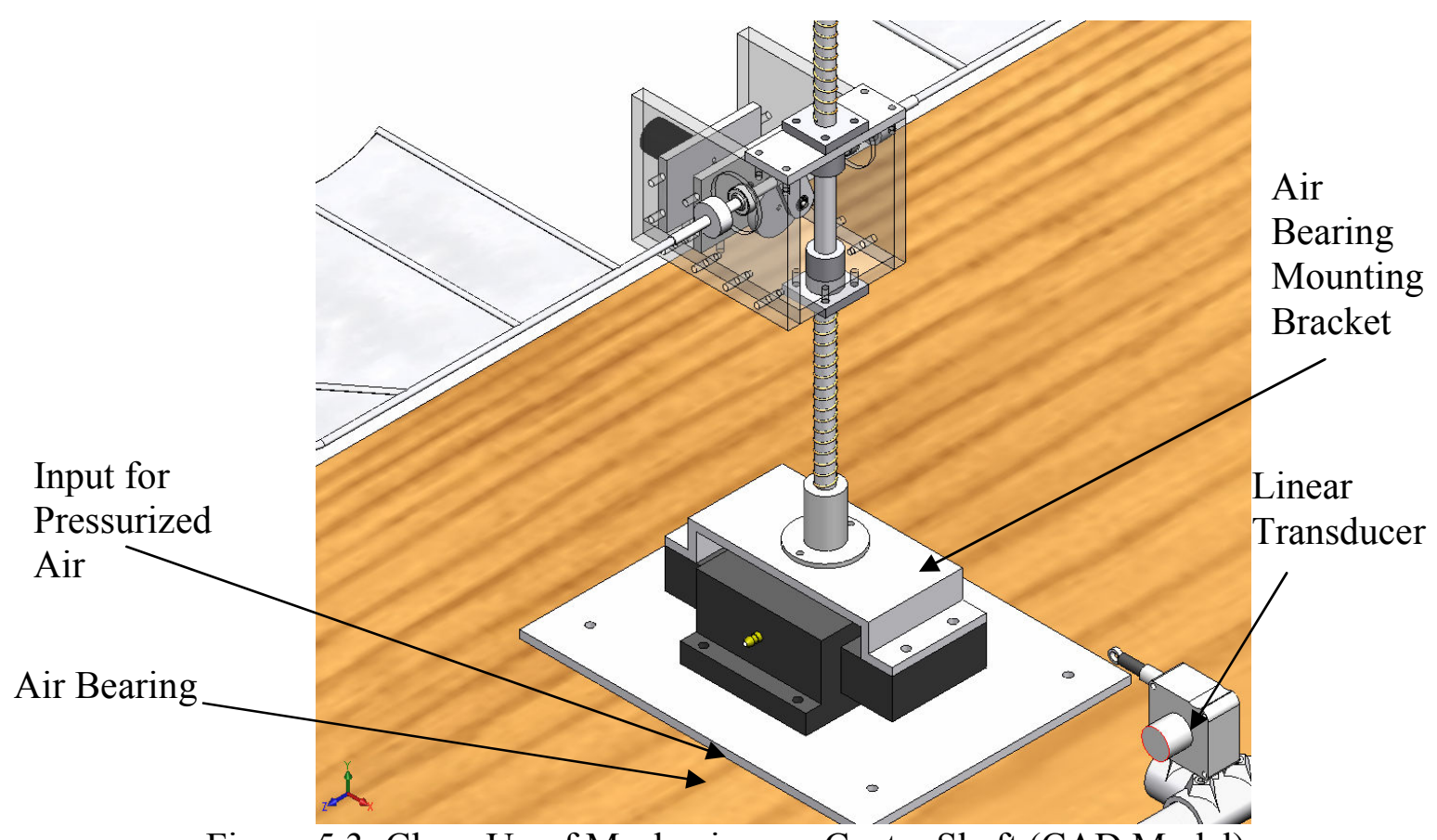

Figure 5.3: Close-Up of Mechanism on Center Shaft (CAD Model)

A metal frame was built around the edges of the test bed. This frame was build using 1 inch aluminum structural tubing. The tubing was connected using 3 -exit corner fittings as well as base-joint fittings, as shown in Figure 5.1. This frame served two purposes. First, it gave a base to mount the linear transducer measuring $\pm \mathrm{X}$ direction motions, as well as a mounting fixture to mount a terminal block which was used in wiring the mechanism electronics (i.e. motor, encoder, transducers). The aluminum tubing was also served as a wire routing frame to neatly hold and run wires from the mechanism and all of its electronic components to the LabView data acquisition cards and control computer. Neatly routing the wires and securing them to a frame ensured that the wires would not get tangled, or tear at connection joints while transmitting data to a computer more than 10 feet away from the mechanism. An actual image of the testing assembly can be seen in Figure 5.4. 


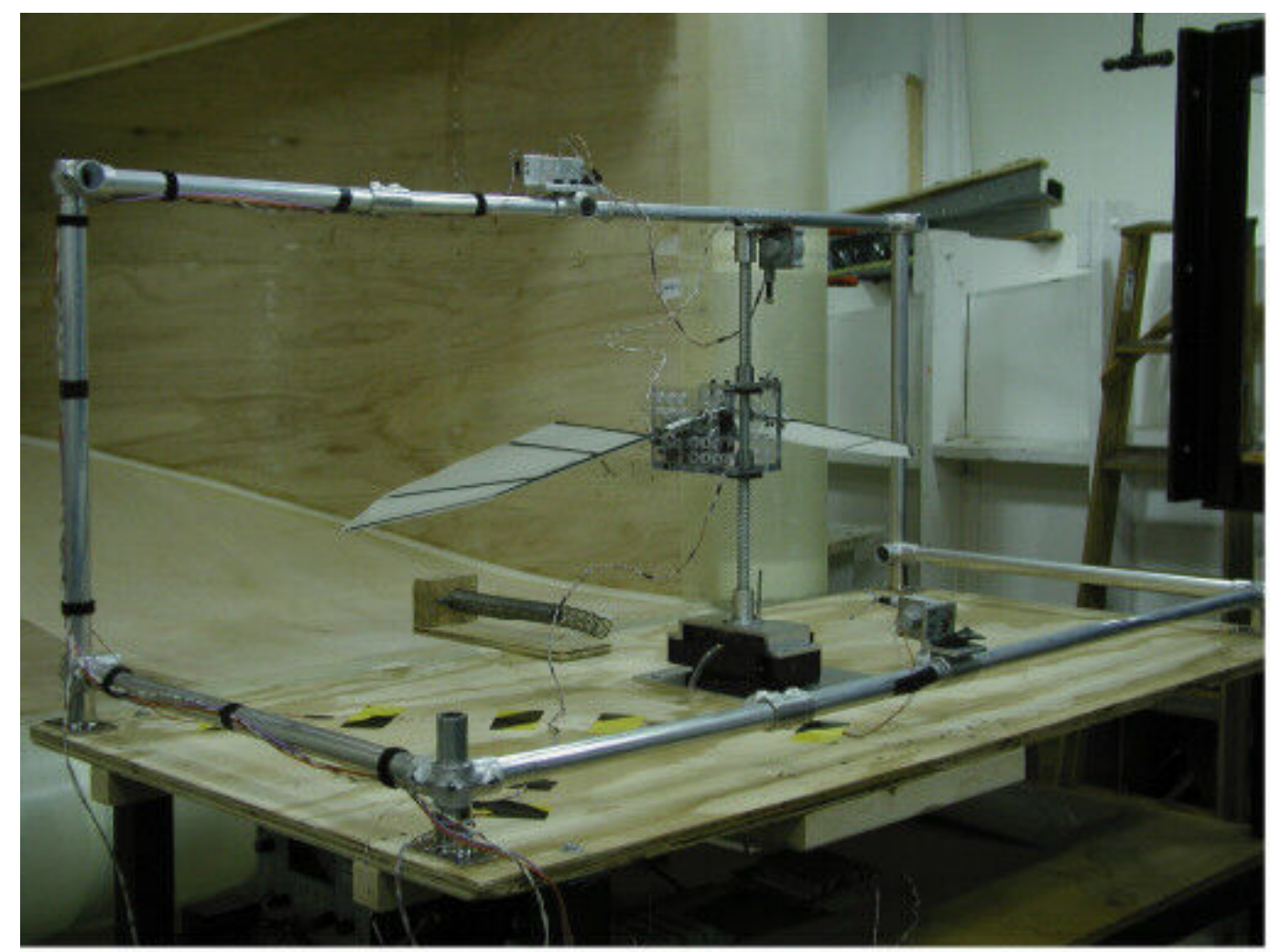

Figure 5.4: Actual View of Mechanism in Test Assembly

\subsection{Springs}

In order to keep the mechanism centered within the testing structure, a series of springs were used. These springs were purchased from Century Spring Corp, and W.B. Jones Spring Co. Table 5.1 below shows the springs used and their various properties. Spring 3 was a custom made spring purchased from W.B. Jones Spring Co.

Table 5.1: Summary of Springs Used for Centering Mechanism in Test Apparatus

\begin{tabular}{|c|c|c|c|c|}
\hline Spring \# & $\begin{array}{c}\text { Outer Diameter } \\
\text { (in) }\end{array}$ & $\begin{array}{c}\text { Inner Diameter } \\
\text { (in) }\end{array}$ & $\begin{array}{c}\text { Free Length } \\
\text { (in) }\end{array}$ & $\begin{array}{c}\text { Spring Constant } \\
\text { (lb/in) }\end{array}$ \\
\hline 1 & 0.640 & 0.570 & 11.0 & 0.280 \\
\hline 2 & 0.687 & 0.563 & 16.0 & 1.60 \\
\hline 3 & 1.250 & 1.100 & 11.0 & 0.250 \\
\hline
\end{tabular}


To keep the mechanism suspended in the vertical direction $( \pm \mathrm{Y})$, a combination

of Spring 1 and Spring 2 were used. Spring 1 was used above the mechanism and Spring 2 was used below it. Spring 2 was a stiffer spring because it also needed to support the weight of the mechanism. Now that the mechanism was constrained between 5 springs ( 3 mentioned in Table 5.1, and the tension of the 2 position transducers) the spring constants would be different than specified by the manufacturers. This meant that the spring constants needed to be measured again. This calibration of the force balance is described in Chapter 6.

\subsection{Wind Tunnel Modification}

To simulate the effects of forward flight, an existing low-speed wind tunnel was used. It was desired to put the entire mechanism, which had a 38 inch wingspan, and test assembly in an incoming flow of $5 \mathrm{~m} / \mathrm{s}$. As the wind tunnel had a 30 inch by $30 \mathrm{inch}$ cross section and a minimum speed of $9 \mathrm{~m} / \mathrm{s}$, modifications were necessary. Since the mechanism with the wings was approximately 38 inches in span, and it was desired to avoid wall interference effects, the closed return tunnel was converted to an open-jet closed return tunnel.

First the 30 inch by 30 inch test section was removed, allowing the air to exit into an open room. The original tunnel consisted of a convergent section where the flow entered a 60 inch by 30 inch cross section which then transitioned to the working cross section. Next, this convergent section was removed, allowing for a lower tunnel velocity and a $60 \times 30$ inch working section. It was also necessary to recapture the air and guide it back into the tunnel. In order to do this, an aft-end collector with a large radius was 
constructed. The collector was a bell-mouth shaped collar made out of 1/16 inch plywood skin with a wooden exoskeleton. A view of the recapture collar, the test assembly and the mechanism in the entire experimental setup can be seen in Figure 9. An actual image of the recapture collar can be seen in Figure 5.5.

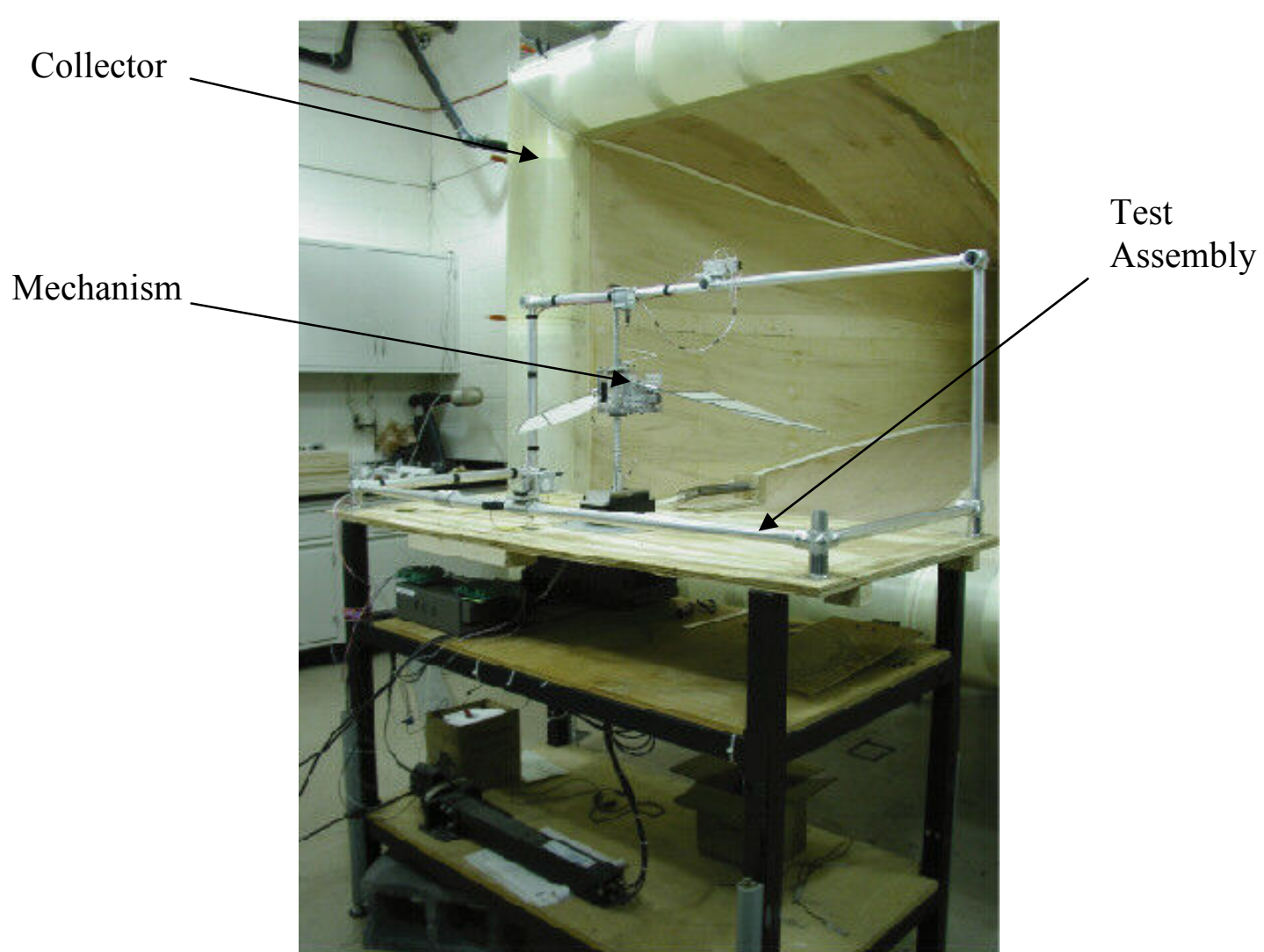

Figure 5.5: Actual View of Wind Tunnel After Modifications

Removing the test section of the wind tunnel, and allowing the flow to enter a larger chamber without passing through a cross section reducing nozzle, allowed for a slower flow as well as reduced wall interference effects. The modified tunnel was able to achieve velocities as low as $4.25 \mathrm{~m} / \mathrm{s}$ and as high as $11.65 \mathrm{~m} / \mathrm{s}$. The flow velocity was approximately $2.5 \%$ lower near the edge of the flow. 


\section{CHAPTER 6: TEST EQUIPMENT CALIBRATION}

One of the first tasks in any testing procedure is to calibrate the measurement equipment. It was necessary to convert the analog voltages output by the position transducers and encoder into distance and frequency measurements. It was also necessary to write a data acquisition program to record the data to be later analyzed.

LabView was used to read the data acquired from the potentiometers, motor and encoder. A NI6036E National Instruments data acquisition (DAQ) card was used to read the voltage levels of the potentiometers as well as the encoder. To connect the devices to the DAQ card, a terminal block was used: model number CB-68LP. The terminal block offered straight line wire/pin connections to the DAQ card in the computer.

\subsection{Calibration of Potentiometers}

\subsubsection{Measuring Spring Deflection: Position Transducers}

Linear position transducers were purchased from Celesco Electronics to measure spring deflection. The transducers chosen were the Compact String Pot SP1 with a 12.75 inch full stroke range. They output a voltage depending on the amount a cable is extended. The SP1 has $0.05 \%$ full stroke repeatability and an accuracy of $0.25 \%$. The cable tension was 7 ounces.

One transducer was used in the vertical direction (lift) and one was used in the horizontal direction (thrust and drag). The transducer measuring thrust and drag was bolted to the actual testing structure, and its cable was extended and attached to the 
mechanism itself. The transducer measuring lift was bolted to the top linear bearing housing and the cable was again extended and attached to the mechanism. As the mechanism moved within the assembly, output voltages were recorded, corresponding to positions. These positions were converted to forces based on spring constants of the springs in the force balance.

\subsubsection{Wiring}

The transducers output an analog voltage signal from $0-12$ volts. There was a direct linear relationship between voltage and distance the cable was pulled, meaning if the cable of the transducer was extended 12 inches, the output voltage will be 12 volts, given a 12 volt supply to the device. However, LabView can only accept voltage signals from -10 volts to +10 volts. Since a 12 volt car battery was used to solely power the transducers (an effort to isolate the signals from ambient noise), a potentiometer was wired to the battery to regulate the voltage to +10 volts.

The ground pins of both the transducers were connected to the common ground on the battery. The supply pins were both connected to the variable pin on standard rotary potentiometer, allowing the voltage to be regulated at +10 volts. Using this potentiometer maintained the voltage at the desired value as the battery drained down below 12 volts.

\subsubsection{Distance Calibration and LabView}

From the signal pin of the transducer the variable voltage level was sampled. The continuous scan function (C-Scan.vi) in LabView was used. This function took time sampled measurements (in this case voltage measurements) of a group of channels. Since 
there were two transducers, two channels were used. This data was stored in a circular buffer and returned a specified number of scan measurements. The sampling rate was 5000 samples per second over a 10 second time period. Next, the data was stored in a data array, and then the using an averaging function, the mean of the data was taken. This was done to compensate for errors in data acquisition, and allowed for better data samples, smoothing out inconsistent peaks. The voltage was then output to the screen. This voltage was output predominantly for monitoring purposes ensuring the transducers were working properly.

Next the voltage acquired through the DAQ card was converted into a distance. There was no longer a 1:1 relationship between voltage and distance since the transducers were receiving 10 volts instead of 12 . An experiment was performed to determine the new ratio. When the transducer was fully released (at the 0 inch position), there were 0 volts across it. However when the potentiometer was fully extended to a measured 12.75 inches, it was noted that the voltage was 9.85 volts across it. Dividing the two yielded a ratio of volts per inch. Equation 6.1 gives an overview of how the required ratio of volts/inch was obtained.

$$
\frac{9.85 \mathrm{~V}}{12.75 \mathrm{in}}=0.773 \frac{\mathrm{V}}{\mathrm{in}}
$$

Using the above obtained ratio of 0.773 volts per inch, the averaged voltage output to the screen was divided by the ratio to yield a stretch distance. The position transducers were attached to the device in the force balance. Now as the mechanism moved, the distance was measured and output to a LabView data panel. 


\subsection{Calibration of Force Balance}

The force balance needed to be calibrated because multiple springs were now used in each direction. In addition the mechanism when placed in the balance, compressed the springs. This in turn yielded new spring constants which needed to be measured and put into the data acquisition program.

In order to measure the new spring constants a typical set of experiments to measure spring rates was carried out: weights were applied to the spring, their displacement was measured, the data was plotted, and the spring constants were obtained from the graph. Since the linear transducers were already connected to the mechanism, weights could be directly attached to the mechanism. Again, the amount the mechanism translated was output to the LabView front panel. This was how distance was measured for the calibration experiments. This experimental data was corroborated with theoretical values as a second check to determine the validity of the results.

\subsubsection{Calibration of $\pm X$ Direction (Thrust)}

First, the new spring constant was calculated theoretically. The spring constant of the Spring 3 (from Table 5.1) was $0.25 \mathrm{lb} / \mathrm{in}$. The position transducer was used to balance it on the other side. The transducer consisted had a cable recoil tension of 7 ounces or $0.4375 \mathrm{lb} / \mathrm{ft}$ or $0.036 \mathrm{lb} / \mathrm{in}\left(\mathrm{k}_{1}\right.$ in Equation 6.2$)$, while it was known the spring constant of the custom made spring was $0.25 \mathrm{lb} / \mathrm{in}$ ( $\mathrm{k}_{2}$ in Equation 6.2). The combined spring constant is determined theoretically in Equation 6.2.

$k_{\text {eff }}=k_{1}+k_{2}=0.25 \mathrm{lb} /$ in $+0.036 \mathrm{lb} /$ in $=0.29 \mathrm{lb} /$ in

Equation 6.2 
A range of weights, from $100 \mathrm{~g}$ to $1 \mathrm{~kg}$ were tied to the mechanism and hung over a low friction pulley. The experiments were repeated 3 times, and the values were averaged. Table A.1 in Appendix A displays the data used for this calibration. Figure 6.1 shows the experimental setup to measure the new spring constant.

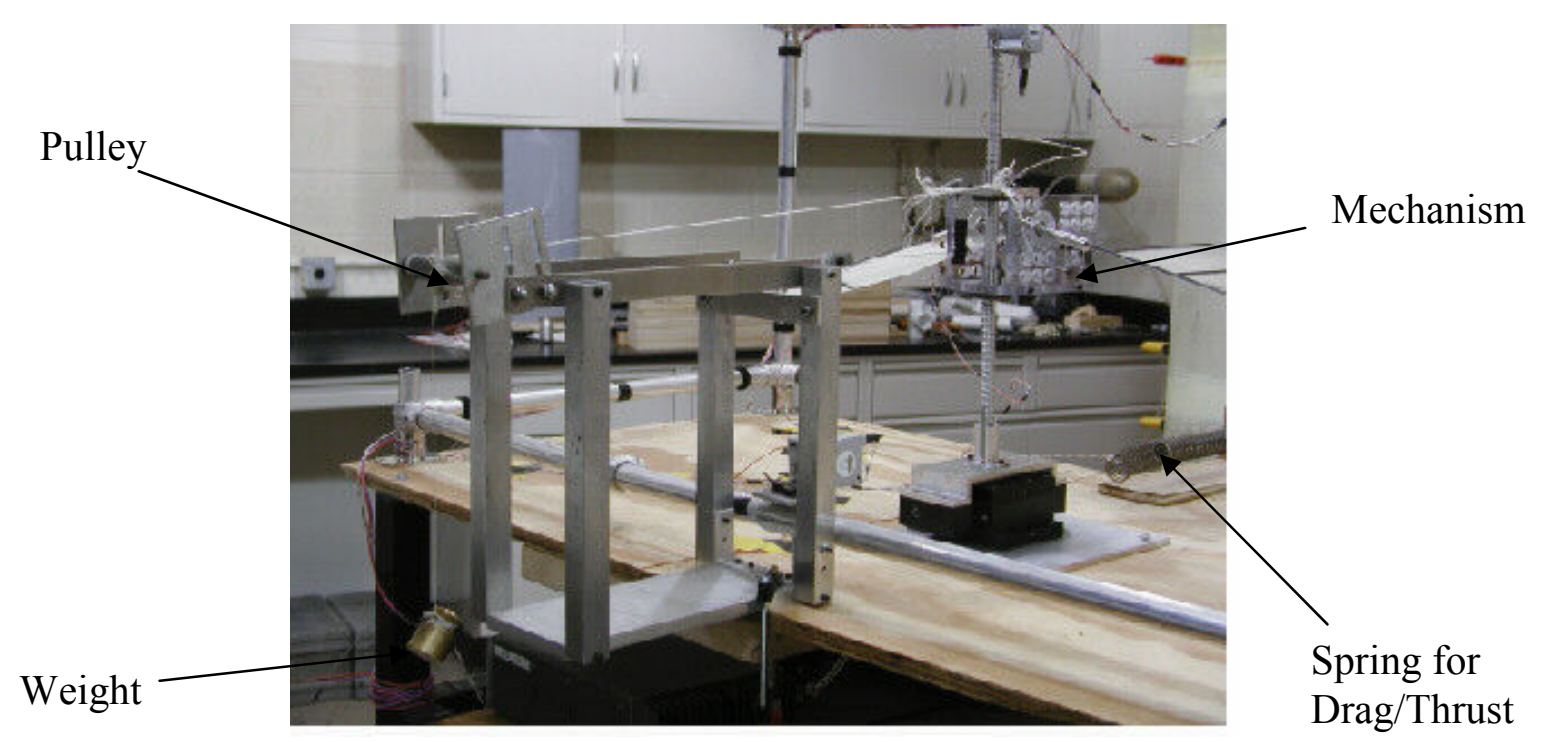

Figure 6.1: View of Force Measurement for Drag and Thrust

When the spring calibration experiment was completed and the data plotted, it was found that the measured spring constant was approximately $0.32 \mathrm{lb} /$ in. Figure A. 1 in Appendix A shows a plot from which the spring constants were obtained. This variation can most likely be due to the friction between the spring and the aluminum rod over which it rests. The static friction between these two can be quite significant, especially when very low loads such as these (less than half a pound) are being used.

\subsubsection{Calibration of \pm Y Direction (Lift)}

To measure the spring constant in $\pm \mathrm{Y}$ direction, weights were again attached to the mechanism and allowed to hang down via the use of a low friction pulley. In order to 
lift the mechanism up, and thus compress the top spring, the pulley was clamped to the top of the testing assembly directly above the top spring. Figure 6.2 displays the procedure for testing the spring constant of the top spring.

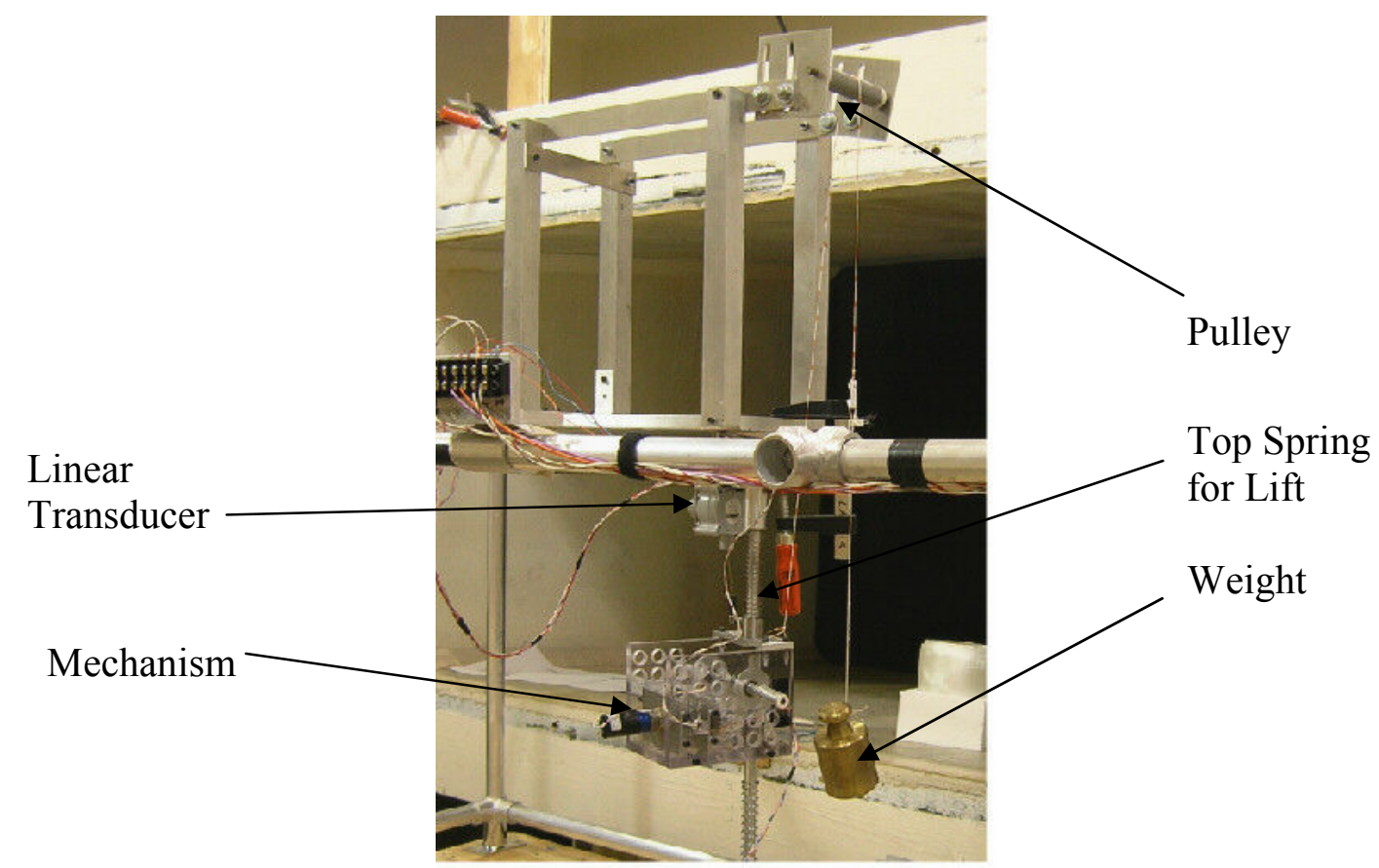

Figure 6.2 : View of Measuring Spring Constant of Bottom Spring

The value of the spring constant was measured to be 0.60 pounds per inch. The specified value from the manufacturer was 0.28 pounds per inch. As the top spring was cut down in length from 12 inches to 6 inches, this yielded a theoretical increase in spring constant of $50 \%$, from 0.28 pounds per inch to 0.56 pounds per inch. The measured value of 0.60 pounds per inch is very close and the 0.04 pounds per inch deviation can be most likely explained through friction, and that the spring was cut down to approximately 6 inches. Equation 6.3 and Equation 6.4 show how the spring constant was estimated theoretically. 


$$
\begin{aligned}
& \frac{l_{\text {new }}}{l_{\text {orig }}}=\frac{6 \mathrm{in}}{12 \mathrm{in}}=0.500 \\
& \frac{0.28 \mathrm{lb} / \text { in }}{0.5 \mathrm{lb} / \mathrm{in}}=0.56 \mathrm{lb} / \mathrm{in}
\end{aligned}
$$

Appendix A displays all of the raw and analyzed data for this calibration measurement.

\subsection{Calibration of Motor and Encoder}

\subsubsection{Wiring of Motor}

The motor was powered directly from a dedicated power supply. It was not feasible to power the motor from LabView as the maximum current able to be provided by the card was $5 \mathrm{~mA}$, and the maximum voltage was $10 \mathrm{~V}$. With this being a 12 volt motor and capable of drawing up to 0.74 amperes it made more sense to use a dedicated power supply. The motor was controlled directly from the power supply by increasing the voltage to increase the rotational speed (and thus flapping frequency) or by lowering the voltage to decrease the rotational speed.

\subsubsection{Wiring of the Optical Encoder}

As previously stated, the optical encoder hub-wheel was mounted directly to the drive shaft, and the encoder module was mounted to the bearing mounting plate. The encoder module consisted of 5 pins: ground, index, channel A, channel B, and supply. 
The encoder module must be supplied with +5 volts and draws typically $57 \mathrm{~mA}$ of current. A dedicated power supply was used to power the encoder module due to voltage and current limitations of the DAQ card. This ensured that the encoder module was supplied with as much current as necessary. The supply pin was connected to the positive node of the power supply, while the ground was connected to the common on the power supply. The ground on the power supply was also used as the common ground. Channels A and B were each connected to channels AI (analog input) 2 and 3. The index channel was connected to AI 4. The grounds for each of the AI pins were connected to the common power supply dedicated for the encoder.

\subsubsection{Encoder Calibration and LabView}

The index channel output of the encoder went high once per revolution, coincident with the low states of channels A and B, nominally $1 / 4$ of one cycle. Channel A and B pulsed high at approximately 0.4 volts and the phase lag or lead between the channels was approximately 90 electrical degrees.

From the pulses recorded from the encoder it was necessary to measure the angular position as well as the speed of the shaft. Measuring angular position was a fairly straightforward task. To do this a LabView program was written which used the inputs

of channel A, channel B and the index channel to determine position and angular speed. This information was acquired, stored in a buffer for 5 seconds and output to a data file. 


\subsection{Data Acquisition}

In order to observe the data trends over a defined period of time, in order to see trends and instantaneous values in force and distance per flap, it was necessary to export the data to a file. A LabView VI was written to do this. It was capable of exporting data as either a plain text document or a spreadsheet file (Excel). The output to this file were columns of data, with columns corresponding to thrust distance, lift distance, lift force, lift distance, flapping frequency, flywheel position, etc.

The front screen of the VI had a "Record Data" button, which when pressed would record " $\mathrm{x}$ " seconds of data, where " $\mathrm{x}$ " was a time in seconds preset. Generally, 5 seconds of data were recorded. As soon as the record button was pressed, the LabView program would start recording data as soon as the first window of the encoder wheel passed through the LED and read "high". All of the necessary parameters were recorded every $0.72^{\circ}$ of the encoder wheel (the distance between encoder windows) This data was written to an array and stored in memory until data was taken for 5 seconds. The program then output this information to an Excel spreadsheet.

\subsection{Angle of Attack Calibration}

One of the main variables in generating aerodynamic forces is the angle of attack of the wings. As previously stated in Chapter 2, the angle of attack is directly related to the amount of forward thrust generated in flapping wing flight. Therefore in this experiment, various angles of attack were explored. The angle of attack calibration was done using a large protractor with a wooden backing attached to a precision machined aluminum baseblock. The block was machined to ensure it was flat with respect to the horizontal. Figure 6.3 displays picture of what the calibration tool looked like. 


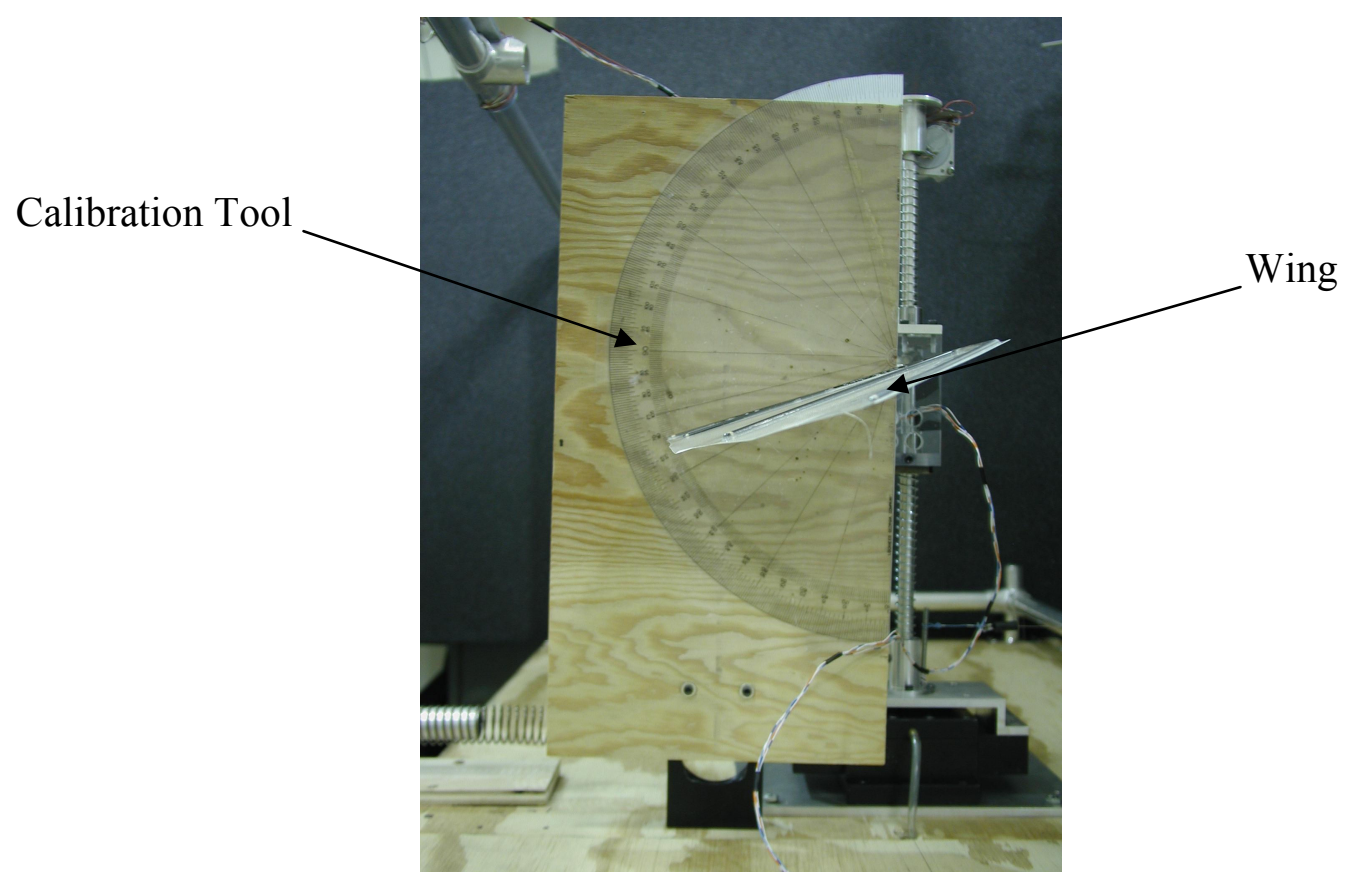

Figure 6.3: Angle of Attack Calibration Tool

The calibration tool was placed behind the root of the wing, in front of the body and eye calibrated to the desired angle. The tool was capable of calibrating for both positive as well as negative angles of attack. 


\section{CHAPTER 7: TESTING}

\subsection{Testing Approach: Test Matrix}

The test parameters studied for this research investigation consisted of an evolving test matrix. An initial matrix was proposed based on literature and research. As testing progressed, certain cases were omitted due to their lack and poor performance. Other cases were investigated further if the mechanism produced good results. Table 7.1 shows the final test matrix used for Wing 1.

Table 7.1: Test Matrix for Wing 1

\begin{tabular}{|c|c|c|c|c|c|c|}
\hline Wind Tunnel Speed: & \multicolumn{3}{|c|}{$0 \mathrm{~m} / \mathrm{s}$} & \multicolumn{3}{c|}{$5 \mathrm{~m} / \mathrm{s}$} \\
\hline Angle of Attack: & $0^{\circ}$ & $7.5^{\circ}$ & $15^{\circ}$ & $0^{\circ}$ & $7.5^{\circ}$ & $15^{\circ}$ \\
\hline Flapping Frequency & \multicolumn{3}{|c|}{ Cases } & \multicolumn{3}{c|}{ Cases } \\
\hline $2 \mathrm{~Hz}$ & & & & & & \\
\hline $3 \mathrm{~Hz}$ & & & & & & \\
\hline $4 \mathrm{~Hz}$ & & & & & & \\
\hline
\end{tabular}

Initially, tests were to be conducted at all of the cases listed above. However, during testing it was believed that the cases highlighted in black would not be of interest based on neighboring results. For example, the case involving testing at $2 \mathrm{~Hz}$, and at an angle of attack of $7.5^{\circ}$ was tested at $0 \mathrm{~m} / \mathrm{s}$ as well as $5 \mathrm{~m} / \mathrm{s}$. No lift was generated flapping at $2 \mathrm{~Hz}$, and virtually no thrust was generated. Thus, it did not make sense to flap at a frequency of $2 \mathrm{~Hz}$ anymore and none of the other $2 \mathrm{~Hz}$ test conditions were investigated further. Originally a flow speed of $10 \mathrm{~m} / \mathrm{s}$ was part of the test matrix. However, after the first test at this flow speed it was discovered that the mechanism did not have enough power to overcome the drag. The mechanism was pushed to the very 
rear of the force balance resulting in 0 forces produced. No further tests were conducted at this flow speed as it was believed no useful information would be observed.

The testing for Wing 2 was an evolving approach as well. Not all of the cases for Wing 1 were repeated with Wing 2 . Only the best cases of Wing 1, i.e. the ones that generated the most lift and thrust, were repeated again with Wing 2. Table 7.2 below shows the testing matrix ultimately used for Wing 2 .

Table 7.2: Test Matrix for Wing 2

\begin{tabular}{|c|c|c|c|c|}
\hline Wind Tunnel Speed: & $0 \mathrm{~m} / \mathrm{s}$ & \multicolumn{3}{|c|}{$5 \mathrm{~m} / \mathrm{s}$} \\
\hline Angle of Attack: & $0^{\circ}$ & $0^{\circ}$ & $7.5^{\circ}$ & $15^{\circ}$ \\
\hline Flapping Frequency & Cases & \multicolumn{3}{|c|}{ Cases } \\
\hline $3 \mathrm{~Hz}$ & & & & \\
\hline $4 \mathrm{~Hz}$ & & & & \\
\hline
\end{tabular}

In order to generate meaningful results from the experiments, a certain set of analyses was performed on the data. First, high-speed video was taken of each case. Using the high-speed video and the analysis software associated with it, it was possible to graph the wing tip and the wing root as a function of time for each set of flaps. Next, using the output from the LabView software and the resulting output encoder counts (and thus position of the flywheel), it was possible to get the lift and thrust forces generated versus the phase of the flap. The lift and thrust forces were then cycle averaged and correlated with wing position obtained from the high speed camera. This would give an idea as to how wing behavior affected the aerodynamic forces generated by the mechanism. 


\subsection{Encoder Position, Wing Tip and Root Position Correlation}

The high-speed video served three purposes. First, it served as a check that the frequency output by the encoder was accurate. Second, when the start times and positions of the encoder and high-speed video were synchronized, it was possible to visually observe exactly how the wing behaved during the flapping cycle and the associated aerodynamic forces generated by that position in the flap. Third, it made it possible to see how the wing flexed during various points in the flapping cycle.

This correlation was done for all of the experiments performed with Wing 1. It was not done for Wing 2 since it had already been proven 6 times with Wing 1 that the encoder position and wing positions line up, and it was a very tedious process. The synchronization discussed here in detail is for a single case; the process for each of the

other cases was identical. The graphs for each of the other cases can be seen in Appendix B. The process discussed in detail is the $0 \mathrm{~m} / \mathrm{s}, 3 \mathrm{~Hz}$ and $0^{\circ}$ AoA case.

Data was recorded every $0.72^{\circ}$ of the encoder wheel. This was the spacing between the encoder windows. One of the columns of the data file was encoder position in degrees, from 0 to 360 . With knowledge of the flapping frequency, it was possible to get an estimate for the time it took for the encoder wheel to turn $0.72^{\circ}$. This time was correlated with the time it took for the wing to make a complete flap. For example, the 0 $\mathrm{m} / \mathrm{s}, 3 \mathrm{~Hz}$, and $0^{\circ}$ AoA case discussed here had an actual flapping frequency of $3.292 \mathrm{~Hz}$. This meant that one flap took approximately 0.3038 seconds.

In order to correlate wing positions from the high-speed camera with position from the encoder, it was necessary to synchronize the two. The high-speed video was advanced frame by frame until the wing started to move, and this position was given time 
0. As the data acquisition program started writing data as soon as the encoder moved 1 window, or $0.72^{\circ}$, the encoder position could be synchronized with the high speed video. Each successive video frame was $1.667 \mathrm{~ms}$ apart as the video camera recorded at 600 frames per second, while the position data was collected for every 6 frames, or every $10 \mathrm{~ms}$. During analysis, an earth-fixed coordinate frame was superimposed on the video, and, every $10 \mathrm{~ms}$, the position of the wing tip and root was recorded using the coordinate system in the video analysis software.

Figure 7.1 shows the encoder signal plotted with the wing displacement of both the root and the tip for 5 flapping cycles. Based on the encoder frequency, each flap took approximately 0.304 seconds $\pm 5 \mathrm{~ms}$. Using the high-speed camera, the average period of the wing's root is approximately 0.308 seconds $\pm 1.6 \mathrm{~ms}$. This data indicates that the force data synced to the encoder and the wing positions can be aligned.

The same analysis performed on other cases produced similar results. From Figure 7.1 it can be seen that the wing root is displaced further on the upstroke than on the downstroke which is due to the mechanical bias in the design as discussed in Chapter 4 .

From the graph, it can be seen that the encoder position lines up very closely with the wing root position. The period of the wing root was an average of approximately $0.308 \mathrm{~ms}$, with the wing tip having an average period of $0.310 \mathrm{~ms}$. The period as established from the encoder is approximately 0.304 seconds. This analysis was done for all of the cases in the test matrix. The time for each flap of the tip and the root matched the period of the encoder wheel very closely. This proves that the high-speed video camera and the encoder position were properly synchronized. 


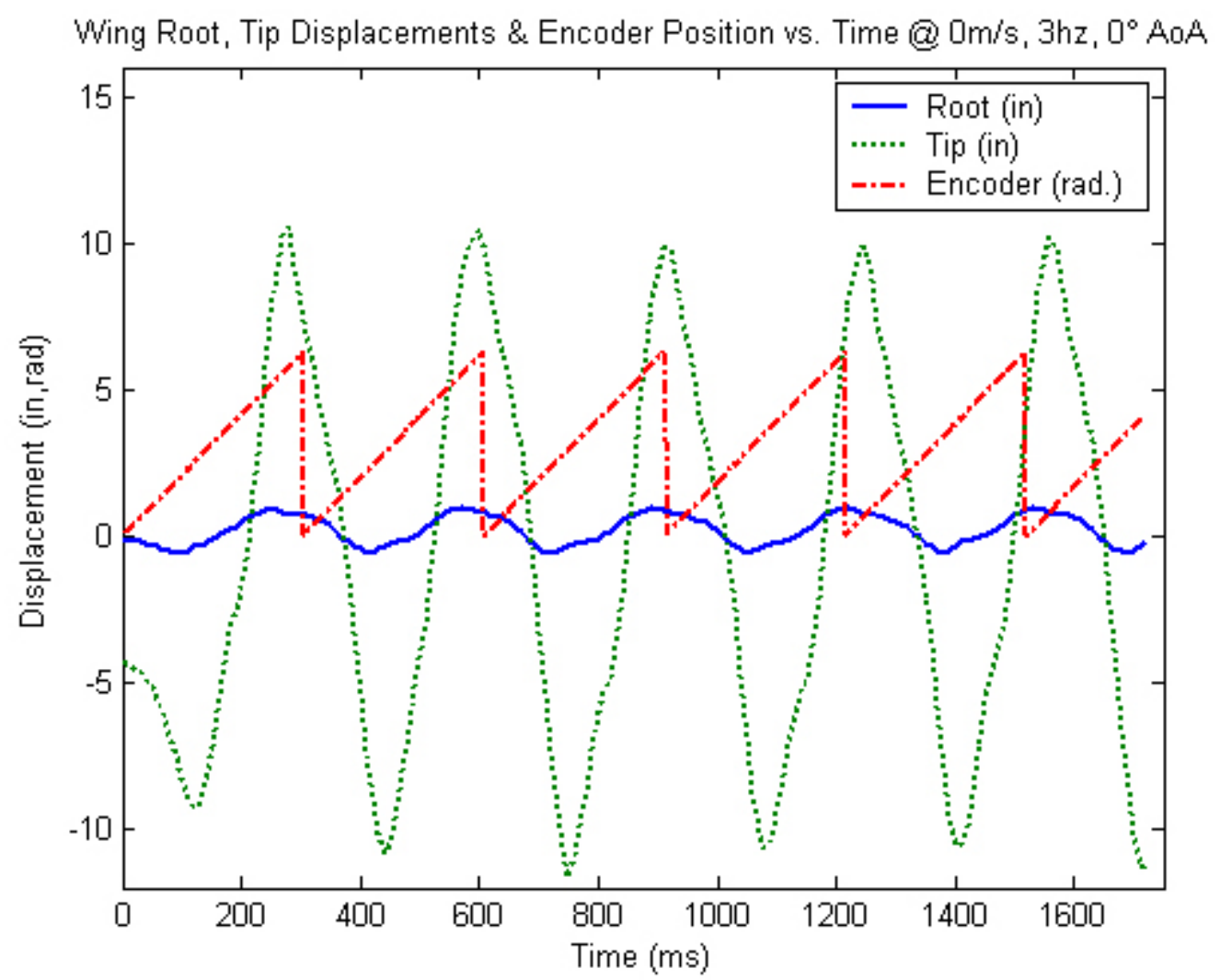

Figure 7.1: Encoder Position, Wing Root \& Tip Displacements vs. Time

\subsection{Filtering of Force Balance Inertial Effects}

An effort was made to separate the inertial forces from the aerodynamic forces present in the force balance as the mechanism flapped its wings. This was done by attaching aluminum rods in the place of each of the wings. These aluminum rods were chosen such that they had the same mass distribution and center of gravity as each of the wings. These rods were then flapped and the data recorded using the data acquisition software as previously described. The inertial motions of the mechanism caused it to move in both $\pm \mathrm{X}$ and $\pm \mathrm{Y}$ directions. These motions were recorded for each of the cases and subtracted from the data acquired when the mechanism was flapped with the actual 
wings to yield pure aerodynamic forces. Figure 7.2 shows an image of the aluminum rods with attached masses connected to the mechanism's main flapping shafts.

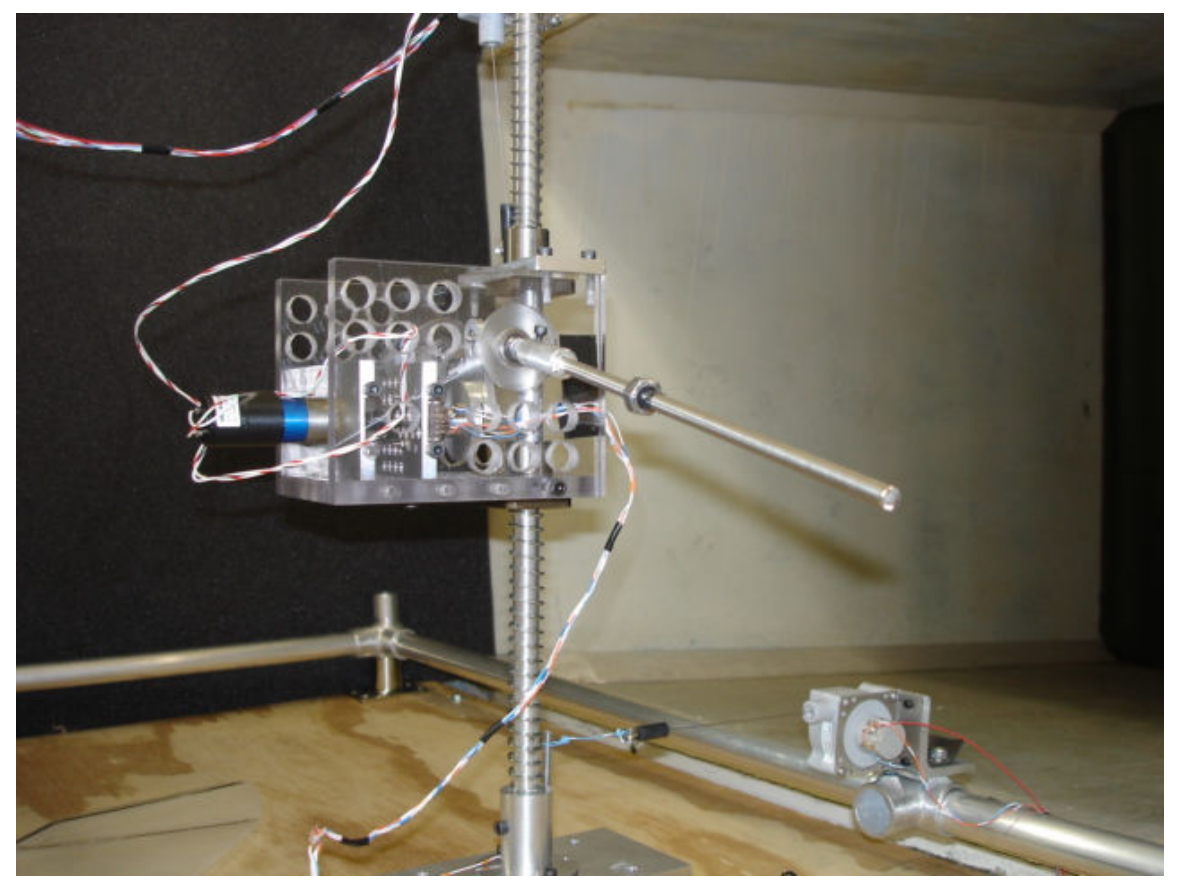

Figure 7.2: Setup for Spring Dynamics Correction

The mechanism was then flapped at 2,3, and $4 \mathrm{~Hz}$ for both Wing 1 and Wing 2 . The data acquisition program was run and same data was recorded as if the mechanism had regular wings attached. The resulting data file consisted of inertial vibrations of the mechanism in the thrust and lift directions. This data was collected for each of the cases investigated by the test matrix and subtracted from the resulting data for the respective test condition. 


\subsection{Aerodynamic Forces Generated Without Flapping}

In order to determine if it was actually beneficial for the mechanism to flap its wings, it was necessary to benchmark the test cases against a no-flap condition. This would give an estimate as to what kind of lift, thrust or drag would be generated by the mechanism when it was not flapping its wings. To do this, the data acquisition program was initialized and set to record for approximately 13 seconds. This experiment was performed on Wing 1. It was not performed on Wing 2 because both wings had exactly the same surface area exposed to the incoming flow.

First, the mechanism was oriented with the wings at $0,7.5$ or $15^{\circ}$. Next, the data acquisition program was set to run for 13 seconds. Third, the wind tunnel was turned on, where the speed increased to 5 meters per second. It took the wind tunnel approximately 5 to 6 seconds to stabilize at 5 meters per second. After 13 seconds, the data acquisition program wrote all of the data stored in its memory to an Excel spreadsheet.

It should be noted that there was a tendency for the wings to return to $0^{\circ}$ when the airflow was turned on. This was due to the clearances in the mechanism which caused the pitching motions. With the flow on, the $0^{\circ}$ offset remained at $0^{\circ}$. The $7.5^{\circ}$ offset stabilized at approximately $2^{\circ}$, while the $15^{\circ}$ offset stabilized at $5^{\circ}$.

From Figure 7.3, it can be seen that drag varied with angle of attack as expected, with higher angles of attack producing higher drag. This was due to increased wing surface area exposed normal to the flow at higher angles which increases drag. Overcoming its drag was one of the criteria for the mechanism designed in this thesis to be "successful". 
To measure lift, a similar approach was taken. Again the data acquisition system was set to record for 13 seconds, and then the tunnel was turned on until the wind speed stabilized at 5 meters per second. However, after the first lift test it was found that the lift force was not large enough to overcome the static friction in the linear bearings on which the mechanism rode. To counter this problem, the mechanism was tapped with a finger during the test. Once tapped, the mechanism would overcome the static friction and stabilize at a different value. This finger tapping was done 4 times and the resulting lift values were averaged. Figure 7.3 below shows the effects of tapping the mechanism to overcome static friction and obtain accurate readings of lift.

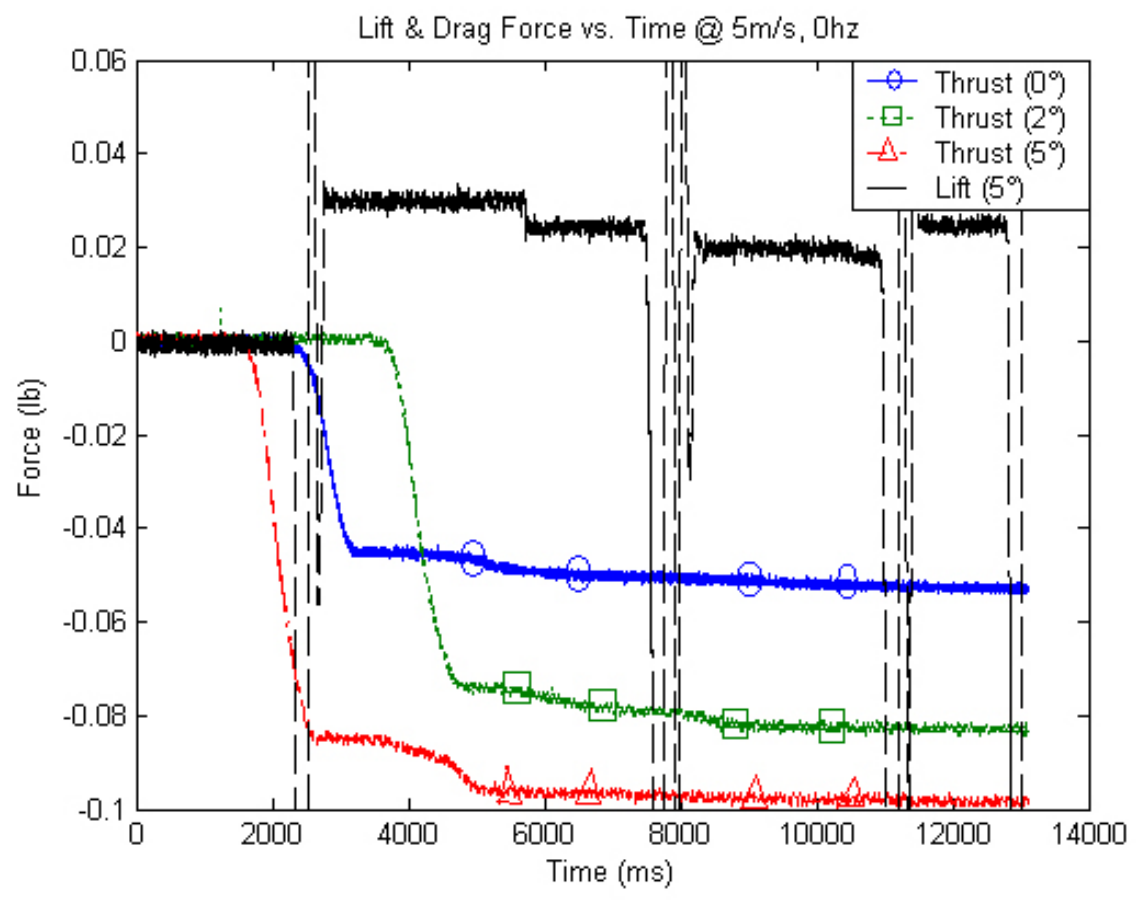

Figure 7.3: Lift \& Drag Force vs. Time @ 5 m/s Without Flapping

To counter the effects of the mechanism's clearances causing the wings to deviate from their set initial angles of attack, a small piece of aluminum was wedged in place. 
The wings were then pinned at $-7.5^{\circ}, 0^{\circ}, 7.5^{\circ}$ and $15^{\circ}$ angles of attack and the lift was measured in $5 \mathrm{~m} / \mathrm{s}$ incoming flow. Figure 7.4 displays the results. The average lift values from when the wings were not pinned and deviated from their initial set angles of attack are also plotted in Figure 7.4. Unsurprisingly, it was found that a negative angle of attack produced negative lift. At $-7.5^{\circ}-0.016 \mathrm{lbs}$ of lift were generated. The lift then steadily increased to $0.032 \mathrm{lbs}$ when the angle of attack was $7.5^{\circ}$. At $15^{\circ}$ positive lift was generated as well $(0.02 \mathrm{lbs})$, but slightly less than at $7.5^{\circ}$. This decline in lift can be attributed to flow separation at the trailing edge of the wing.

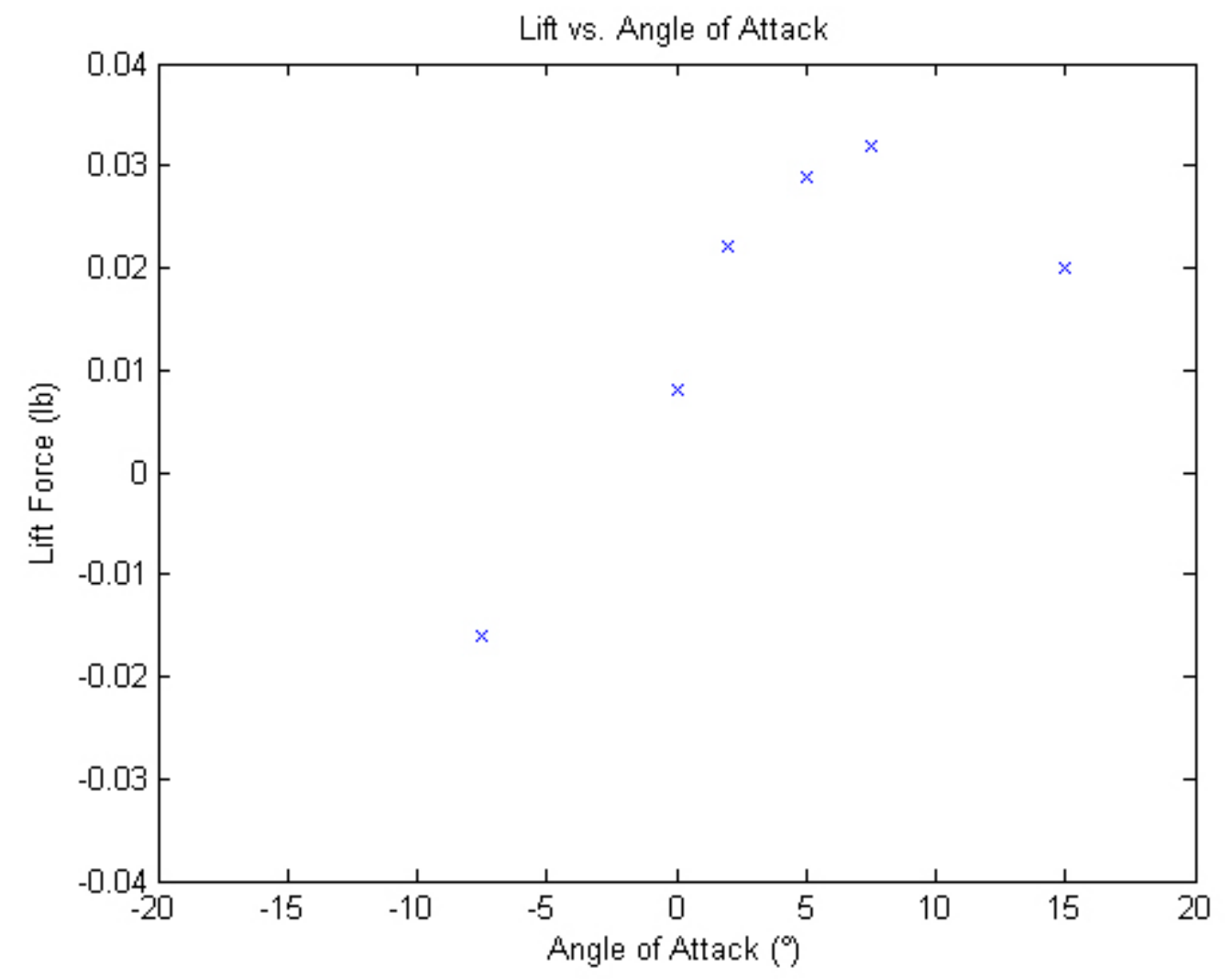

Figure 7.4: Lift vs. Angle of Attack@ 5 m/s Without Flapping 


\section{CHAPTER 8: ANALYSIS OF RESULTS}

\subsection{Wing 1 Phase Lag}

One of the most noticeable effects of having a flexible wing was that the wing flexed such that the wingtip generally lagged the wing root. Video evidence of this phase lag can be seen in Figure 8.1 and Figure 8.2 below. These images are from the $0 \mathrm{~m} / \mathrm{s}, 3$ $\mathrm{Hz}$, and $0^{\circ}$ angle of attack case. The images taken in Figure 8.1 and Figure 8.2 are stills captured from the high-speed video camera. Note the obvious phase lag on the upstroke in Figure 8.1 where the root of the wing is already well on its way in the upward motion, while the tip has just started the upstroke. Figure 8.2 shows a similar result for the downstroke, where the root is already into the downstroke while the tip is just beginning to travel downward.

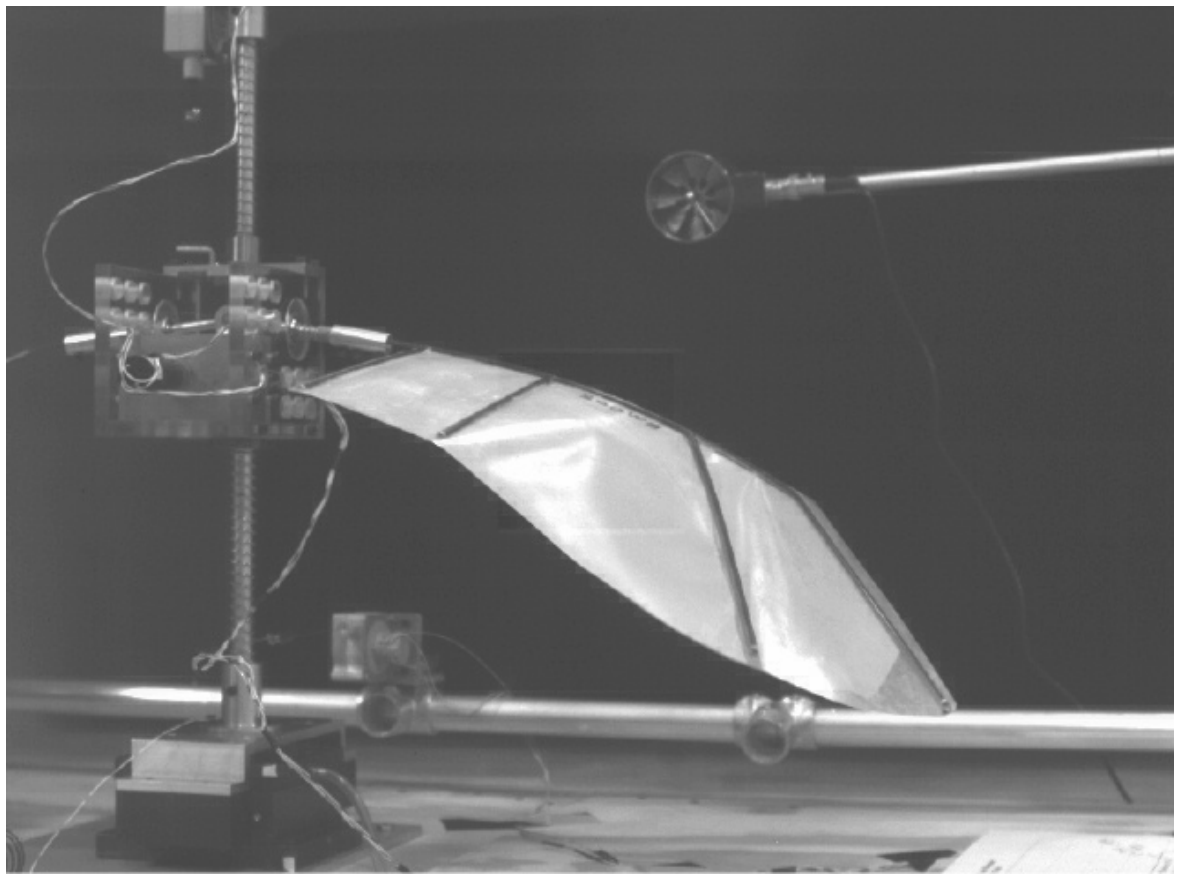

Figure 8.1: High Speed Video Still Image of Wing 1 Beginning Upstroke 


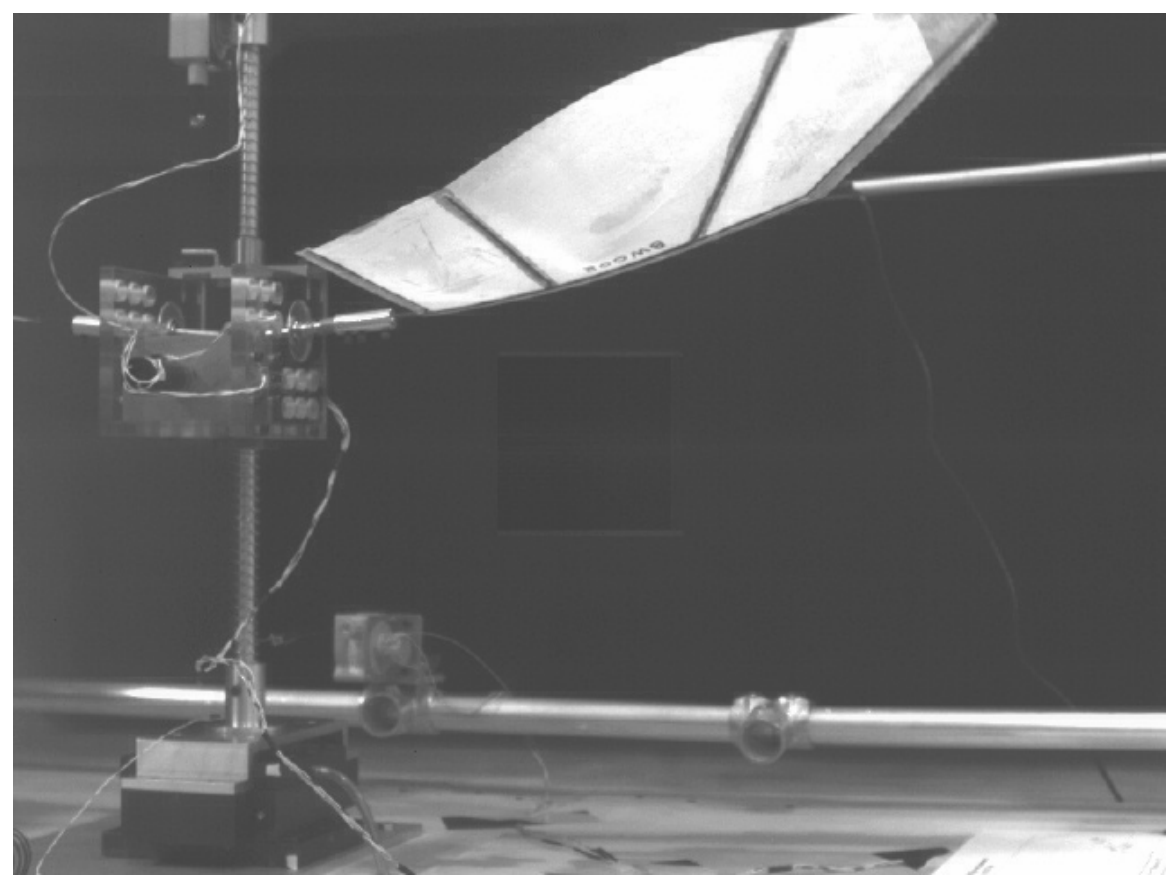

Figure 8.2: High Speed Video Still Image of Wing 1 on Downstroke

Figure 8.3 below shows the wing root and tip positions with theoretical curves fit to each for the Wing 1 case tested at $0 \mathrm{~m} / \mathrm{s}, 3 \mathrm{~Hz}$, and $0^{\circ}$ AoA. The curves were fit using a sinusoidal function of the form:

$f(t)=A \cdot \sin (\omega(t+\Delta t))+B$

Equation 8.1

In Equation 8.1, $\mathrm{t}$ is time, $\omega$ is frequency in radians, $A$ is the amplitude of the flapping motion, $\Delta t$ is the phase shift, and $B$ is the offset of the curve used to account for the bias in the mechanism. It was found that the experimental data was closely approximated by the sinusoidal functions, however there were some differences. From the curve fits, it was found that the difference in phase between the wing root and the wing tip was $3^{\circ}$ on average. 


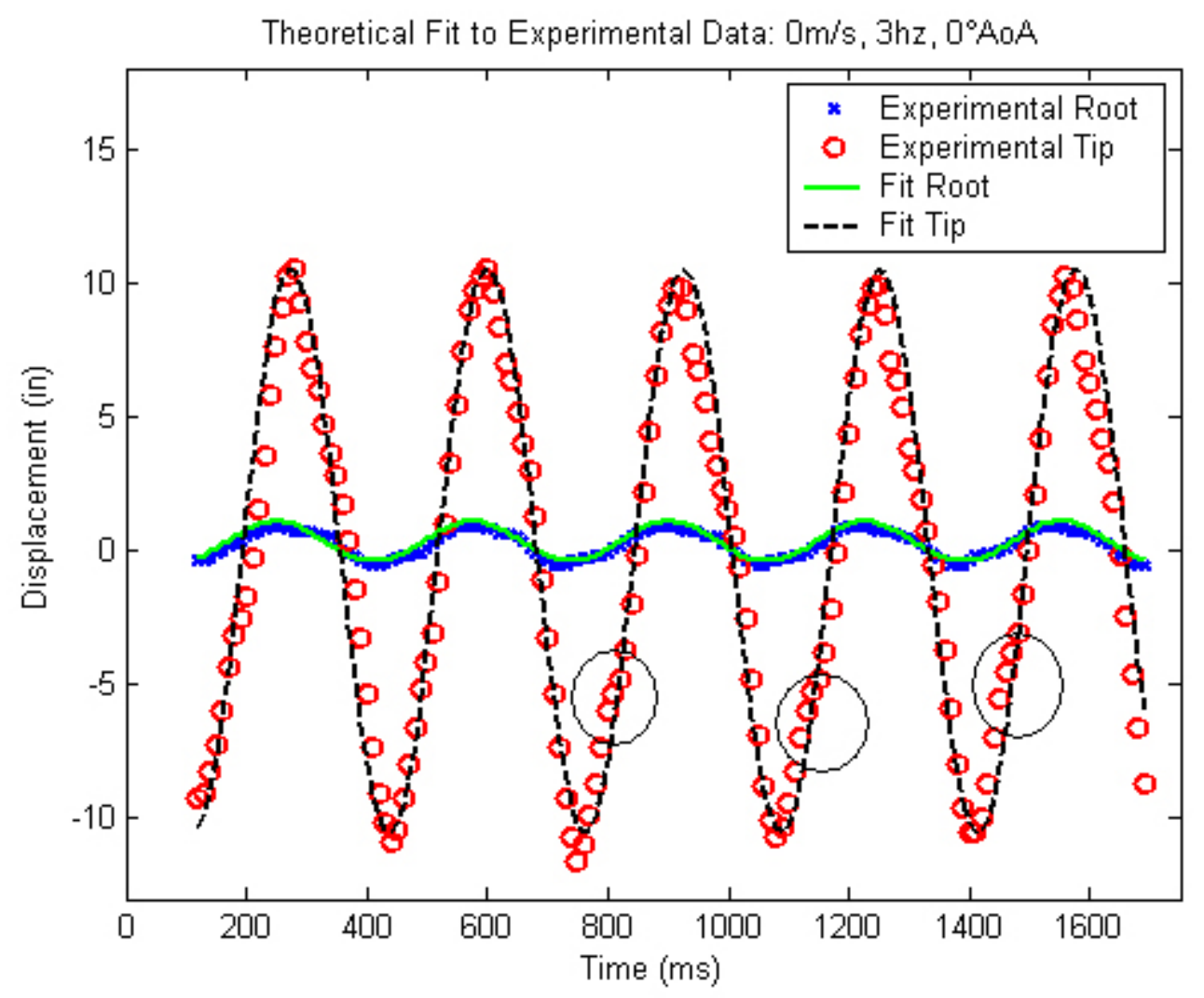

Figure 8.3: Wing 1 Root \& Tip Displacement with Curve Fits

Phase lag was calculated for 2 discrete points: when the wing when the wing was at the end of the downstroke, and also when the wing was in the center of the flap on the upstroke. The center of the flap on the upstroke was chosen because at this point the wing had its highest velocity, for both the tip and the root. Equation 8.2 was used to calculate the phase lag at the end of the downstroke, while Equation 8.3 was used to calculate the phase lag at the center of the upstroke.

$\frac{t_{\text {Tip }}-t_{\text {Root }}}{t_{1 \text { Flap }}} \cdot 360^{\circ}$

Equation 8.2 
$\frac{t_{0, \text { Tip }}-t_{0, \text { Root }}}{t_{1 \text { Flap }}} \cdot 360^{\circ}$

Equation 8.3

In Equation 8.2, $t_{T i p}$ is the time the wingtip is at its minimum position. $T_{\text {Root }}$ is the time the root is at its minimum position, and $t_{1 \text { Flap }}$ is the time the mechanism takes to complete one complete flap. In Equation 8.3, $t_{0 \text {, Tip }}$ is the time the wingtip is at its minimum position. $T_{0, \text { Root }}$ is the time the root is at its minimum position, and again $t_{1 \text { Flap }}$ is the time the mechanism takes to complete one complete flap. From the above equations, it was found that when Wing 1 was changing direction from the downstroke to the upstroke, the wingtip lagged the root by an average of $35.5^{\circ}$. However, when the root was well on its way on the upstroke, the tip trailed by as much as an average of $58^{\circ}$, roughly corresponding to the position depicted in Figure 8.1.

Upon further examination of Figure 8.1, it can be seen that the wing has buckled in between the second and third structural members. Over time this has obvious negative effects as the wing will most likely fail due to fatigue. However it is not clear if the wing buckling has adverse effects on the generation of aerodynamic forces. Examining Figure 8.3 , it can be seen the buckling phenomenon repeats. Kinks in the wing tip position on the upstroke occur at regular intervals such as at times of $800 \mathrm{~ms}, 1125 \mathrm{~ms}$, and $1450 \mathrm{~ms}$. This wing buckling is also apparent in the lift, but is not significant. This is most likely due to the adaptive nature of the wing's membrane which can react to situations such as these. A parallel can be drawn between buckling behavior and such effects as encountering a gust or hitting a stationary object which may cause wing buckling. The wings ability to correct for these phenomena without having a significant effect on the generation of thrust and lift is one of the major benefits of having flexible wings. 
A third effect of having a flexible wing is also apparent in Figure 8.3 where the velocity of the wing tip can be seen to vary with time. The wing tip velocity is greater near the end of the downstroke relative to the beginning of the downstroke as evidenced by the greater vertical spacing between the points which were taken at constant time increments. Similar behavior is seen on the upstroke where the tip speed is greater near the end of the upstroke. This behavior was related to phase lag, where the wing tip lagged the root as it traversed the flap. On the downstroke, the maximum wing tip velocity was reached just after the wing passed the midpoint of the downstroke. At this point the velocity was found to be approximately $5.67 \mathrm{~m} / \mathrm{s}$. A slightly higher velocity of $5.8 \mathrm{~m} / \mathrm{s}$ was measured on the upstroke at the wing tip. This increase in speed of the wing due to flexibility should result in higher forces on the wing, and is discussed in Section

\subsection{4 and Section 8.5.2.}

\subsection{Wing 2 Phase Lag}

Figure 8.4 and Figure 8.5 below show the resultant phase lag of Wing 2 during the flapping cycle of the $5 \mathrm{~m} / \mathrm{s}, 4 \mathrm{~Hz}, 7.5^{\circ}$ AoA case. From Figure 8.4, it can be seen that the wing tip is well on its way on the upstroke as the wing tip is flexing in an effort to slow down and compensate for the change in direction. Figure 8.5 shows the phase lag as the wing is beginning the downstroke. As was the case with Wing 1, the phase lag on the upstroke is more dominant than that of the downstroke. This was due to the nature of the wing fabrication process; the wing was not equally pliable in both directions. Even based on the just the images from the high speed video camera, it is visually obvious that the phase lag is much smaller than that of Wing 1. 


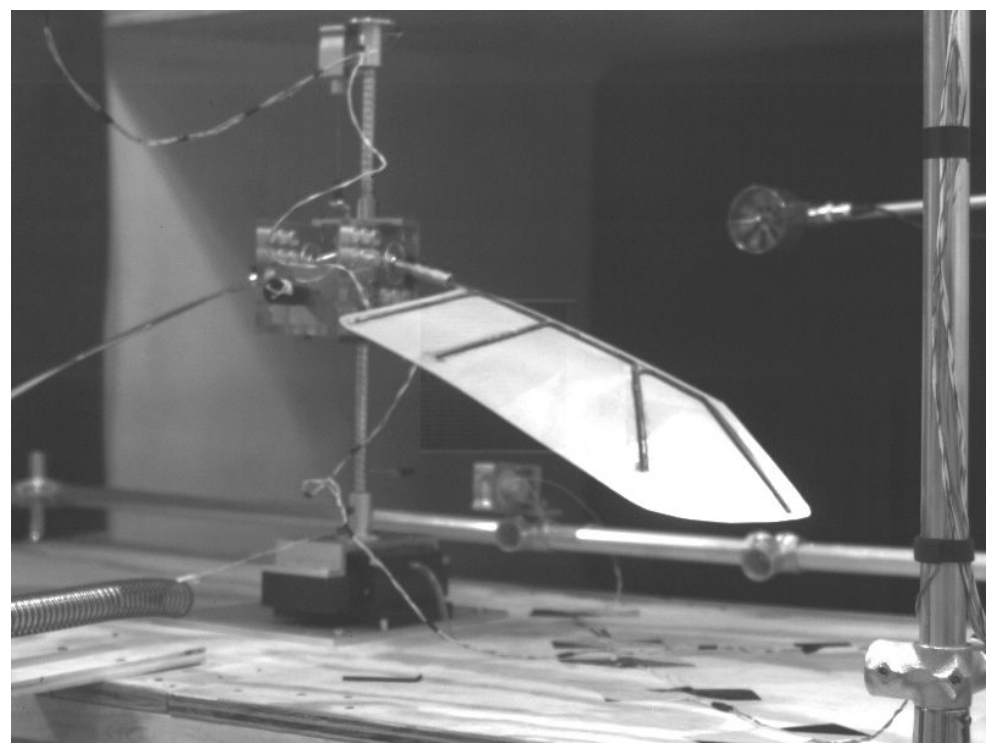

Figure 8.4: High Speed Video Still Image of Wing 2 Beginning Upstroke

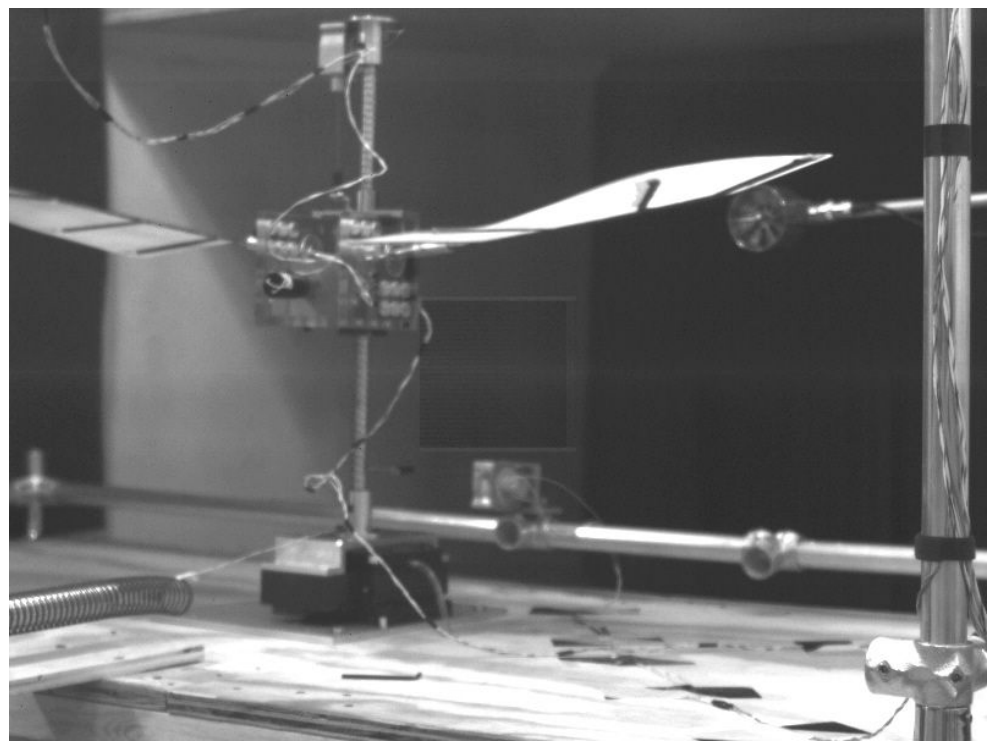

Figure 8.5: High Speed Video Still Image of Wing 2 Beginning Downstroke

Figure 8.6 shows a plot of the wing root and tip displacement as a function of time with theoretical curves fit to the data using Equation 8.1. When performing the high speed video analysis on Wing 2, the data was only recorded out to 2 flaps excluding the startup transients. Phase lag for Wing 2 was calculated the same way as for Wing 1 using 
Equation 8.2 and Equation 8.3 as described in Section 8.1. From Figure 8.6 below it appears that the curve fit for the tip does not match the experimental data very well. The largest variation appears to be on the downstroke, while the curves appear to match the data for the upstroke quite well. This is most likely due to the fact the leading edge of Wing 2 is very stiff until the very tip, approximately 2 to 3 inches inboard from the tip.

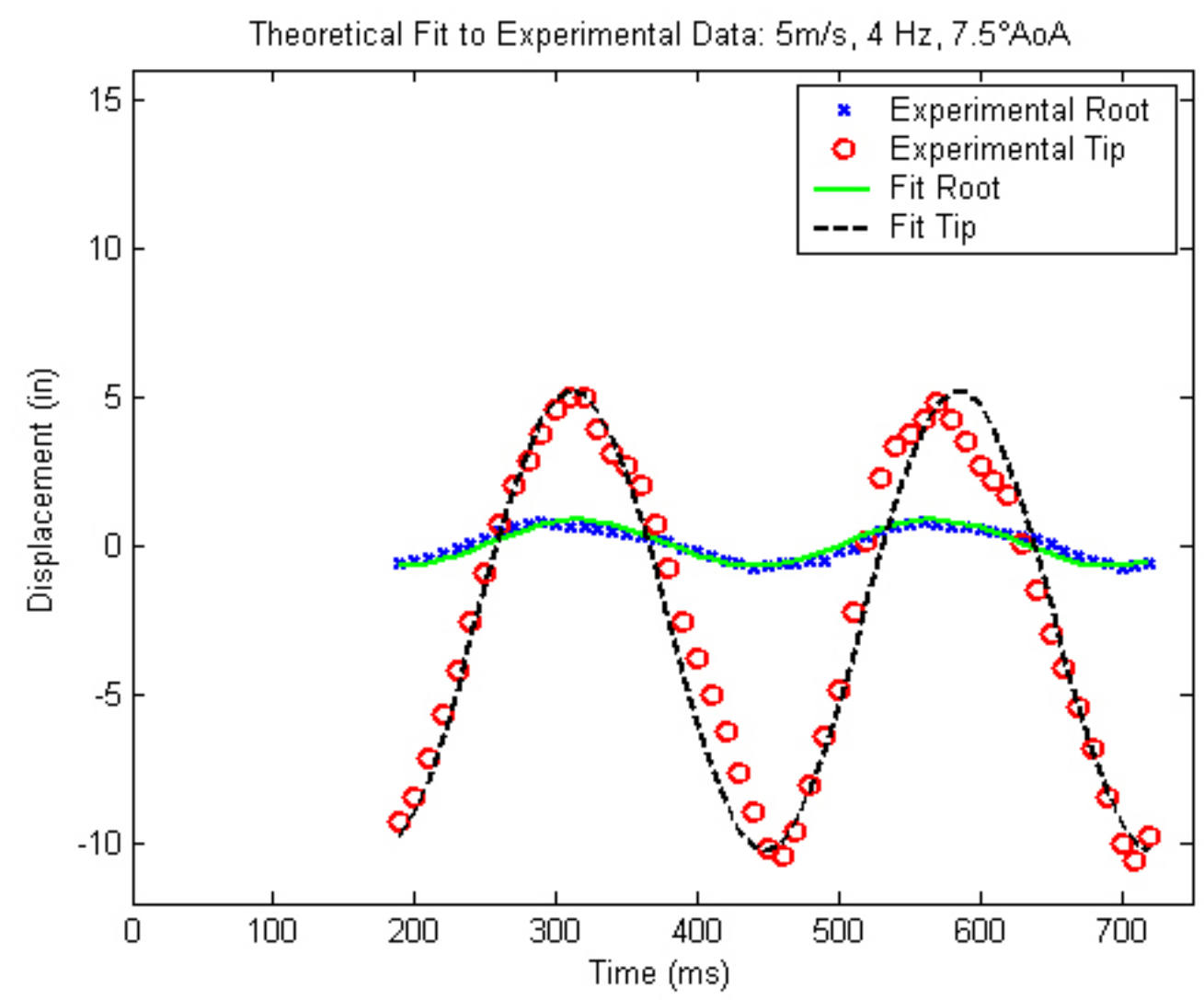

Figure 8.6: Wing 2 Root \& Tip Displacement with Curve Fits

As was the case with Wing 1, it was found that most of the phase lag for Wing 2 occurred as the wing changed direction from the downstroke to the upstroke. The phase lag at this point was calculated to be an average of approximately $27.7^{\circ}$, roughly corresponding to the image shown in Figure 8.4. This is much smaller than the value of 
$35.5^{\circ}$ with Wing 1 . The phase lag when the wing was at the center of its upstroke was found to be an average of $23.5^{\circ}$, which is much smaller than the value of $58^{\circ}$ for Wing 1 .

It should be noted that Wing 1 had greater phase lag when it was at the center of the upstroke than when it was at the end of the downstroke. However, Wing 2 had greater phase lag at the end of the downstroke. The reason for this is most likely because Wing 1 was overly flexible due to buckling. The lag between Wing 1 and Wing 2 only changed by approximately $7.9^{\circ}$ during the center of the flap, but by $34.5^{\circ}$ at the bottom of the flap. These differences suggest that it is almost inevitable that phase lag will occur during the center of the upstroke, as the tip will always be trailing the root by some angle unless the wing is perfectly rigid. However, the incorporation of a stiffer wing can at least help reduce the phase lag at the point where the downstroke ends and the upstroke begins.

\subsection{Wing Pitching Motions}

Figure 8.7 shows the pitching motions of Wing 1 and Wing 2 as they complete one flap. These pitching motions were obtained from the data acquired from the highspeed video camera. As Wing 1 starts its flap, at the $0^{\circ}$ position, it has a positive angle of attack. As it continues through the first $30^{\circ}$ of the flap cycle, the angle of attack (relative to the earth) decreases approximately $15^{\circ}$. At this point the angle of attack was constant and slightly negative. This is the case throughout the majority of the downstroke and starts to increase again at approximately $180^{\circ}$ and levels off for the upstroke at about $240^{\circ}$. These pitching motions are similar to those produced in other flapping wing mechanisms. 


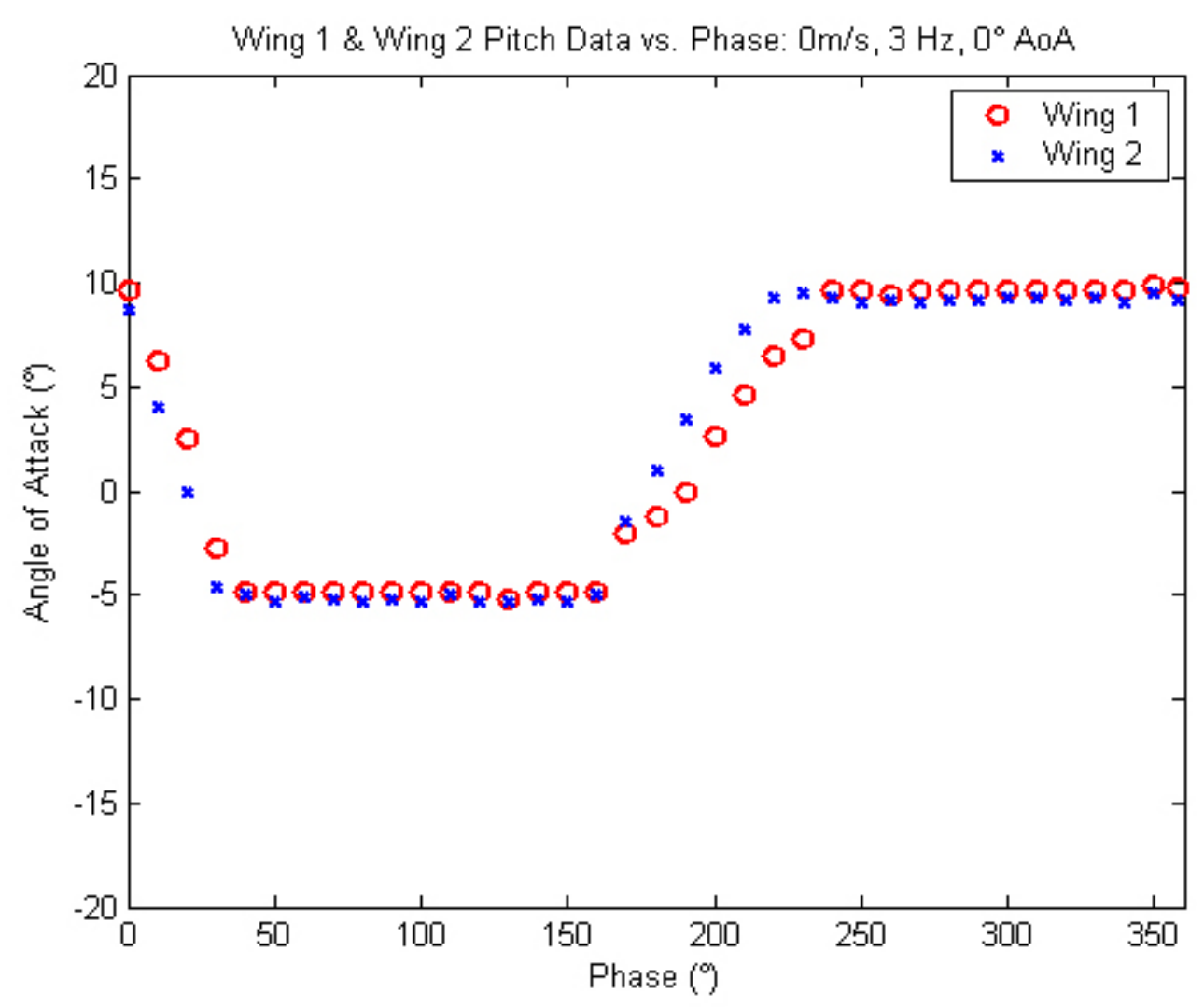

Figure 8.7: Wing 1 Pitching Motions Produced During Flapping

From the graph it can be seen that the pitch envelope for both wings did not noticeably change. There is still a about a $15^{\circ}$ variance in which the wing moved from its set position. The main difference between the two wings is that Wing 2 changed pitch at a faster rate than Wing 1. The main reason for this was due to increased stiffness. The increased stiffness does not lend itself to as much damping and phase lag in the flapping motion, and as a result is able to change directions quicker.

The main reason for this variability in pitch were clearances in the connection between the main flapping shafts and the crankshafts where the shafts were pinned together. From the plot, the variability is approximately $15^{\circ}$. There was also some change in pitch due to the flexible nature of the wings, but was almost negligible when 
compared to the cause of pitch from the mechanism. It is unlikely that the pitching envelope will increase or decrease due to increasing airspeed or flapping frequency. This is because the maximum and minimum angles are governed by the amount of clearance between the main flapping shafts and the pin used to hold them together. As the initial angle of attack of the mechanism is altered, the peaks will differ. This essentially introduces a bias in the pitch envelope changing the maximum and minimum points. However it should be noted that as the mechanism continues to flap over an extended period of time, the envelope will likely increase due to wear between the connections.

\subsection{Analysis of $1^{\text {st }}$ Generation Wing}

\subsubsection{Results: Lift and Thrust Force vs. Time}

After all of the experiments in the test matrix described in Section 7.1 were completed, the data was analyzed. To observe trends, the lift and thrust forces were plotted versus time. Figure 8.8 below shows lift and thrust force versus time for the 0 $\mathrm{m} / \mathrm{s}, 3 \mathrm{~Hz}$, and $0^{\circ}$ AoA case. This data is graphed out until approximately 4.5 seconds. This analysis was done for each of the other cases in the test matrix, but is not shown because the data repeatedly followed the pattern shown in Figure 8.8. It should be noted that a startup transient is visible in both thrust and lift generation up to approximately 550 ms. 


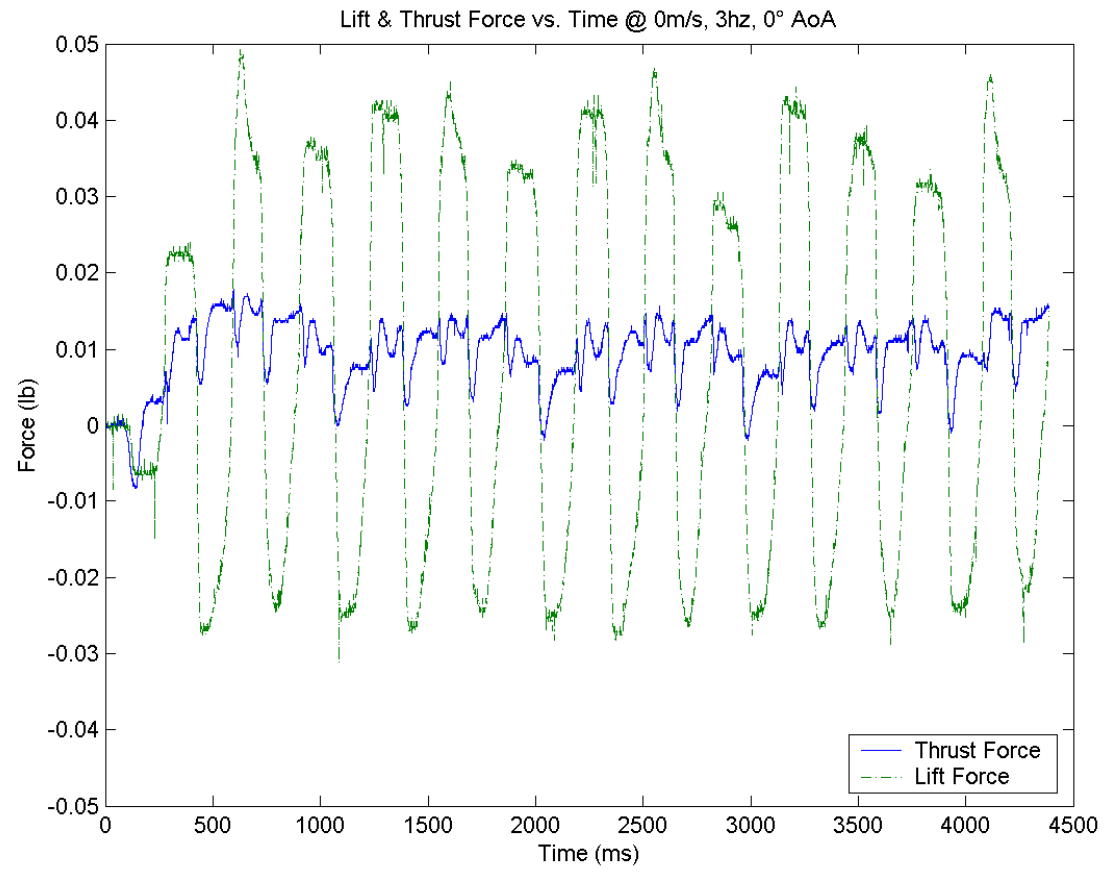

Figure 8.8: Lift \& Thrust vs. Time @ 0 m/s, $3 \mathrm{~Hz}, \& 0^{\circ}$ AoA

From Figure 8.8, it can be seen that the forces for both thrust as well as lift are periodic. The lift force has a minimum at approximately $-0.028 \mathrm{lbs}$ and peaks at about $0.041 \mathrm{lbs}$ (average). This means that the mechanism is able to generate positive lift on a cycle averaged basis. The thrust measurements show that the mechanism produces positive thrust throughout the flapping cycle, and consistently for the duration of the test.

The slight periodic nature of the thrust is due to the inertial effects of the mechanism. In the graph above, the inertial effects have not been removed. When flapping the rods as described in Section 7.3, some inertial effects were present in the thrust direction. This is because the clearances in the mechanism and the swivel bearings used did not purely constrain the flapping in the vertical direction. 


\subsubsection{Results: Lift and Thrust Force vs. Wing Position (Phase)}

In order to cycle average the forces a Matlab program was written. First the inertial effects in both the lift and thrust directions were subtracted from the data. Next, the first two complete flaps were ignored as they could be misleading due to startup transients. The data was then cycle averaged over 10 flaps from $0^{\circ}$ to $360^{\circ}$. It was known that the mechanism flapped from $0^{\circ}$ to $360^{\circ} 10$ times. All of the lift forces at the $0^{\circ}$ position were averaged, as were the thrust forces. This was done for $0.72^{\circ}$, or the next turn of the encoder wheel. The same process was followed for each of the successive recorded degrees, and the resulting data was plotted. Figure 8.9 is a cycle averaged plot of the $0 \mathrm{~m} / \mathrm{s}, 3 \mathrm{~Hz}$, and $0^{\circ}$ AoA case. Plots of the remaining cases in the test matrix can be seen in Appendix B.

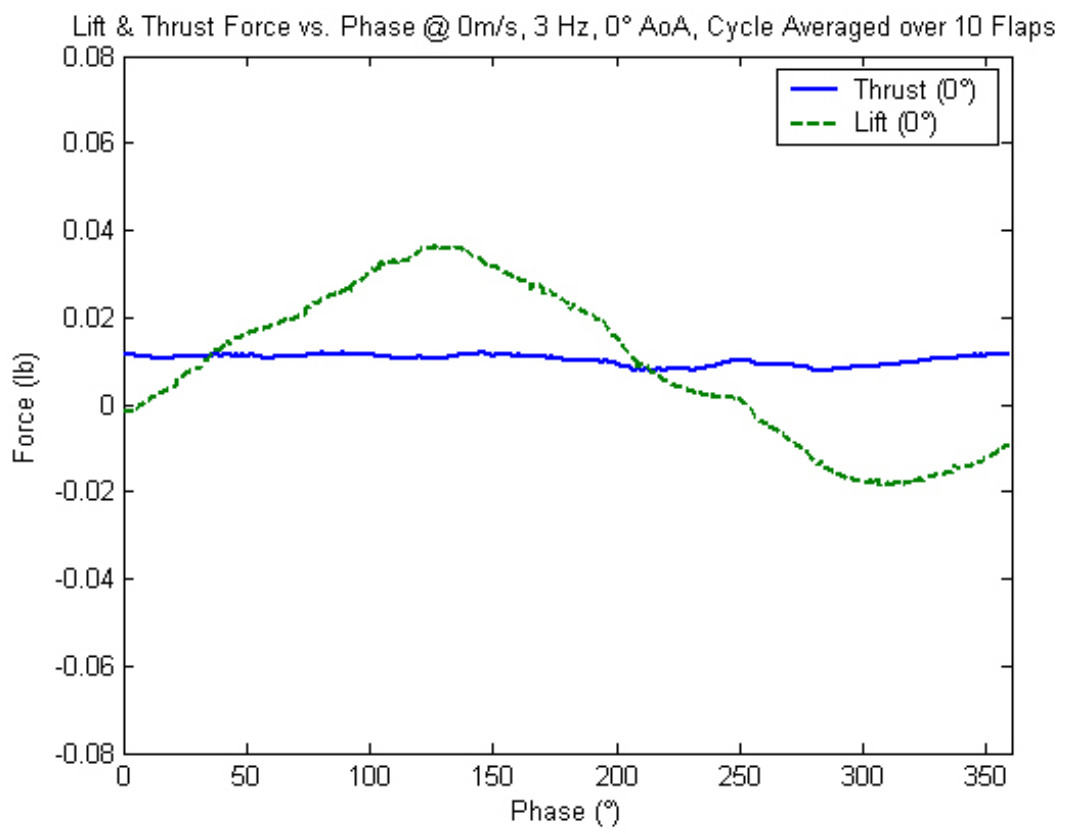

Figure 8.9: Lift \& Thrust vs. Phase @ 0 m/s, 3 Hz, \& $0^{\circ}$ AoA 
With the information in Figure 8.9 it is possible to get an understanding of wing position and the resulting aerodynamic forces resulting at each point in the stroke. The start position of $0^{\circ}$ refers to the wing root being at a maximum height position: at the very start of the downstroke.

From Figure 8.9 it can been seen that the shape of the thrust and lift curves are different. This is not only true for $0 \mathrm{~m} / \mathrm{s}, 3 \mathrm{~Hz}, 0^{\circ}$ case, but for all of the other cases as well (see Appendix B). The generation of lift appears to be periodic in nature. As the wing flaps downward from its initial starting position, the generation of lift begins to increase. Somewhere during the downstroke, the lift peaks and as the end of the downstroke approaches and the lift force begins to decrease. During the upstroke negative lift is generated. This cycle continues as the mechanism flaps. This appears to be as expected, with results following similar trends based on experiments performed by others.

Thrust generation is slightly different, as the flapping wing mechanism appears to constantly produce thrust. The reason for this is that the wing is changing its shape and angle of attack dynamically. On the downstroke the wing is pitched down, forcing air in the $-Y$ direction, while in the upstroke the wing sweeps forward and up, minimizing the movement of air in the direction causing negative thrust. For all cases the thrust is relatively constant throughout the cycle. The magnitude of the thrust appears to slightly increase for the higher frequency, forward flight case. Note that in all cases, the net thrust is overcoming the natural drag of the mechanism as shown in Figure 7.3. 


\subsubsection{Lift and Thrust Data to High Speed Video Correlation}

Lift and thrust forces were graphed versus wing position (or phase) in Section 8.4.2. The graphs in that section gave a numerical indication of wing position and the kinds of lift and thrust forces generated at those positions. However, it was useful to see what the actual wing position was and how its orientation in phase affected the generation of aerodynamic forces. This analysis was done for the 4 most interesting cases in the test matrix. These cases and the associated wing positions can be seen in plots from Figure 8.10 to Figure 8.13 .

In order to do this, still images were captured from the high speed video taken for each case. Correlating the wing position from the video camera with the position from the encoder was done by time as previously discussed in Section 7.2. A particular wing position (in encoder degrees) corresponded to a time interval calculated based on the frequency of the flap. This time from the encoder data was cross referenced with the time on the high speed video camera. Since the times were lined up from the start of the flapping, it was straightforward to obtain wing position screenshots from the high speed camera. For example, in Figure 8.10, the time associated with an encoder angle of $125^{\circ}$ was $537 \mathrm{~ms}$. In the high speed video, a time of $537 \mathrm{~ms}$, corresponded to frame number 1594. The high speed video was then paused at frame 1594 and a screenshot of this image was taken. This was the process followed for each of the 5 wing positions shown on the graphs below. Figure 8.10 through Figure 8.13 show the high speed video captures of Wing 1 correlated to the cycle averaged force. This analysis was done for the 4 cases which produced the most lift and thrust in the test matrix. 
In all of the 4 cases it was found that positive lift occurred on the downstroke, while thrust was always being generated. For all 4 graphs the $0^{\circ}$ location is where the wing root is at its maximum height. At this point the wing is starting its downward motion, resulting in the generation of positive lift.

Case 1 was when the mechanism flapped at $0 \mathrm{~m} / \mathrm{s}, 3 \mathrm{~Hz}, 0^{\circ} \mathrm{AoA}$, and the results can be seen in Figure 8.10. As the wing continued to flap downwards, the lift force increased until it reached a peak at approximately $140^{\circ}$ and the lift force at this point was approximately $0.036 \mathrm{lbs}$. After this, the generation of lift started to decrease and reached a minimum at about $275^{\circ}$, but the force become negative when the wing was at about $250^{\circ}$. A minimum in lift was reached when the mechanism was on its upstroke. The cycle then continued to repeat itself. Note that the peak positive lift is greater than the peak negative lift and that the duration of positive lift is greater than that of the negative lift, thus indicating that net lift is generated. The average lift generated was approximately $0.009 \mathrm{lbs}$, while the average net thrust generated was $0.010 \mathrm{lbs}$. 


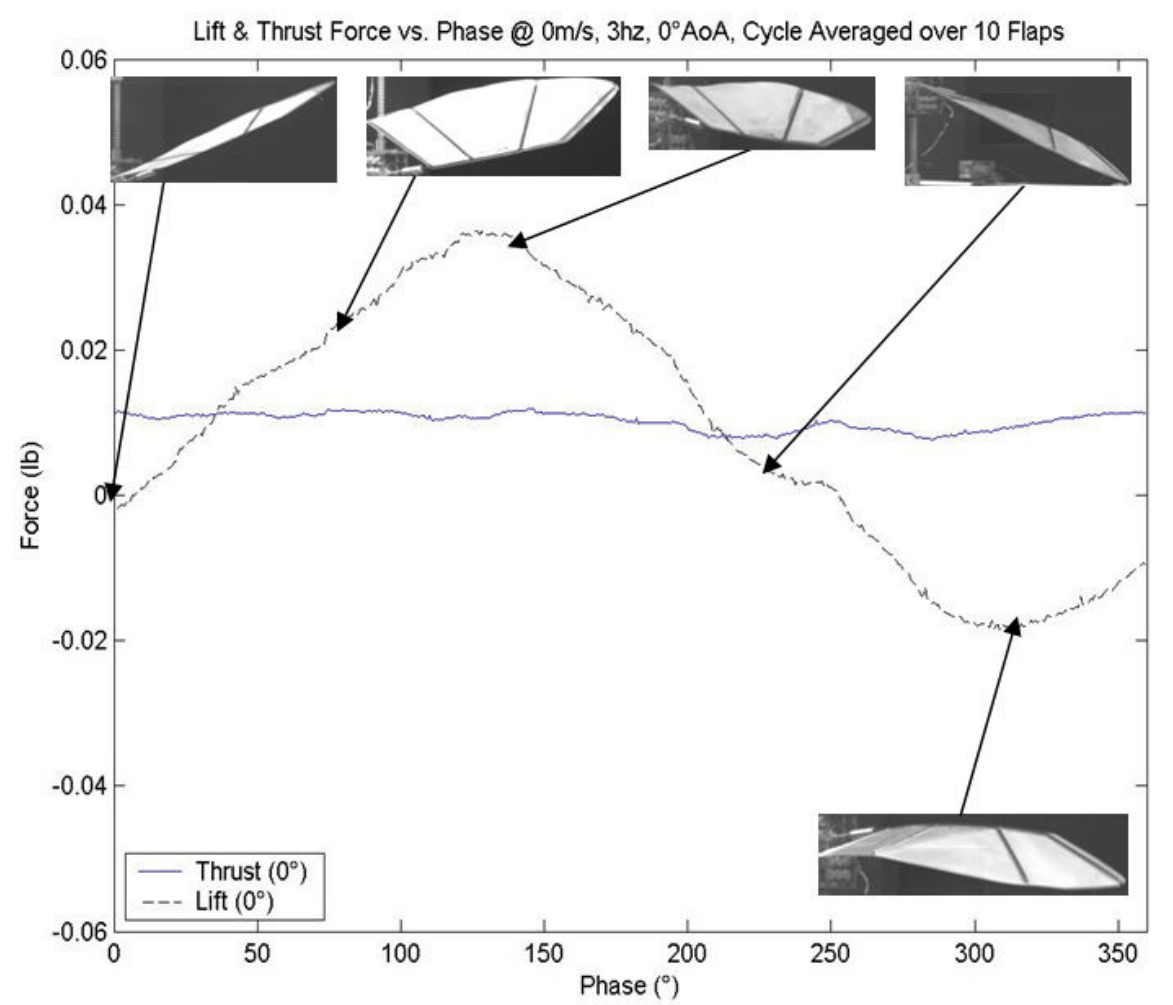

Figure 8.10: Wing 1 Position, Force \& Phase Correlation @ 0 m/s, 3 Hz, \& $0^{\circ}$ AoA

Case 2 shown in Figure 8.11 includes forward flight where the mechanism is flapped at $5 \mathrm{~m} / \mathrm{s}, 3 \mathrm{~Hz}, 7.5^{\circ}$ AoA. The lift curve looks slightly different than a no flow and $0^{\circ}$ AoA condition. Again the wing started at a maximum height position at $0^{\circ}$. Up to about $100^{\circ}$, the lift increased almost linearly, and past this point there was a sharp increase in the rate at which the lift force was generated. The wing reached its first positive peak in lift force of $0.038 \mathrm{lbs}$ at $156^{\circ}$. At this point the wing was just slightly past being horizontal to the ground. A second lower positive peak of $0.031 \mathrm{lbs}$ was reached at $200^{\circ}$, at which point the wing's root was very close to its minimum position, while the phase lag caused the tip to trail the root when it approached its minimum position and this continued to generate lift. It took up to approximately $180^{\circ}$ to $220^{\circ}$ to complete the downstroke. This was due to clearances in the mechanism where although 
the flywheel would turn between $180^{\circ}$ and $220^{\circ}$, it would not cause any force on the flapping shafts. The location of the spacing which caused this was at the connection point where the titanium connecting pin was attached to the main flapping shafts.

After this point the lift force begins to decrease significantly as the wing was well on its way on the upstroke. At approximately $275^{\circ}$ a minimum is reached on lift generation. Although the peak lift produced was essentially the same between the first two cases, the duration of the positive lift was greater. This is attributed to the inclusion of the incoming flow. The average lift generated during this cycle was $0.004 \mathrm{lbs}$, while the average thrust generated was $0.051 \mathrm{lbs}$. The peak lift and thrust generated here are greater than in Case 1.

Recall the no flapping condition when the mechanism was put in a $5 \mathrm{~m} / \mathrm{s}$ flow at a $7.5^{\circ}$ angle of attack where the average lift generated was approximately $0.031 \mathrm{lbs}$. The peak lift generated when flapping at the $5 \mathrm{~m} / \mathrm{s}, 3 \mathrm{~Hz}, 7.5^{\circ}$ is approximately $0.038 \mathrm{lbs}$. The mechanism naturally produces $0.08 \mathrm{lbs}$ of parasitic drag when not flapping (Figure 7.3). The average thrust force produced by the mechanism while flapping was approximately $0.051 \mathrm{lbs}$ for the $5 \mathrm{~m} / \mathrm{s}, 3 \mathrm{~Hz}, 7.5$ AoA case. This means that the mechanism was able to produce enough force to overcome its own drag and generate sustained net thrust. This increase in peak lift and average thrust shows that there is some benefit to flapping. 


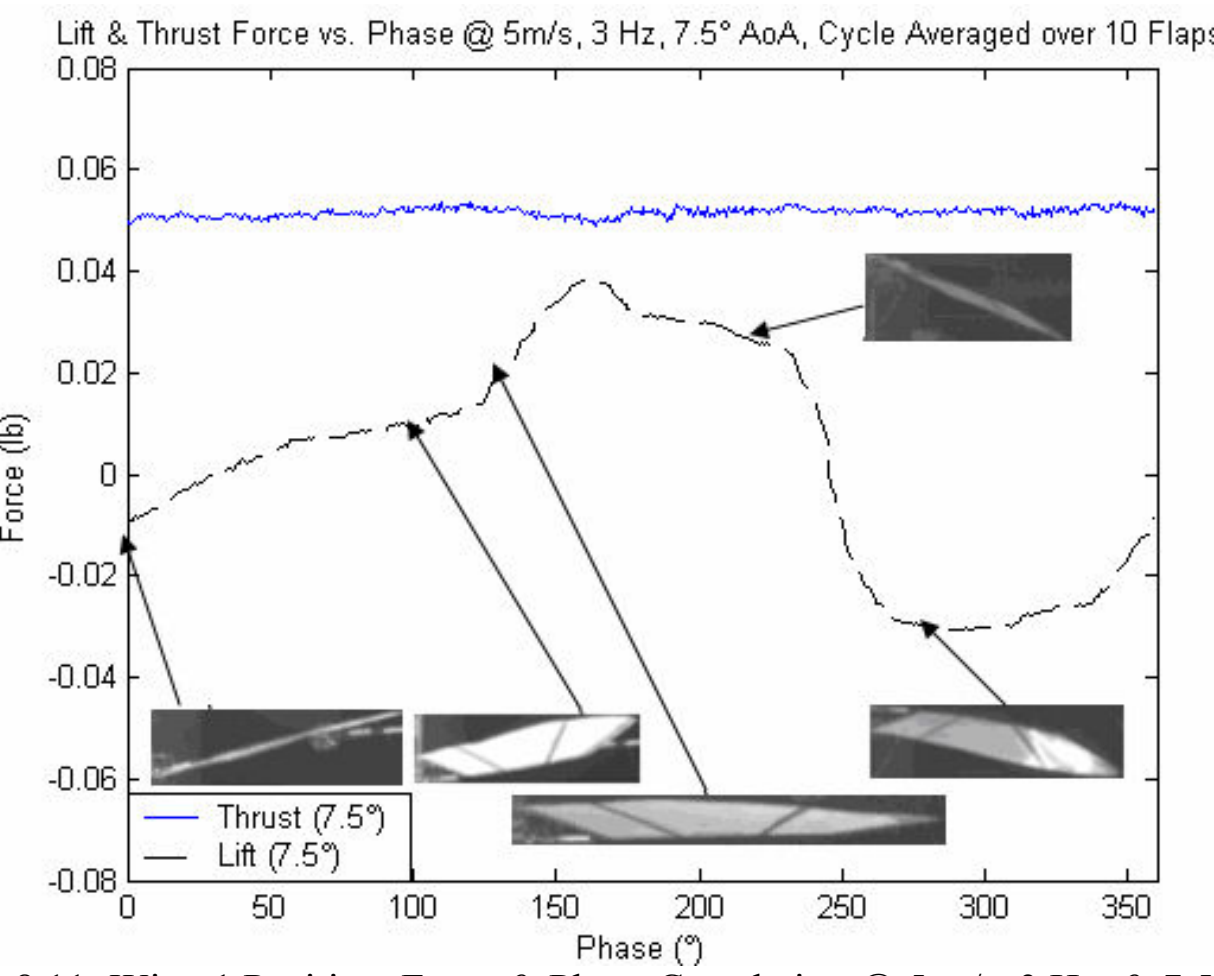

Figure 8.11: Wing 1 Position, Force \& Phase Correlation @ 5 m/s, 3 Hz, \& 7.5 AoA

Case 3 shown in Figure 8.12 is the $5 \mathrm{~m} / \mathrm{s}, 4 \mathrm{~Hz}, 7.5^{\circ}$ AoA condition. The wing again started at a maximum height position at $0^{\circ}$. It reached its first peak of $0.043 \mathrm{lbs}$ when the wing was at about $80^{\circ}$, which is $60^{\circ}$ earlier than in the no-flow case, and reached its second higher peak of $0.52 \mathrm{lbs}$ at about $200^{\circ}$. Compared to the $5 \mathrm{~m} / \mathrm{s}, 3 \mathrm{~Hz}$, $0^{\circ}$ AoA case and the $5 \mathrm{~m} / \mathrm{s}, 3 \mathrm{~Hz}, 7.5^{\circ} \mathrm{AoA}$, the duration of the positive lift greatly increased as well as the magnitude of the force. After this point the lift decreased from $210^{\circ}$ to about $275^{\circ}$, when it reached its minimum which was lower in magnitude than for the $0 \mathrm{~m} / \mathrm{s}$ case. The presence of the external flow and the increase in flapping frequency altered the performance of the flexible flapping wing. The duration of the positive lift was again increased as seen in the $5 \mathrm{~m} / \mathrm{s}, 3 \mathrm{~Hz}, 7.5^{\circ}$ AoA case. This suggests that the increased flow was a factor in increasing the duration lift. 


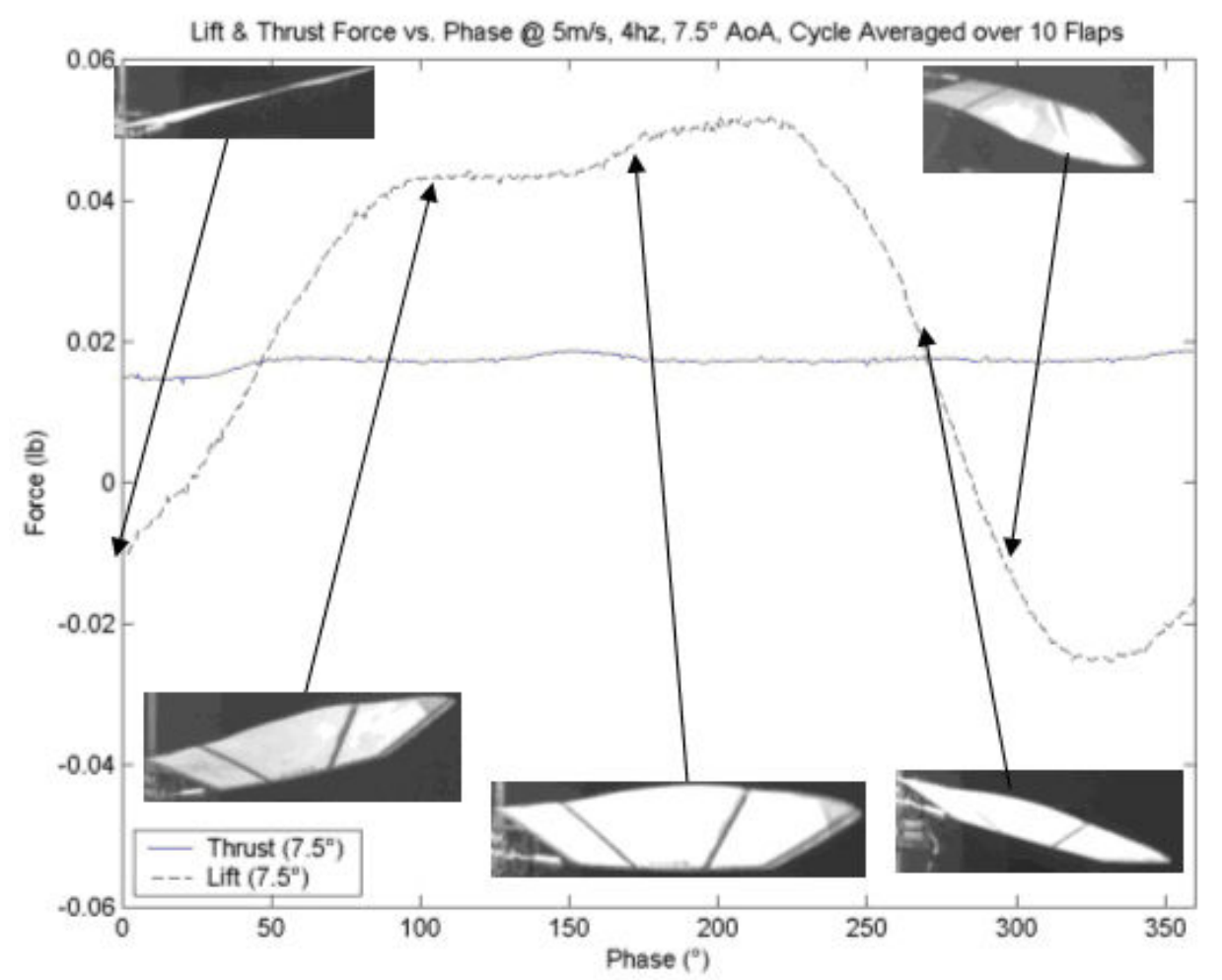

Figure 8.12: Wing 1 Position, Force \& Phase Correlation @ 5 m/s, 4 Hz, \& 7.5 AoA

The average lift generated during this flapping cycle was $0.043 \mathrm{lbs}$ and the average thrust generated was $0.017 \mathrm{lbs}$. Compared to Case 1, Case 3 generated more peak and average lift as well as higher average thrust. The main reason the lift was greater was because the flapping frequency was increased to $4 \mathrm{~Hz}$ and there was an incoming air flow of $5 \mathrm{~m} / \mathrm{s}$. The increase in thrust force was due to the increase in angle of attack from $0^{\circ}$ to $7.5^{\circ}$

The last case studied with Wing 1 in detail was Case 4: $5 \mathrm{~m} / \mathrm{s}, 4 \mathrm{~Hz}, 15^{\circ}$ AoA. Starting from the $0^{\circ}$ position, the lift increased until it reached a peak value of $0.036 \mathrm{lbs}$ at about $150^{\circ}$. Between approximately $200^{\circ}$ to $300^{\circ}$ lift generation decreased, with a minimum occurring at about $310^{\circ}$ when the wing was well on its way on the upstroke. The minimum in lift was much lower than the other three cases, while the peak lift was 
approximately $0.036 \mathrm{lbs}$. This maximum in lift was approximately the same as the $0 \mathrm{~m} / \mathrm{s}$ $3 \mathrm{~Hz}, 0^{\circ} \mathrm{AoA}$ and the $5 \mathrm{~m} / \mathrm{s}, 3 \mathrm{~Hz}, 7.5^{\circ}$ AoA cases. The average lift generated was 0.001 lbs, while the average net thrust generated was approximately $-0.007 \mathrm{lbs}$.

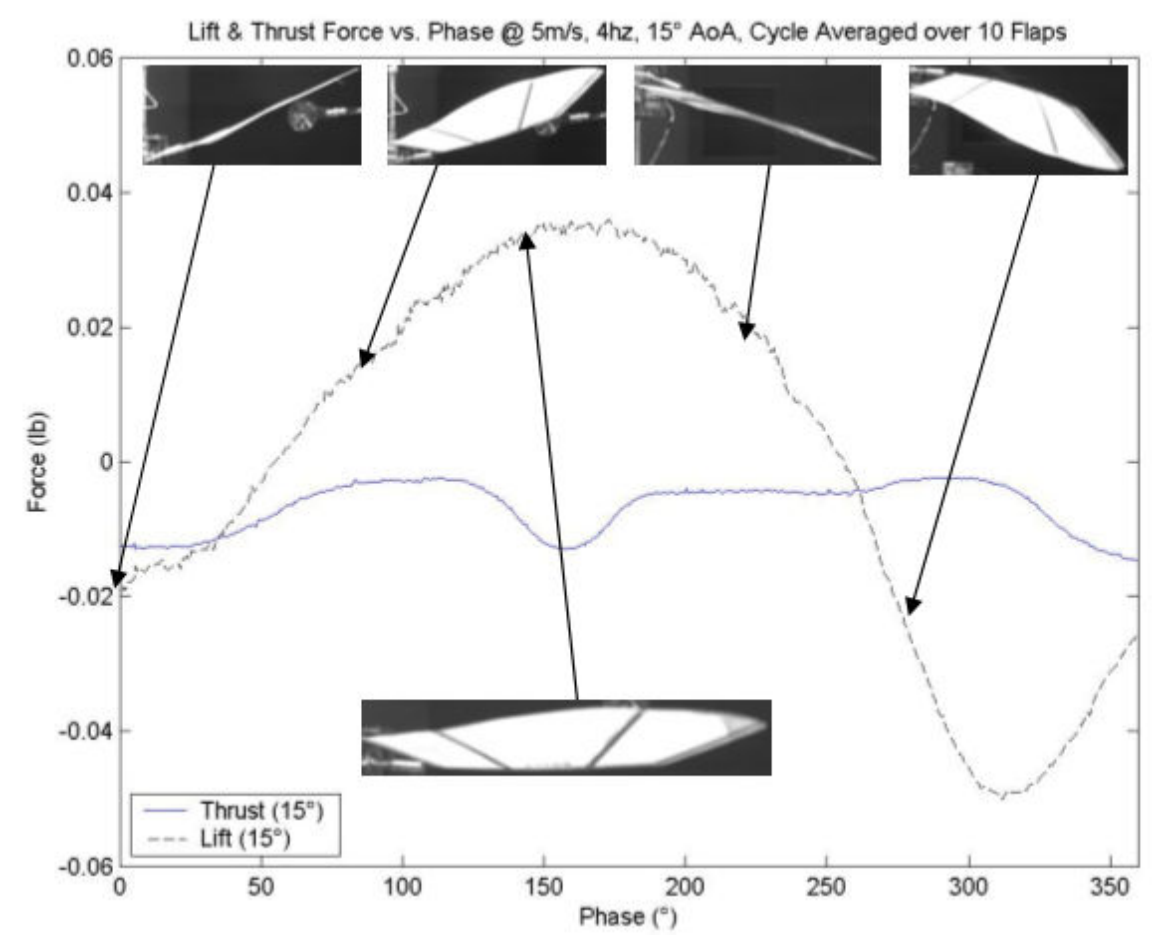

Figure 8.13: Wing 1 Position, Force \& Phase Correlation @ $5 \mathrm{~m} / \mathrm{s}, 4 \mathrm{~Hz}, \& 7.5^{\circ}$ AoA

This suggests that flapping frequency has limited the generation of lift in the first two cases, while angle of attack was the limiting cause in the $4^{\text {th }}$ case. In order to ascertain whether this was indeed the case, a simple experiment was conducted. Short 2 inch strings were taped to the wing and the mechanism was flapped at $5 \mathrm{~m} / \mathrm{s}, 4 \mathrm{~Hz}$, and $15^{\circ}$ AoA. High speed video was recorded of the flap. Figure 8.14 shows a still from the flap. A $15^{\circ}$ angle of attack was too high and the wing was stalling due to very high turbulence. 


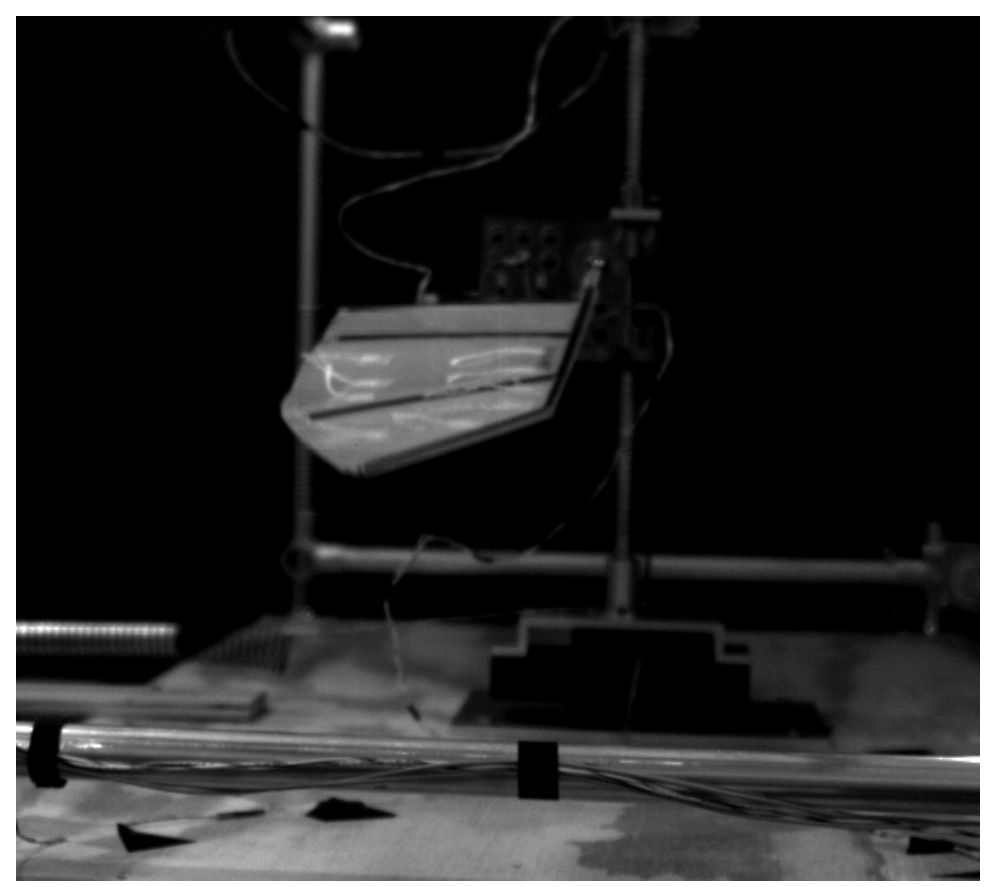

Figure 8.14: High Speed Video Showing Stall@ 5 m/s, $4 \mathrm{~Hz}, 15^{\circ}$ AoA

From Figure 8.14 it can be seen that on the downstroke there was turbulent flow present which caused flow separation. The pieces of the string on the leading edge stayed in a very orderly arranged pattern, while more than half of the pieces on the trailing edge were crooked and sideways. This indicated stall and separation of the laminar boundary layer.

\section{$\underline{\text { 8.4.4 }} \underline{\text { Wing } 1 \text { Velocity Analysis }}$}

The role of wing flexibility was estimated on the wing relative velocity. It was found that the increase in relative velocity was enhanced by the flexible nature of the wing. The highest velocities were found during the wing's downstroke flap. This analysis was based from the high speed video camera. During the flap, the highest point of the root velocity was found and measured. Next, a specific location was chosen on the wing approximately 12 inches outboard from the root. This point was taken as the center 
of pressure of the wing. The point in the flap when this location traveled the fastest was found and the velocity was measured. The same was done to obtain the maximum velocity of the wing tip.

The highest velocity of the wing root for the $0 \mathrm{~m} / \mathrm{s}, 3 \mathrm{~Hz}, 0^{\circ}$ AoA case, was found to be $0.5 \mathrm{~m} / \mathrm{s}$, and occurred as the wing root approached $150^{\circ}$. Assuming a rigid wing, the velocity at the $3 / 4$ span point (12 inches outboard from the root) would have been approximately $3 \mathrm{~m} / \mathrm{s}$. However, the wing velocity for the flexible wing was $3.5 \mathrm{~m} / \mathrm{s}$ at the $3 / 4$ span point. For the wing tip, a rigid wing would have a velocity of $4 \mathrm{~m} / \mathrm{s}$ where the velocity at the tip of the flexible wing was found to be $5.67 \mathrm{~m} / \mathrm{s}$. Since the force produced by the wing is proportional to the square of the velocity, the flexible wings should produce more lift than their rigid counterparts. If the $3 / 4$ span point is taken as the center of pressure of the wing, then $36 \%$ more force should be produced. It should also be noted that this peak velocity portion of the cycle is very near that of the peak lift shown in Figure 8.10.

For Case 2 at $5 \mathrm{~m} / \mathrm{s}, 3 \mathrm{hz}$, and $7.5^{\circ}$ AoA, the peak speed of the wing root was found to be $0.54 \mathrm{~m} / \mathrm{s}$. This was at approximately $150^{\circ}$ corresponding with the $156^{\circ}$ location in the flap of the first peak of maximum lift. Assuming the wing was rigid, a point at the $3 / 4$ span point would be about $3.24 \mathrm{~m} / \mathrm{s}$, while the velocity at the wingtip (16 inches outboard from the root) would be approximately $4.32 \mathrm{~m} / \mathrm{s}$. The wing velocity of the flexible wing at the $3 / 4$ span point was found to be $3.71 \mathrm{~m} / \mathrm{s}$, while the speed of the wingtip was measured at $5.8 \mathrm{~m} / \mathrm{s}$. With the addition of the incoming flow of $5 \mathrm{~m} / \mathrm{s}$ at the $3 / 4$ span point, the flexible wing has a relative wind of approximately $6.22 \mathrm{~m} / \mathrm{s}$ versus $4.9 \mathrm{~m} / \mathrm{s}$ for the rigid wing. This shows again that the flexible wing should perform better than its 
rigid counterpart. The addition of the incoming flow as well as the angle of attack appears to increase the wing velocities as well. A possible reason for this increase in velocity due to a higher angle of attack is because the surface area normal to the flapping direction was reduced. Having a $0^{\circ}$ AoA should cause the highest positive and negative lift force since the wing has the most surface area exposed normal to the direction of flap and since drag is directionally proportional to the surface area. Increasing the angle of attack reduced the surface area normal to the direction of the flap and thus decreased the drag force, thereby increasing the velocity.

For the third case of $5 \mathrm{~m} / \mathrm{s}, 4 \mathrm{~Hz}, 7.5^{\circ}$ AoA, the peak speed of the wing root was found to be $0.635 \mathrm{~m} / \mathrm{s}$. Again, assuming a rigid wing, the velocity at the $3 / 4$ span location was $3.81 \mathrm{~m} / \mathrm{s}$. The velocity for the flexible wing at a point 12 inches outboard was found to be $4.5 \mathrm{~m} / \mathrm{s}$. With an incoming flow of $5 \mathrm{~m} / \mathrm{s}$, the relative wind was $6.73 \mathrm{~m} / \mathrm{s}$ for the flexible wing versus $6.29 \mathrm{~m} / \mathrm{s}$ for the theoretical rigid wing. Thus the flexible wing would be expected to produce on the order of $15 \%$ more lift than its rigid counterpart. Note that the advantage gained by the flexible wing has decreased as the forward velocity increases. Further, the advantage of flapping is also decreased with forward speed. However, the forward velocity is not the only factor as seen in the $2^{\text {nd }}$ and $3^{\text {rd }}$ cases, where velocity increased only marginally; therefore, relative angle of attack was an important factor as well.

The fourth case was the $5 \mathrm{~m} / \mathrm{s}, 4 \mathrm{~Hz}$, and $15^{\circ}$ AoA case. The velocity of the wing's root was measured to be approximately $0.621 \mathrm{~m} / \mathrm{s}$ at the peak point. Taking a rigid wing and extrapolating the velocity at the $3 / 4$ span would be approximately $3.7 \mathrm{~m} / \mathrm{s}$ while the velocity at the tip would be approximately $5 \mathrm{~m} / \mathrm{s}$. The flexible wing showed that it 
moved air with a velocity of approximately $4.3 \mathrm{~m} / \mathrm{s}$ at the $3 / 4$ span point. With the incoming flow of $5 \mathrm{~m} / \mathrm{s}$, the increase in air velocity for the flexible wing at this point was $6.6 \mathrm{~m} / \mathrm{s}$ and $6.2 \mathrm{~m} / \mathrm{s}$ for the rigid wing.

Although the data might seem to indicate that an increase in wing flexibility leads to an increase in lift, there must be some reasonable limit for the amount of flexibility the wing has. This was concluded after looking at the high speed camera as well as observing the forces generated by Wing 1. The buckling phenomenon as previously described caused the wing to lose structural stability. This in turn caused the wing to produce less lift and thrust. A second negative effect was the phase lag apparent in Wing 1. The wing tip trailed the root by as much as $60^{\circ}$, another factor which most likely reduced lift and thrust forces.

\subsection{Analysis of $2^{\text {nd }}$ Generation Wings}

\subsubsection{Lift and Thrust Data to High Speed Video Correlation}

The same method of correlating wing positions from the high speed camera to the encoder positions on the drive shaft was carried out and this correlation can be seen in Figure 8.15 through Figure 8.21. From these graphs, it can be seen that Wing 2 had maximum and minimum peaks in lift at similar points to Wing 1 . The thrust generation is similar as well in that it is constant.

For Case $1,0 \mathrm{~m} / \mathrm{s}, 3 \mathrm{~Hz}, 0^{\circ}$ AoA shown in Figure 8.15, it can be seen that the lift force started to increase steadily until it reached a maximum at approximately $130^{\circ}$. The maximum lift generated during this cycle was $0.08 \mathrm{lbs}$. The peak was slightly earlier

than that of Wing 1, and approximately twice as much positive lift was generated. At this 
point, the wing was just past the horizontal point with respect to the ground. As the wing finished the downstroke and continued through the upstroke, the lift started to steadily drop and reached a minimum peak at $310^{\circ}$. This was the fastest point on the upstroke, and thus makes sense that a minimum was seen at this location in the flap. The average lift produced was $0.019 \mathrm{lbs}$, while the average thrust generated was $0.032 \mathrm{lbs}$. In contrast, Wing 1 produced $0.01 \mathrm{lbs}$ of average lift and $0.01 \mathrm{lbs}$ of average thrust. Comparing this flapping condition between Wing 1 and Wing 2, the impact of wing flexibility can be seen. Wing 2 stayed quite rigid compared to Wing 1 during the flap and exhibited no buckling.

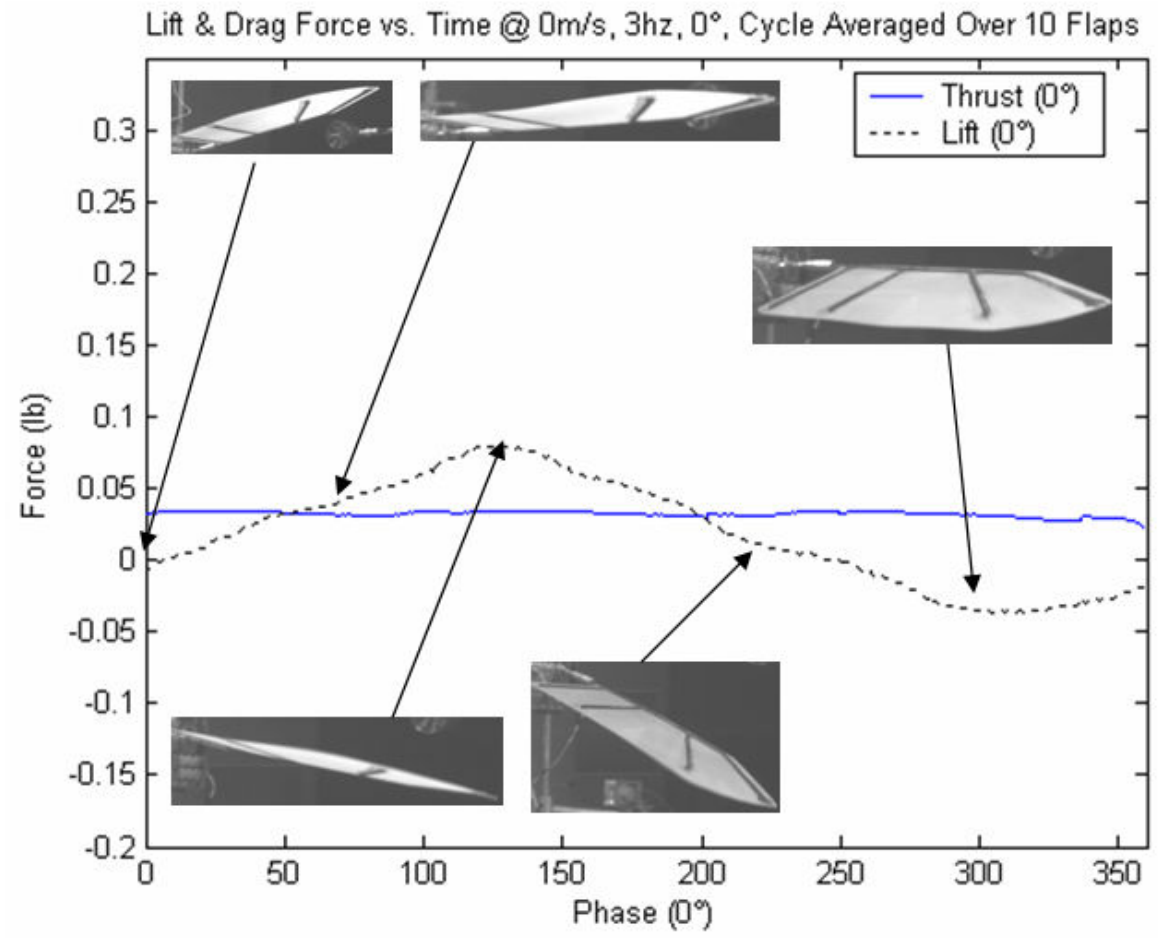

Figure 8.15: Wing 2 Position, Force \& Phase Correlation @ 0 m/s, $3 \mathrm{~Hz}, \& 0^{\circ}$ AoA

The flapping condition of Case $2\left(5 \mathrm{~m} / \mathrm{s}, 3 \mathrm{~Hz}, 7.5^{\circ} \mathrm{AoA}\right)$ incorporated the inclusion of forward flight. The results were similar to those of Wing 1 . From the $0^{\circ}$ 
initial point, where the wing was just starting the downstroke, the lift force started to increase, and reached its first peak of $0.199 \mathrm{lbs}$ at approximately $135^{\circ}$. There was a second maximum peak which occurred at approximately $220^{\circ}$ where the value of instantaneous lift was $0.15 \mathrm{lbs}$. From this point the lift decreased at a much higher rate and become negative when it was in the middle of its upstroke at about $270^{\circ}$. Wing 2 reached its maximum before Wing 1 and the resulting peak lift was much higher. The two maximums of Wing 2 were spread over $80^{\circ}$. This increase in lift duration was most likely due to the incoming air flow. The average lift generated during this flapping cycle was 0.075 , while the average thrust produced was $0.051 \mathrm{lbs}$. Flapping Wing 1 at this same condition produced $0.004 \mathrm{lbs}$ of average lift and $0.053 \mathrm{lbs}$ of average thrust. There was a significant improvement changing to Wing 2 in increasing the average lift; as the lift was increased by an order magnitude. There was very little change in thrust generated however. The reason for this was that there was some difference in wing positions between Wing 1 and Wing 2 during the flapping cycle, and this can be seen in Figure 8.16 and Figure 8.11. This was specifically evident at $120^{\circ}$ and $310^{\circ}$ in the flap. At the $120^{\circ}$ point the flexible wing has a higher angle of attack on the downstroke than the less flexible wing. At the $310^{\circ}$ point Wing 1 exhibited large buckling deformation while Wing 2 had a higher angle of attack on the upstroke. This was a direct effect of increasing the wing stiffness. 


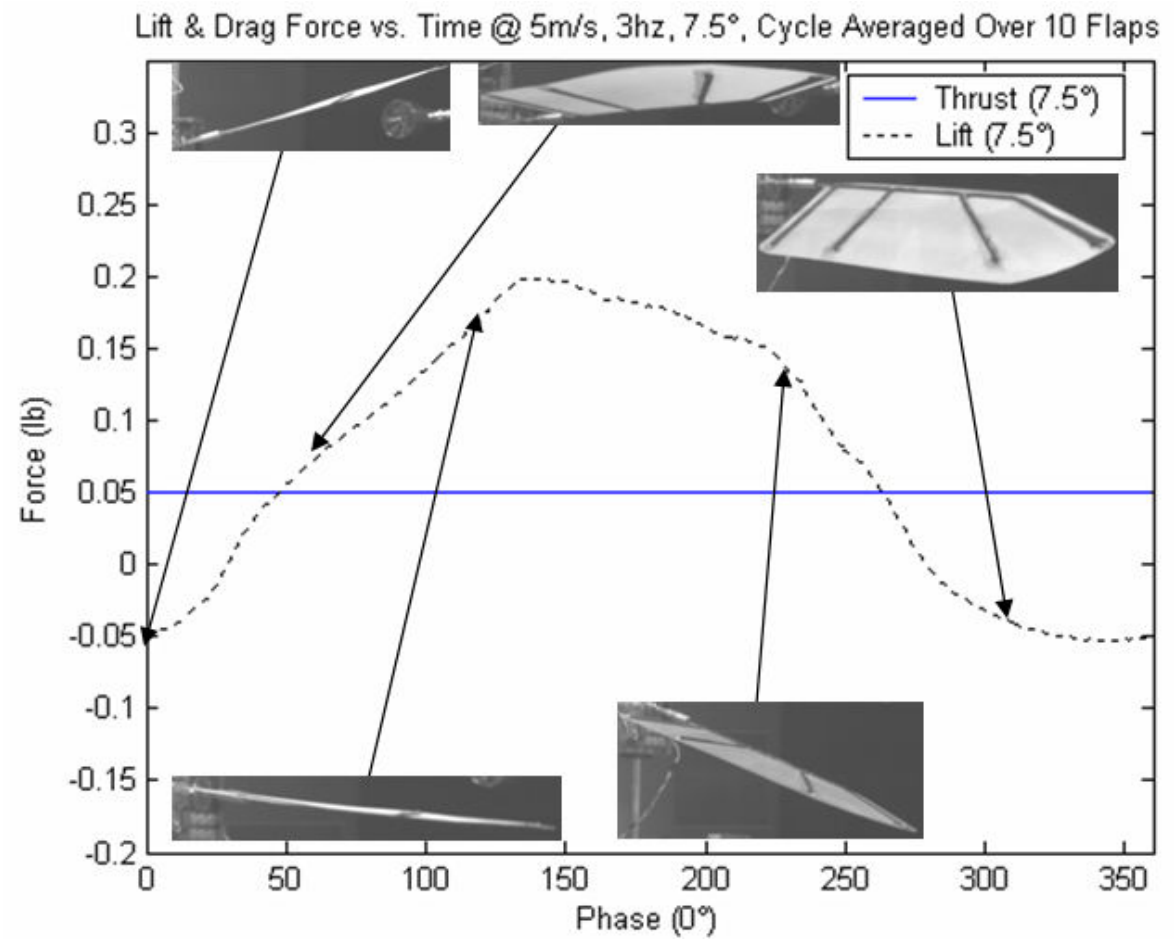

Figure 8.16: Wing 2 Position, Force \& Phase Correlation @ $5 \mathrm{~m} / \mathrm{s}, 3 \mathrm{~Hz}, \& 7.5^{\circ}$ AoA

Case 3 is the $5 \mathrm{~m} / \mathrm{s}, 4 \mathrm{~Hz}, 7.5^{\circ}$ AoA condition (Figure 8.19). This case was similar to that of Wing 1 in that there were 2 peaks of maximum lift. Unlike Wing 1 , the lift produced by Wing 2 reached a maximum of $0.293 \mathrm{lbs}$ at approximately $140^{\circ}$ very sharply. At approximately $220^{\circ}$ the lift force dropped quite steeply to a lesser peak of $0.165 \mathrm{lbs}$, unlike Wing 1 whose lift curve was more spread out. At $300^{\circ}$ the wing started to produce negative lift, and this point it was well on its way on the upstroke. This was the best lift case where the mechanism produces almost $0.3 \mathrm{lbs}$ of lift. This was also the best thrust condition where the mechanism produces $0.06 \mathrm{lbs}$ of net thrust. At the $100^{\circ}$ position it can be seen that the wing is quite flat on the downstroke, meaning it was more parallel to the flapping motion than Wing 1 at the same condition. This meant that it was able to move more air and produce more lift force. On the upstroke at $300^{\circ}$ Wing 2 had a 
very steep angle of attack; this minimized down force and increased net lift produced. The average lift produced was $0.143 \mathrm{lbs}$, while the average thrust produced was approximately $0.067 \mathrm{lbs}$. By contrast, Wing 1 at the same flapping condition produced $0.043 \mathrm{lbs}$ of average lift and $0.067 \mathrm{lbs}$ of average thrust.

The relative angle of attack of the flexible wing was a function of the span. Taking a point 4 inches outboard from the root of the wing, it was found that both Wing 1 and Wing 2 had an angle of attack of $4^{\circ}$ relative to the horizontal at approximately the $100^{\circ}$ position point in the flapping phase. Incorporating the velocity analysis for Wing 1 (Section 8.4.4) and for Wing2 (Section 8.5.2) Figure 8.17 shows the relative angles of attack of both wings at a point 4 inches outboard from the root of the wing. 4 inches was chosen because it was believed that this was a point where both wing would be relatively rigid compared to each other, since the stiffest sections of both wings were closest to the tip.
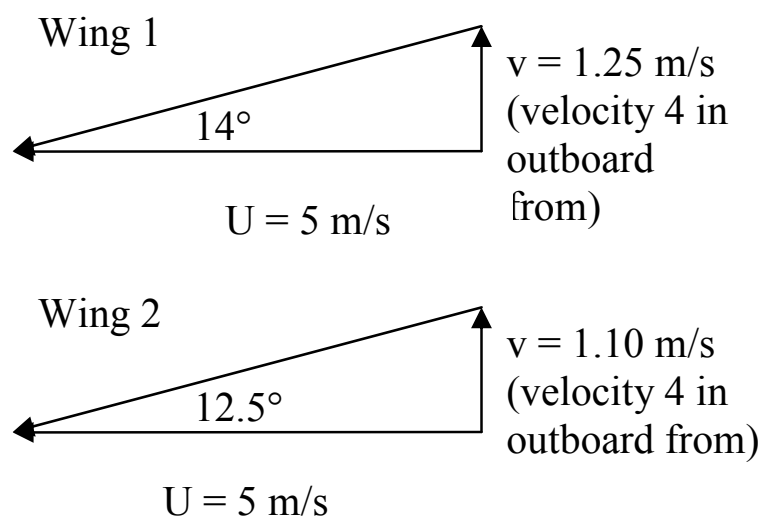

Figure 8.17: Relative AoAs for Wing1 and Wing 2, 4 inches Outboard from Root

From the velocity analysis, it was found that the Wing 1 had a $14^{\circ}$ wind (or relative velocity), while the wind for Wing 2 was $12^{\circ}$. Subtracting off the angle of attack 
of both wings at the $100^{\circ}$ point in the flap, it was found that the resultant relative angle of attack for Wing 1 was $10^{\circ}$ and for Wing 2 was $8^{\circ}$. This confirmed that the area closest to the root was indeed stiffer for Wing 2 over Wing 1.

Figure 8.18 below shows the velocity analysis performed for both wings at the $3 / 4$ span point, at approximately $100^{\circ}$ in the flap. This was again done using the velocity analysis for Wing 1 from Section 8.4.4 and for Wing 2 from Section 8.5.2. For Wing 1 it was found that the wind from the velocity analysis was approximately $53.4^{\circ}$, while for Wing 2 it was $52.3^{\circ}$. The relative velocity of the wing at the $100^{\circ}$ point in the flap at a position 12 outboard from the root of the wing was found to be $9^{\circ}$ for Wing 1 and $5^{\circ}$ for Wing 2. This showed that the stiffer Wing 2 twisted less during the flap than the more flexible Wing 1. After subtracting off the angles of attack of both wings at the $100^{\circ}$ position in the flap, it was found that Wing 1 had a resultant relative angle of attack of $44^{\circ}$ and Wing 2 for Wing 2 it was $47^{\circ}$. 

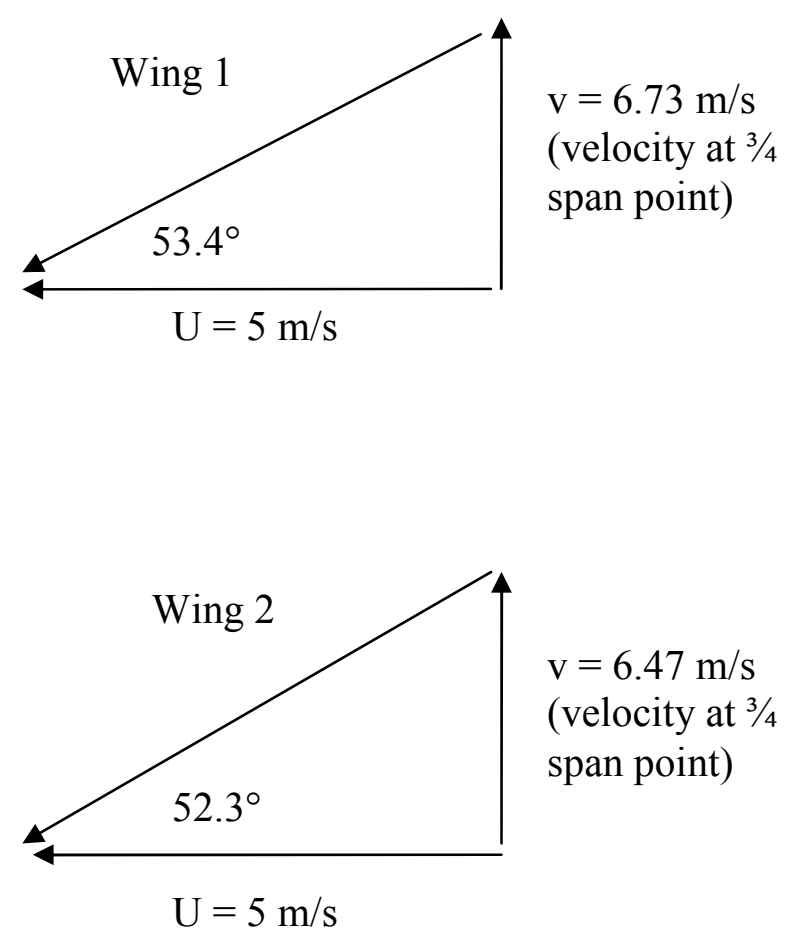

Figure 8.18: Relative AoAs for Wing 1 and Wing 2, at the 3/4 Span Point

The reason Wing 2 had a higher relative angle of attack than Wing 1 was because of the adaptive shaping phenomenon property inherent in all flexible membrane structures. With the incoming free stream velocity, the trailing edge of Wing 1 was able to twist and thus adapt to the incoming air more than the stiffer wing. This caused the relative angle of attack to be less than Wing 2.

The $5 \mathrm{~m} / \mathrm{s}, 4 \mathrm{~Hz}, 7.5^{\circ}$ AoA was the case where the most lift was generated for both sets of wings. However Wing 2 generated much more average and peak lift than did Wing 1. The reason for this is most likely due to the fact that angle of attack was a function of the span for both wings. Wing 1 started at a $4^{\circ}$ angle of attack and the relative angle of attack increased to $44^{\circ}$. Wing 2 also started at a $4^{\circ}$ angle of attack, but the relative angle of attack increased to 47 degrees. It is possible that the increase in relative angle of attack for Wing 2 occurred further outboard from the root that it did for 
Wing 1. This would result in Wing 2 being stiffer for a larger amount of span than Wing 1. In flapping systems lift is predominantly generated over the area of the wing closest to the root as that is the stiffest section of the wing. Therefore, the larger area of increased stiffness of the $2^{\text {nd }}$ wing is a possible the reason Wing 2 generated more lift than Wing 1.

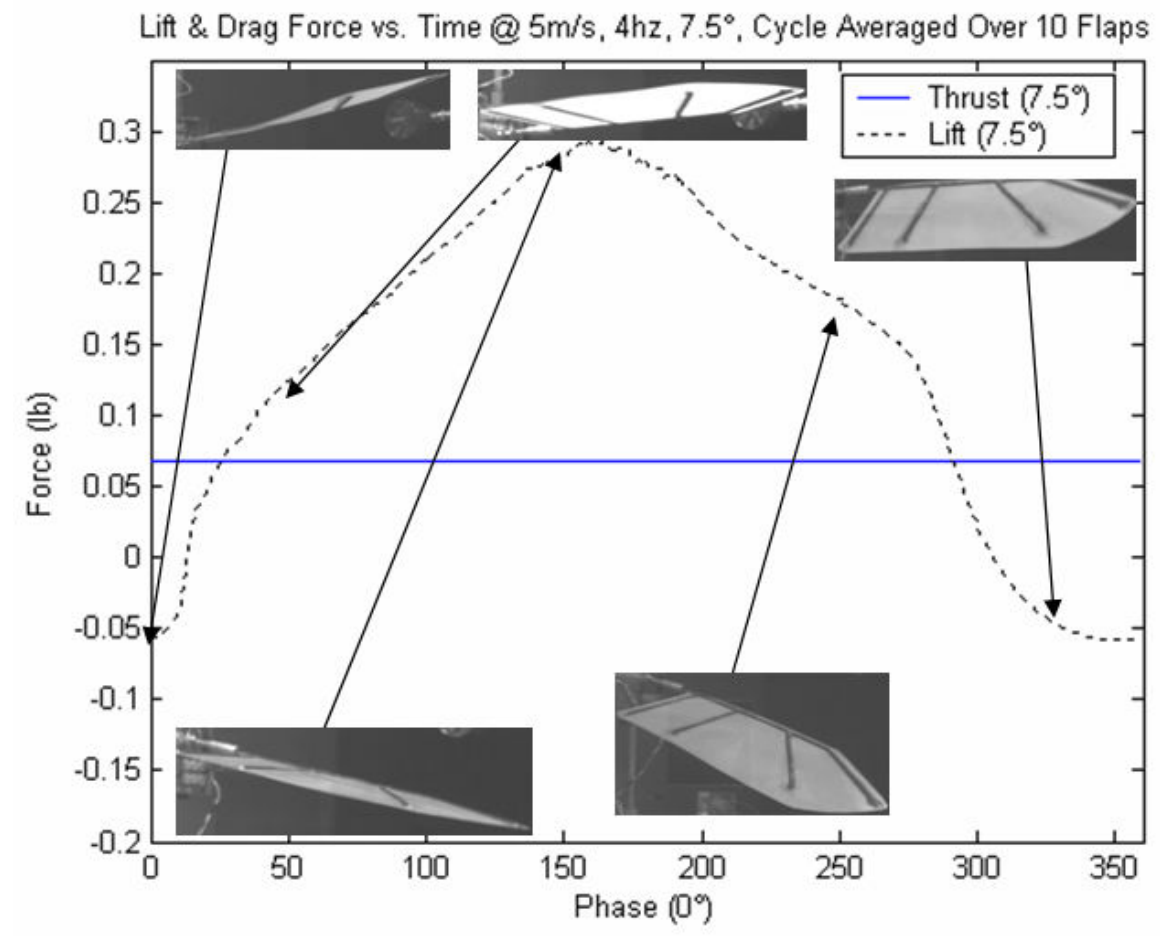

Figure 8.19: Wing 2 Position, Force \& Phase Correlation @ 5 m/s, 4 Hz, \& 7.5 AoA

Further comparing the wing positions of Wing 1 and Wing 2 in Figure 8.12 and

Figure 8.19 respectively, the impact of wing flexibility on the angle of attack can be seen at $150^{\circ}, 230^{\circ}$ and $330^{\circ}$ in the flap. It can be seen that Wing 2 mostly stayed parallel to the ground on the downstroke while on the upstroke having a higher angle of attack. The high flexibility of Wing 1 caused it to bend too readily to changes in motion. These abrupt changes caused Wing 1 to buckle, preventing it from increasing its angle of attack on the upstroke. This resulted in lower average lift and thrust forces. 
Figure 8.20 shows the aerodynamic force vectors associated with the $5 \mathrm{~m} / \mathrm{s}, 4 \mathrm{~Hz}$, $7.5^{\circ}$ AoA case. These vectors show the direction of the total force generated by the mechanism during one flap. The wingtip position is plotted versus phase to indicate the point in the flap. The force vectors were obtained by performing a vector sum of the lift and thrust forces generated by the mechanism as shown in Figure 8.19. From Figure 8.20 , it can be seen that at the very beginning of the downstroke the lift force is negative. It becomes positive at approximately $30^{\circ}$ in the flap, reaches its peak at approximately $140^{\circ}$. The vectors always point towards the right of the graph, indicating the forward position. Once again this means that thrust is constantly being generated.

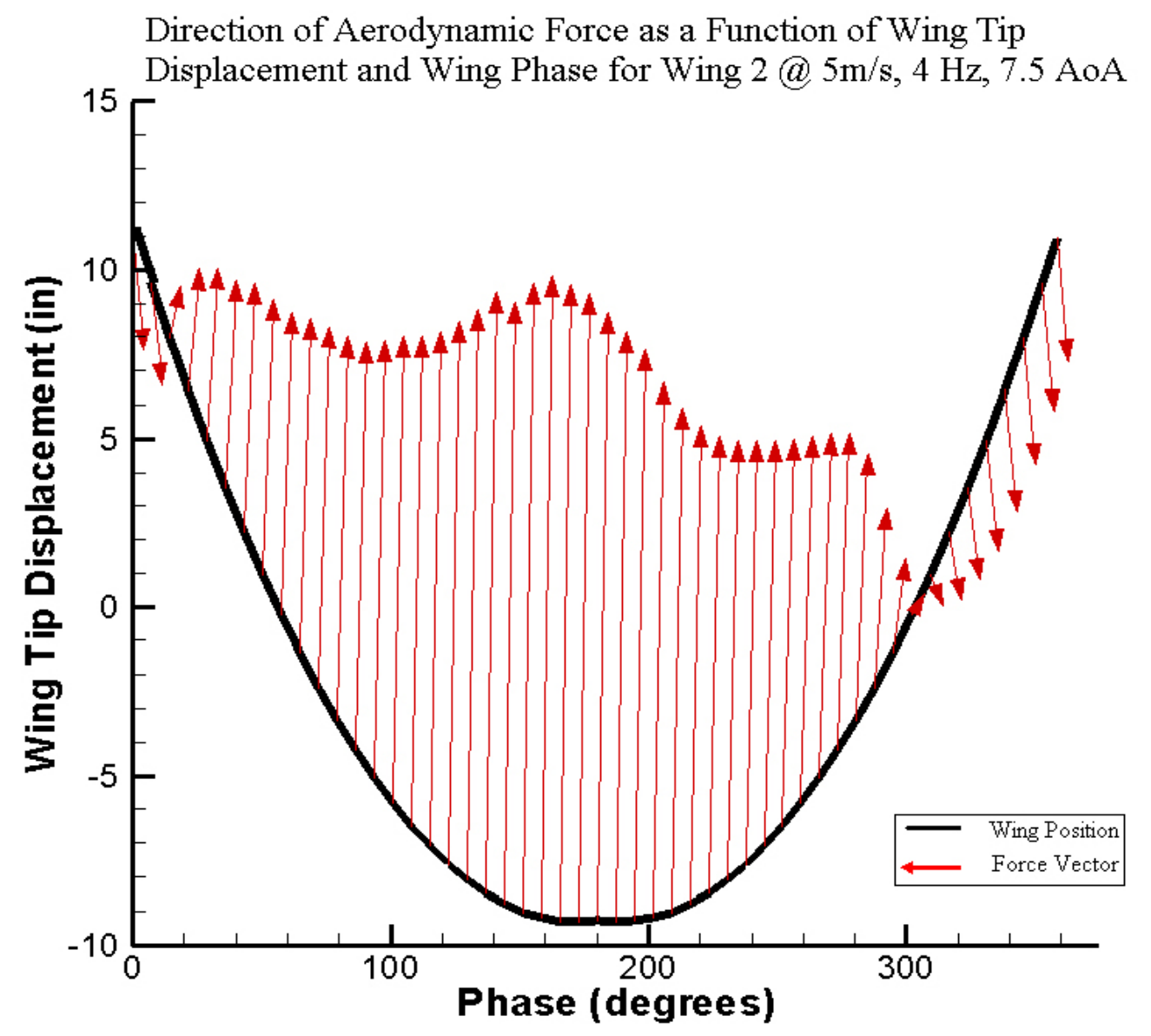

Figure 8.20: Aerodynamic Force Vectors vs. Wing Position in Flapping Cycle 
The fourth case was at $5 \mathrm{~m} / \mathrm{s}, 4 \mathrm{~Hz}, 15^{\circ}$ AoA. At this test condition Wing 1 was again outperformed by Wing 2 . The peak lift produced by Wing 1 was $0.05 \mathrm{lbs}$, while the peak lift produced by Wing 2 was almost $0.227 \mathrm{lbs}$. The thrust performance was increased as well, with the average thrust of $0.022 \mathrm{lbs}$ being generated by Wing 2 . The mechanism produced positive lift at $65^{\circ}$ and the rate of lift generation increased steeply until a peak was reached at about $160^{\circ}$. At this point the wing was just past the horizontal point with reference to the ground. From this point lift production decreased to a minimum at about $300^{\circ}$ during which point the wing was already well on its way on the upstroke.

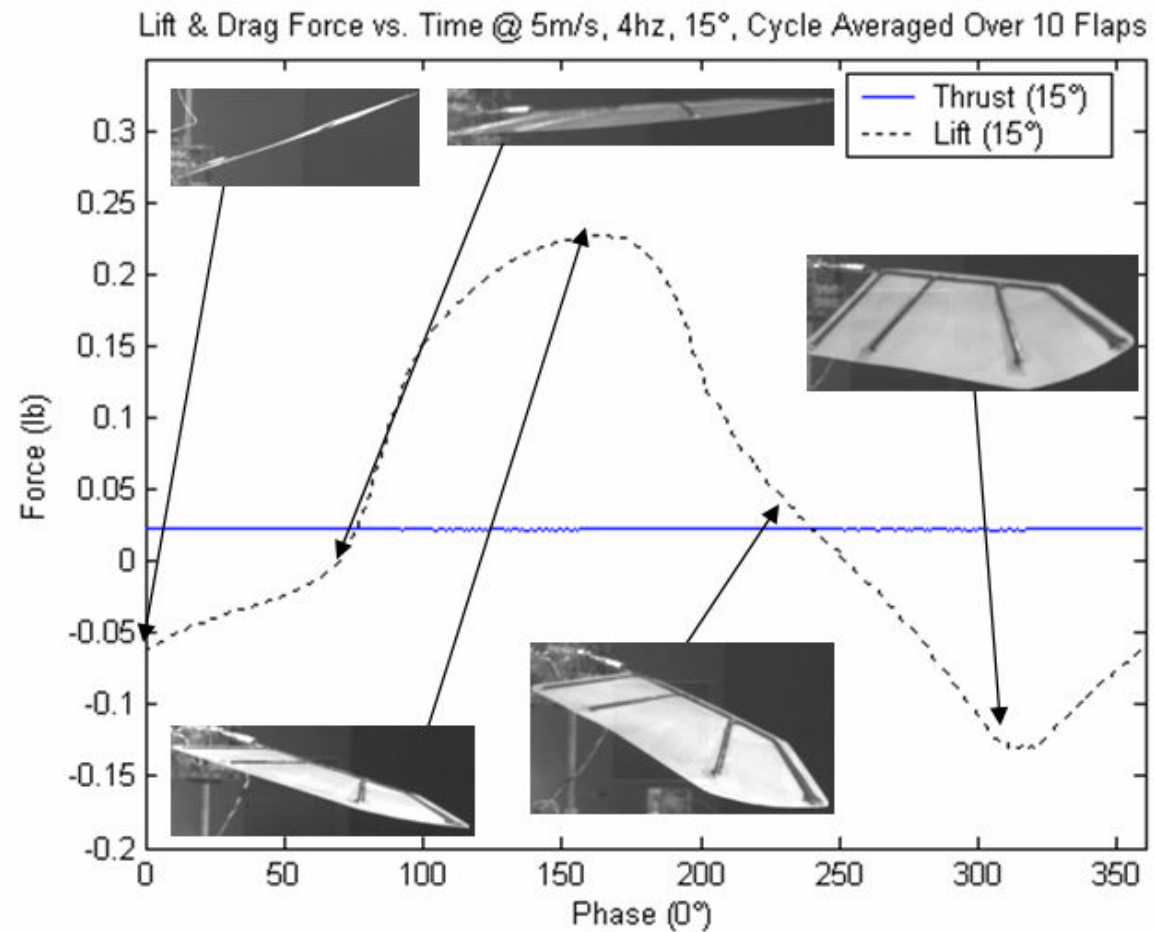

Figure 8.21: Wing 2 Position, Force \& Phase Correlation @ 5 m/s, 4 Hz, \& 15AoA

Comparing Figure 8.13 with Figure 8.21, there are two points where the role of wing flexibility is evident: $75^{\circ}$ and approximately $300^{\circ}$. The increased stiffness of Wing 
2 caused a sharp increase in lift at $75^{\circ}$ as opposed to Wing 1 , which increased to its point of peak lift gradually. The second point was the minimum in lift force at about $300^{\circ}$ with Wing 2. There was an abrupt change from negative lift generation to positive lift generation, and the cause is most likely the sharp rise in angle of attack with Wing 2.

Looking at the same point in Figure 8.13, it can be seen that the wing has buckled and the angle of attack on the upstroke is lower than that in Wing 2.

\section{$\underline{\text { 8.5.2 }}$ Wing 2 Velocity Analysis}

A velocity analysis described similar to that described in Section 8.4.4 was performed on Wing 2 to examine the role of flexibility on relative velocity. Again starting with the $0 \mathrm{~m} / \mathrm{s}, 3 \mathrm{~Hz}, 0^{\circ}$ AoA case, it was found that the velocity of the wing's root was approximately $0.48 \mathrm{~m} / \mathrm{s}$. It was no surprise that the speed of the wing root was about equal as that of Wing 1 for the same flapping condition. The deviation was due to slight variances in the flapping frequency around the nominal value. For example the actual flapping frequency for this case with Wing 1 was $3.2 \mathrm{~Hz}$, but with Wing 2 it was $2.9 \mathrm{~Hz}$. The velocity of a rigid wing at the $3 / 4$ span point was extrapolated to be $2.88 \mathrm{~m} / \mathrm{s}$, and $3.84 \mathrm{~m} / \mathrm{s}$ at the wingtip. The velocity of the flexible wing at the $3 / 4$ point was found to be $3.2 \mathrm{~m} / \mathrm{s}$ and approximately $4.91 \mathrm{~m} / \mathrm{s}$ at the wingtip. This was as expected as the second wing was less flexible than Wing 1, but still more flexible than a purely rigid wing. Again, this increased performance with respect to a purely rigid wing was due to the flexible wing's bending ability as it passed through the maximum velocity point in the flapping cycle.

The second case was the $5 \mathrm{~m} / \mathrm{s}, 3 \mathrm{~Hz}, 7.5^{\circ}$ AoA case where the root velocity was $0.51 \mathrm{~m} / \mathrm{s}$. Extrapolating a rigid wing out to the $3 / 4$ span point yielded a wing velocity of 
$3.06 \mathrm{~m} / \mathrm{s}$, and $4.08 \mathrm{~m} / \mathrm{s}$ at the tip. The wing velocity of the flexible wing at the $3 / 4$ span point was $3.47 \mathrm{~m} / \mathrm{s}$, and the velocity at the tip was approximately $5.1 \mathrm{~m} / \mathrm{s}$. Again, it can be seen that the velocities of Wing 2 were slightly less than the velocities of Wing 1, but higher than that of a purely rigid wing. With the inclusion of the incoming flow of $5 \mathrm{~m} / \mathrm{s}$ the velocity of the flexible wing at the $3 / 4$ point was approximately $6.09 \mathrm{~m} / \mathrm{s}$, while the rigid wing would be $5.86 \mathrm{~m} / \mathrm{s}$. This shows that Wing 2 caused a higher relative wind than a purely rigid wing, and this should in theory produce more lift force.

The third case was again taken to be $5 \mathrm{~m} / \mathrm{s}, 4 \mathrm{~Hz}, 7.5^{\circ}$ AoA. The root velocity at this point was $0.55 \mathrm{~m} / \mathrm{s}$. The velocity of a purely rigid wing at the $3 / 4$ point would be 3.42 $\mathrm{m} / \mathrm{s}$ and would be $4.56 \mathrm{~m} / \mathrm{s}$ at the wing tip. The $3 / 4$ span point of the flexible wing had a velocity of approximately $4.11 \mathrm{~m} / \mathrm{s}$. With the incoming flow of $5 \mathrm{~m} / \mathrm{s}$, the velocity of the air moved by the flexible wing was $6.47 \mathrm{~m} / \mathrm{s}$, while the air moved by a rigid wing would be $6.06 \mathrm{~m} / \mathrm{s}$.

The fourth and final case was $5 \mathrm{~m} / \mathrm{s}, 4 \mathrm{~Hz}, 15^{\circ}$ AoA. The velocity of the root was $0.54 \mathrm{~m} / \mathrm{s}$. Again, velocities of a rigid wing would be $3.24 \mathrm{~m} / \mathrm{s}$ and $4.32 \mathrm{~m} / \mathrm{s}$ for the $3 / 4$ span point and the wing tip respectively. The velocity of Wing 2 at this $3 / 4$ span point was found to be approximately $3.92 \mathrm{~m} / \mathrm{s}$. The incoming flow of $5 \mathrm{~m} / \mathrm{s}$ caused air to have a velocity of $6.35 \mathrm{~m} / \mathrm{s}$ at the $3 / 4$ span point, while its rigid counterpart would cause air to move at a velocity of $5.95 \mathrm{~m} / \mathrm{s}$. Again, this wing moved air at a faster velocity than a rigid wing, but slower air than the more flexible Wing 1. Although the air velocity is less than Wing 1, the lift and thrust forces generated are far greater. This suggests that although it is helpful to have a flexible wing, there is some point where having too much flexibility has adverse effects. 


\subsection{Summary of Wing 1 and Wing 2 Performance}

Figure 8.22 through Figure 8.25 show the increased performance of Wing 2 over Wing 1. Table 8.1 below shows a summary of wing root and tip velocities of Wing 1 and Wing 2 in addition to peak and average lift and thrust forces between both sets of wings.

Table 8.1: Summary of Experimental Results

\begin{tabular}{|c|c|c|c|c|c|c|c|c|}
\hline Condition & Wing & $\begin{array}{c}\text { Root } \\
\text { Velocity } \\
\text { (m/s) }\end{array}$ & $\begin{array}{c}3 / 4 \\
\text { Span } \\
\text { Point } \\
\text { Velocity } \\
(\mathrm{m} / \mathrm{s})\end{array}$ & $\begin{array}{c}\text { Velocity } \\
\text { of } 3 / 4 \\
\text { Point } \\
\text { with } 5 \\
\mathrm{~m} / \mathrm{s} \\
\text { Flow } \\
(\mathrm{m} / \mathrm{s})\end{array}$ & $\begin{array}{l}\text { Peak } \\
\text { Lift } \\
\text { (lb) }\end{array}$ & $\begin{array}{c}\text { Average } \\
\text { Lift (lb) }\end{array}$ & $\begin{array}{l}\text { Peak } \\
\text { Net } \\
\text { Thrust } \\
\text { (lb) }\end{array}$ & $\begin{array}{c}\text { Average } \\
\text { Thrust } \\
\text { (lb) }\end{array}$ \\
\hline \multirow{3}{*}{$\begin{array}{c}0 \mathrm{~m} / \mathrm{s}, 3 \\
\mathrm{~Hz}, 0^{\circ} \\
\mathrm{AoA}\end{array}$} & $\begin{array}{l}\text { Wing } \\
1 \text { : }\end{array}$ & 0.50 & 3.50 & $\mathrm{~N} / \mathrm{A}$ & 0.036 & 0.009 & 0.011 & 0.010 \\
\hline & $\begin{array}{l}\text { Wing } \\
2:\end{array}$ & 0.48 & 3.20 & $\mathrm{~N} / \mathrm{A}$ & 0.080 & 0.019 & 0.034 & 0.032 \\
\hline & $\begin{array}{l}\text { Rigid } \\
\text { (Avg): }\end{array}$ & 0.49 & 2.94 & $\mathrm{~N} / \mathrm{A}$ & $\mathrm{N} / \mathrm{A}$ & $\mathrm{N} / \mathrm{A}$ & $\mathrm{N} / \mathrm{A}$ & $\mathrm{N} / \mathrm{A}$ \\
\hline \multirow{3}{*}{$\begin{array}{c}5 \mathrm{~m} / \mathrm{s}, 3 \\
\mathrm{~Hz}, 7.5^{\circ} \\
\text { AoA }\end{array}$} & $\begin{array}{l}\text { Wing } \\
1:\end{array}$ & 0.54 & 3.71 & 6.22 & 0.038 & 0.004 & 0.053 & 0.051 \\
\hline & $\begin{array}{l}\text { Wing } \\
2 \text { : }\end{array}$ & 0.51 & 3.47 & 6.09 & 0.199 & 0.075 & 0.051 & 0.050 \\
\hline & $\begin{array}{l}\text { Rigid } \\
\text { (Avg): }\end{array}$ & 0.53 & 3.19 & 5.38 & $\mathrm{~N} / \mathrm{A}$ & $\mathrm{N} / \mathrm{A}$ & $\mathrm{N} / \mathrm{A}$ & $\mathrm{N} / \mathrm{A}$ \\
\hline \multirow{3}{*}{$\begin{array}{c}5 \mathrm{~m} / \mathrm{s}, 4 \\
\mathrm{~Hz}, 7.5^{\circ} \\
\mathrm{AoA}\end{array}$} & $\begin{array}{l}\text { Wing } \\
1:\end{array}$ & 0.64 & 4.50 & 6.73 & 0.052 & 0.043 & 0.019 & 0.017 \\
\hline & $\begin{array}{l}\text { Wing } \\
2:\end{array}$ & 0.55 & 4.11 & 6.47 & 0.293 & 0.143 & 0.068 & 0.067 \\
\hline & $\begin{array}{l}\text { Rigid } \\
\text { (Avg): }\end{array}$ & 0.60 & 3.62 & 6.18 & $\mathrm{~N} / \mathrm{A}$ & $\mathrm{N} / \mathrm{A}$ & $\mathrm{N} / \mathrm{A}$ & $\mathrm{N} / \mathrm{A}$ \\
\hline \multirow{3}{*}{$\begin{array}{c}5 \mathrm{~m} / \mathrm{s}, 4 \\
\mathrm{~Hz}, 15^{\circ} \\
\mathrm{AoA}\end{array}$} & $\begin{array}{l}\text { Wing } \\
1 \text { : }\end{array}$ & 0.62 & 4.30 & 6.60 & 0.036 & 0.001 & -0.003 & -0.007 \\
\hline & $\begin{array}{l}\text { Wing } \\
2 \text { : }\end{array}$ & 0.54 & 3.92 & 6.35 & 0.227 & 0.040 & 0.022 & 0.022 \\
\hline & $\begin{array}{l}\text { Rigid } \\
\text { (Avg): }\end{array}$ & 0.58 & 3.47 & 6.08 & $\mathrm{~N} / \mathrm{A}$ & N/A & $\mathrm{N} / \mathrm{A}$ & $\mathrm{N} / \mathrm{A}$ \\
\hline
\end{tabular}

From Table 8.1 above and the figures below, it can be seen that there was a dramatic increase in lift and thrust generated by the second, stiffer wing. The shapes of 
the lift curves of both wings exhibit similar sinusoidal type shapes. The thrust curves generated by both wings are similar in that both sets appear to generate constant force.

Lift is predominantly generated on the downstroke, with negative lift being generated on the upstroke, matching conventional knowledge. The increase in positive lift and thrust was attributed to the stiffer nature of the wing structural members. As previously mentioned in Section 8.4.4, the flexible wings appeared to show increased performance over their rigid counterparts. However, it is believed that if a wing is too flexible it will have adverse effects, as described in Section 8.1.

From the figures below, it can be seen that the lift curves are generally sinusoidal in nature while the thrust curves are closer to constant functions. In all cases the second wing produced more peak lift and average lift and thrust than the first wing. Figure 8.23 and Figure 8.24 show that the $7.5^{\circ}$ angle of attack produced more average lift than the other cases with the second set of wings. The duration of positive lift was greatest for these two cases as well, with both wings exhibiting multiple peaks of positive lift. The graphs show that both wings produced their peak lift at approximately the same point in the flapping cycle, within that testing scenario. 


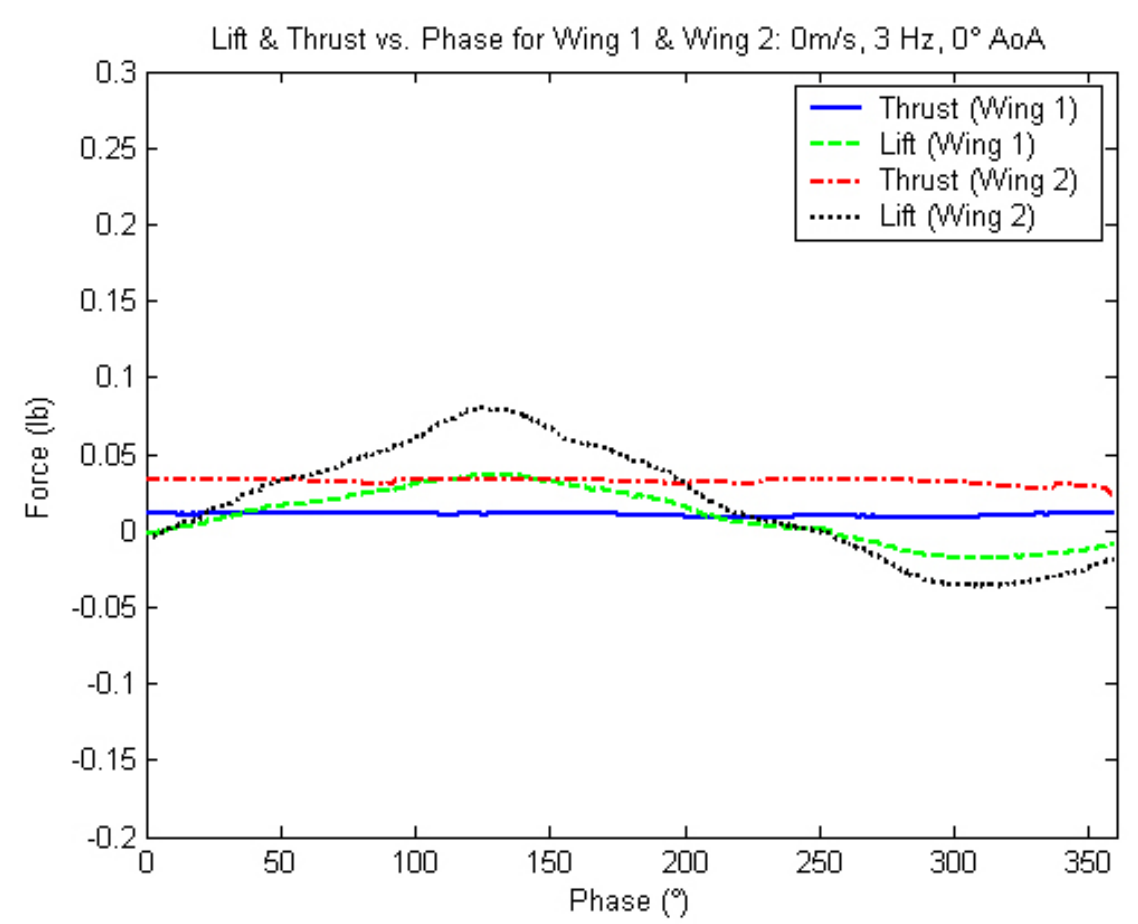

Figure 8.22: Lift \& Thrust vs. Phase @ 0 m/s, $3 \mathrm{~Hz}, \& 0^{\circ}$ AoA

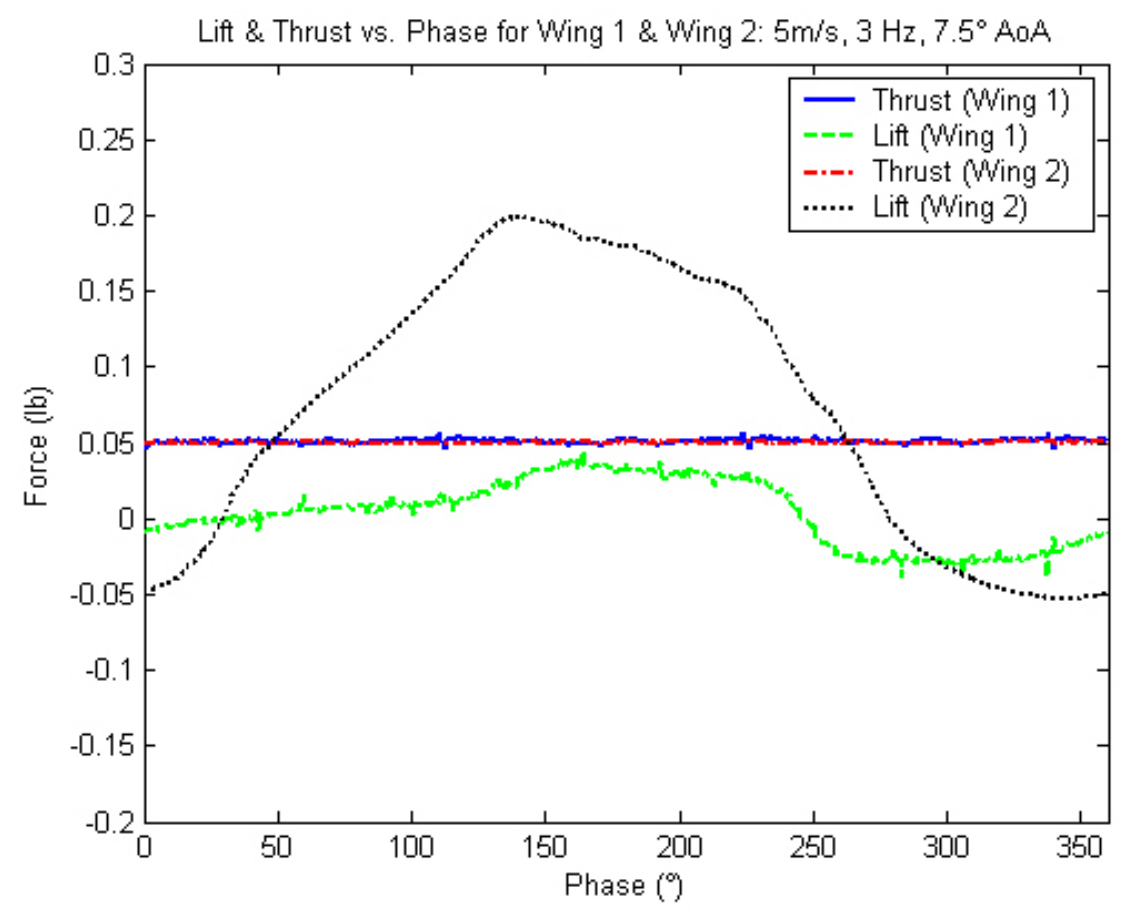

Figure 8.23: Lift \& Thrust vs. Phase @ 5 m/s, 3 Hz, \& 7.5 AoA 


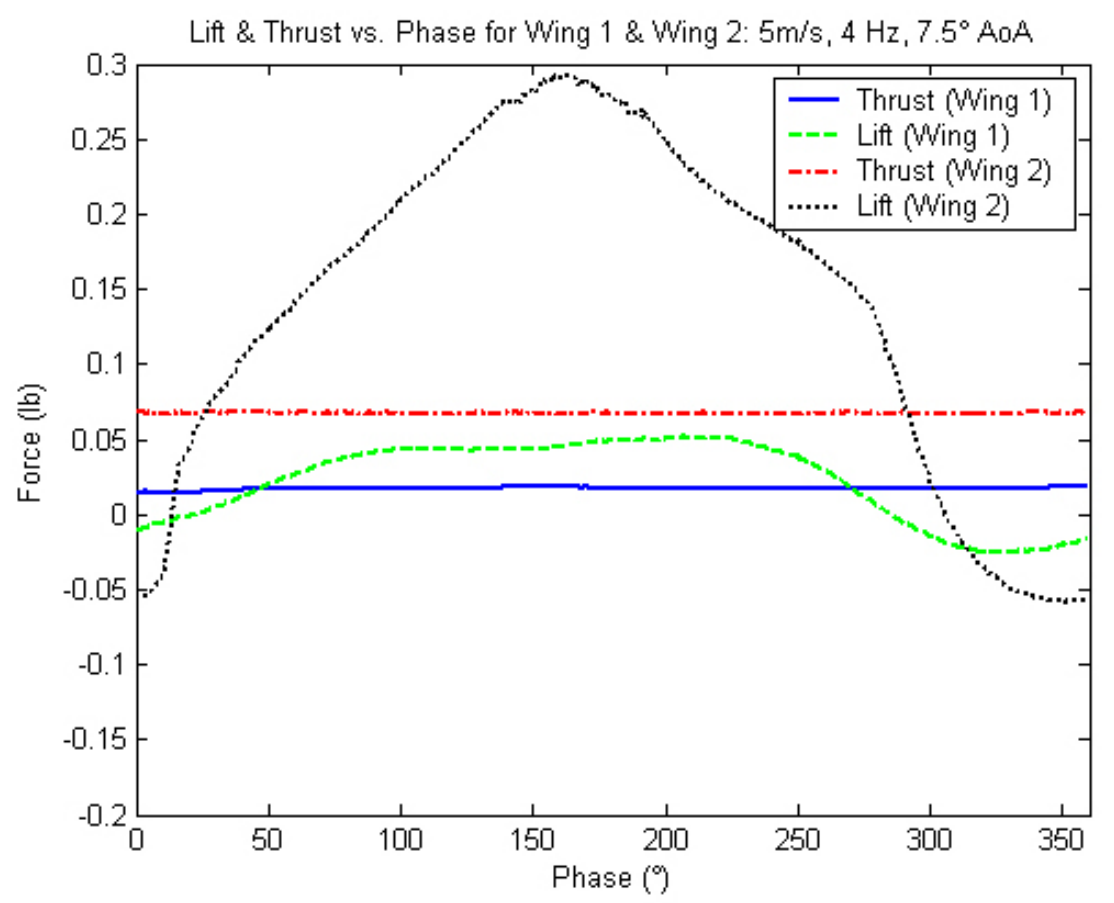

Figure 8.24: Lift \& Thrust vs. Phase @ 5 m/s, 4 Hz, \& 7.5 AoA

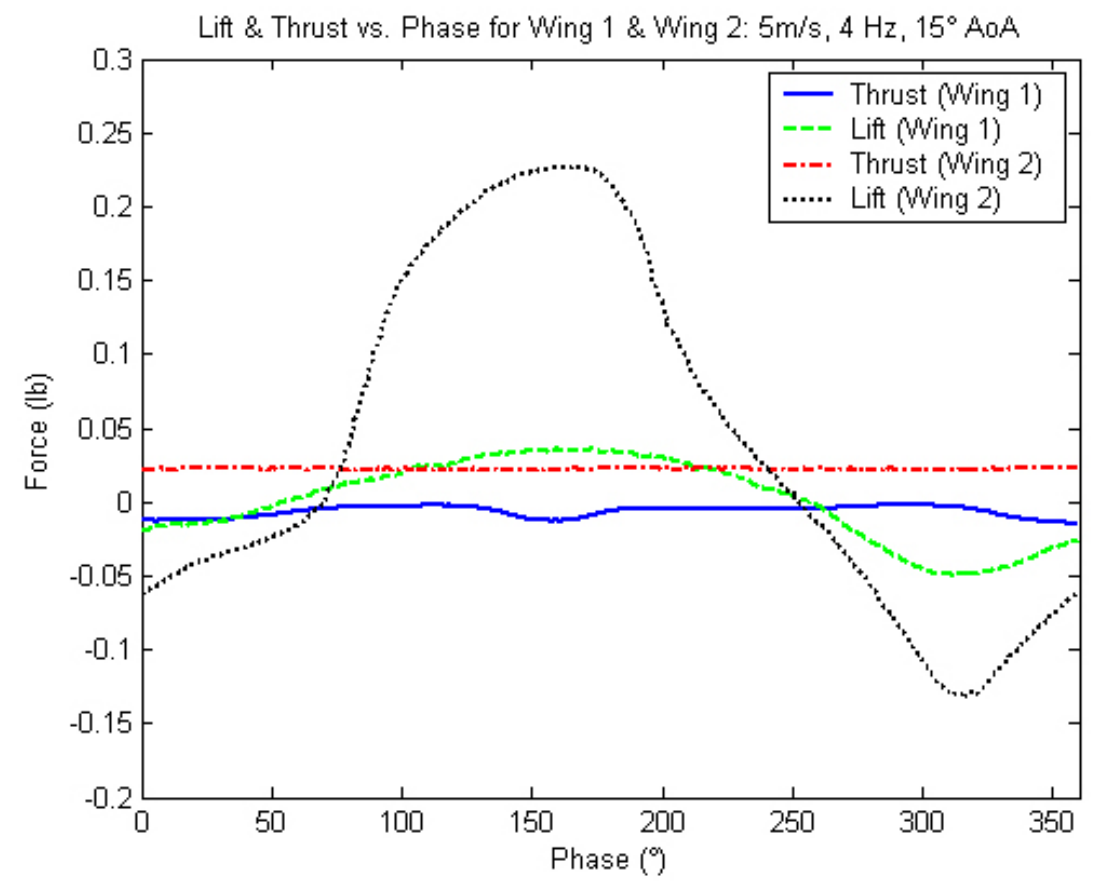

Figure 8.25: Lift \& Thrust vs. Phase @ 5 m/s, 4 Hz, \& $15^{\circ}$ AoA 


\section{CHAPTER 9: UNCERTAINTY ANALYSIS}

Since this thesis was inpart concerned with experimental testing, it was important to look at the various sources of uncertainty. There were two primary sources where uncertainty was a factor in this research. The first was in calibrating the force balance and the second was in the repeatability associated with the lift and thrust data acquisition and analysis.

\subsection{Force Balance Uncertainty}

As previously described in Section 6.2 the force balance used for testing needed to be calibrated. This involved measuring new spring constants in the force balance. In order to obtain values as accurate as possible, the experiment to measure the values of the new spring constants were repeated 3 times and averaged. Table A.1 and Table A.2 show the data from these experiments. Table 9.1 below displays the average, standard deviation and variance values for the data obtained from measuring the spring constants.

Table 9.1: Error Analysis for Force Balance

\begin{tabular}{cccccccc} 
Force & \multicolumn{2}{c}{ Thrust/Drag Direction } & \multicolumn{3}{c}{ Lift Direction } \\
(Ib) & Average & $\begin{array}{c}\text { Std. } \\
\text { Dev }\end{array}$ & Variance & $\begin{array}{c}\text { Force } \\
\text { (lb) }\end{array}$ & Average & $\begin{array}{c}\text { Std. } \\
\text { Dev }\end{array}$ & Variance \\
0.044 & 4.412 & -0.096 & 0.009 & 0.450 & 3.970 & 0.027 & 0.001 \\
0.066 & 4.380 & -0.145 & 0.021 & 1.006 & 3.086 & 0.068 & 0.005 \\
0.110 & 4.171 & -0.086 & 0.007 & 1.550 & 2.216 & 0.086 & 0.007 \\
0.220 & 3.875 & -0.028 & 0.001 & 2.108 & 1.220 & 0.074 & 0.005 \\
0.331 & 3.334 & -0.226 & 0.051 & 2.650 & 0.322 & 0.013 & 0.000 \\
0.441 & 3.519 & -0.001 & 0.000 & & & &
\end{tabular}


The methods used for the uncertainty analysis are from the book Experimentation and Uncertainty Analysis for Engineers, by Coleman and Steele [25]. In Table 9.1 the standard deviation and the variance were obtained from Equation 9.1 and Equation 9.2 respectively.

$$
\begin{aligned}
& S_{X}=\frac{1}{N-1} \sum_{i=1}^{N}\left(X_{i}-\bar{X}\right)^{1 / 2} \\
& S_{X}^{2}=\frac{1}{N-1} \sum_{i=1}^{N}\left(X_{i}-\bar{X}\right)
\end{aligned}
$$

From the above data in Table 9.1 it can be seen that the error associated with the measurements from the 3 trials was small and showed repeatability. Thus, allowing the results to be used in calculating the required spring constants to obtain lift and thrust force values.

\subsection{Lift and Thrust Uncertainty}

Figure 9.1 below shows a plot of the uncertainty associated with the lift and forces at the $5 \mathrm{~m} / \mathrm{s}, 4 \mathrm{~Hz}, 7.5^{\circ}$ AoA with Wing 2. This case was chosen because it had the conditions which generated the highest aerodynamic forces. The graph below shows the error (represented by error bars) in the measurement system from flap to flap in one test. This was done by having the mechanism flap 10 flap cycles at the aforementioned case, and averaging the lift and thrust data over 10 flaps for each point in the flap. From this calculation mean thrust and lift forces were obtained. The standard deviation of the mean 
for each point in the flap was found using Equation 9.1. Estimating a $t$ distribution and $95 \%$ confidence interval, error bars were found.

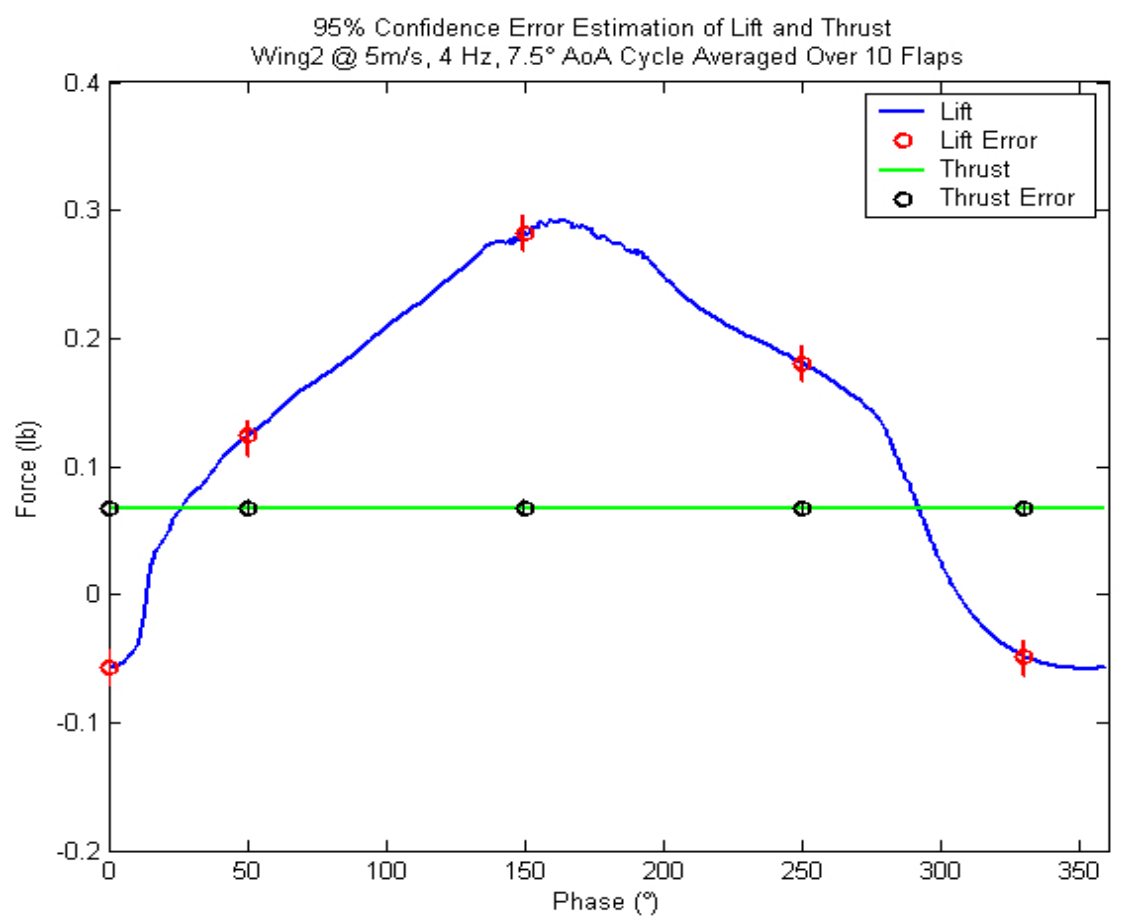

Figure 9.1: Uncertainty Curve for $5 \mathrm{~m} / \mathrm{s}, 4 \mathrm{~Hz}, 7.5^{\circ}$ AoA with Wing 2

From the graph it can be seen that the error for the lift curve is quite small, an average of approximately $\pm 0.015 \mathrm{lbs}$ at each point. The error in thrust force is even smaller, an average of approximately $0.01 \mathrm{lbs}$ at each point. This shows that there was very little variability in lift and thrust forces generated by each individual flap in the 10 flap cycle. The smallest force applied to the force balance was $0.044 \mathrm{lbs}$ in the calibration stage. The smallest amount of error shown above was approximately $0.01 \mathrm{lbs}$. In order to make sure that the force balance was indeed capable of registering at this low weight, a $0.01 \mathrm{lb}$ load was applied to it and there was indeed a change in displacement. 
Figure 9.2 below shows day to day repeatability between tests for the $5 \mathrm{~m} / \mathrm{s}, 4 \mathrm{~Hz}$, $7.5^{\circ}$ AoA case. Two additional tests were carried out on two separate days and their cycle averaged lift and thrust values were compared to those of the initial test. Again, the analysis was performed with this case because the aerodynamic forces generated were the highest and because of this noise should be lower when compared with other test conditions where the forces were less.

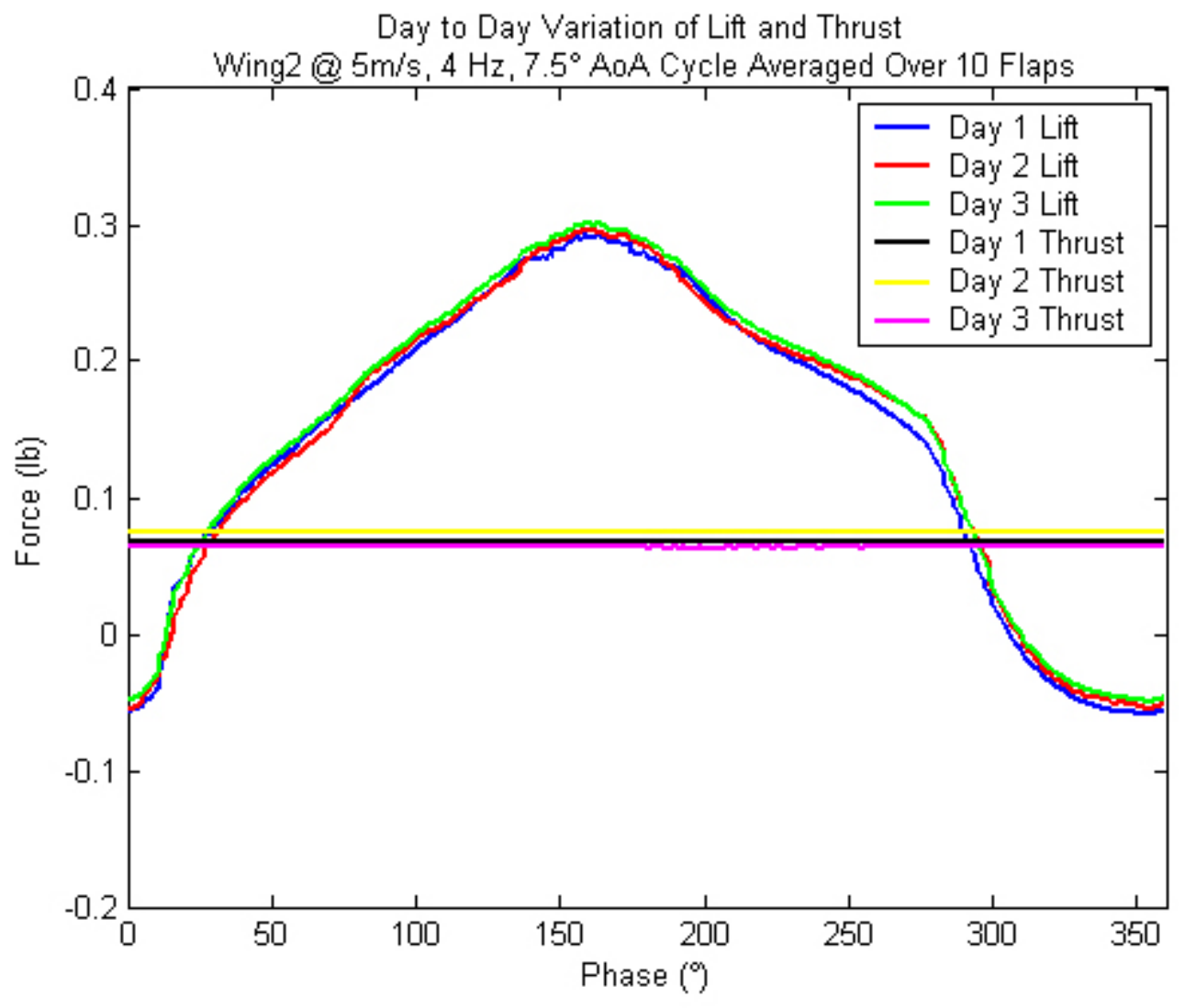

Figure 9.2: Repeatability $5 \mathrm{~m} / \mathrm{s}, 4 \mathrm{~Hz}, 7.5^{\circ}$ AoA with Wing 2

From Figure 9.2 above, it can be seen that there is very variation in day to day repeatability. Both the lift and thrust curves from day 2 and day 3 match those the lift and thrust curves from day 1 quite closely. 
In order to see how the error scaled with force, the experimental error was found for the $0 \mathrm{~m} / \mathrm{s}, 3 \mathrm{~Hz}, 0^{\circ}$ AoA case with Wing 1. A plot of this can be seen in Figure 9.3 below. Again, 6 points were selected based on the high speed video analysis as described in Chapter 8 and plotted with a 95\% confidence interval $t$ distribution. From the graph it can be seen that the error bars are relatively much larger than with the $5 \mathrm{~m} / \mathrm{s}, 4 \mathrm{~Hz}, 7.5^{\circ}$

AoA case.

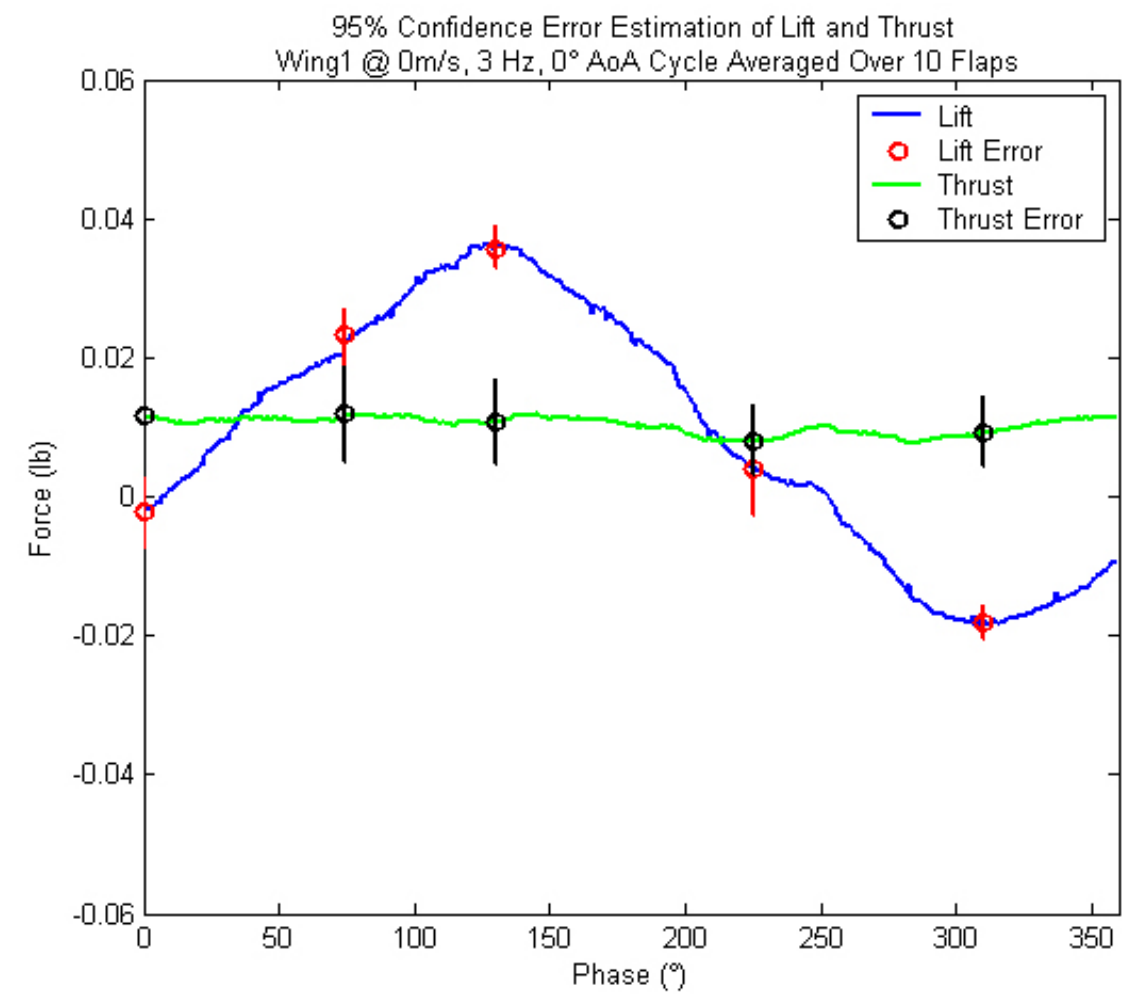

Figure 9.3: Uncertainty Curve for $0 \mathrm{~m} / \mathrm{s}, 3 \mathrm{~Hz}, 0^{\circ}$ AoA with Wing 1

The average standard deviation for the lift case was approximately $0.01 \mathrm{lbs}$, and $0.02 \mathrm{lbs}$ for the thrust. It can be seen that the highest error was at $75^{\circ}$ and $225^{\circ}$. At these positions in the flap, the wing was traveling at the lowest velocities, either just starting the downstroke or the upstroke. The maximum error at this point was $0.014 \mathrm{lbs}$, while 
the least error occurred at the minimum and maximum points where the error was 0.01 lbs. At these locations the wing was traveling with the fastest velocity.

The main reason that there was more error associated with this test situation was most likely due to the very low forces involved. The peak lift generated during this case was only $0.036 \mathrm{lbs}$, while the average thrust generated was approximately $0.1 \mathrm{lbs}$. It is possible that noise in the system could be a factor in contributing to the error as the system worked at the lower end of its operating envelope. The error here is acceptable because it is very unlikely that the mechanism will be operating at these conditions again due to the very low forces generated. 


\section{CHAPTER 10: CONCLUDING REMARKS}

\subsection{Summary}

This thesis attempted to investigate the role of wing flexibility in flapping wing flight. Considerable effort was put into designing and fabricating a low budget mechanism capable of producing controllable flapping motions and passive flapping motions. The mechanism was made from lightweight materials and used inexpensive commercial off the shelf parts. In designing the mechanism, it was found that the best way to produce flapping motions was through the use of a scotch yoke/crankshaft mechanism. Both motions were produced through a single motor. It was also found that the motor used to provide the flapping motions, while able to accomplish the task of flapping at the target frequencies, was slightly underpowered. It would be better to use a stronger motor, although the increased weight would be a factor to consider.

Additionally, it was found that the mechanism was still too heavy. Although after the weight reduction efforts the mechanism's weight was significantly reduced, additional work could be done to streamline the body removing excess material. Two elements of the design which contributed most to the weight were the aluminum bearing and motor mounts as well as the linear ball bearing which allowed the mechanism to translate in the vertical axis. Aluminum was chosen because of its ready availability and low cost. Using more expensive but lighter materials in its place, it would be possible to reduce the weight significantly. It was found that the linear ball bearings were over specified for the 0.5 inch vertical shaft over which they rode. Using a smaller vertical shaft would allow for the use of smaller and lighter bearings. 
Two families of flexible wings were fabricated, tested and built using carbon fiber and fiberglass. These wings were simplified versions of wings from a large bat. There were some important lessons learned from fabricating and testing the flexible wings. It was better to have a stiff leading edge, so the wing did not buckle and lose stability. The major lesson learned from the fabrication process was that it was very helpful to have a mold system which allowed for the repeated fabrication of symmetric wings.

To test the flapping wing mechanism, a force balance testing structure was designed and built as well. In designing the force balance, it was found that friction played a large role. The first design, which used linear ball bearings to allow the mechanism to traverse, had too great of a static friction coefficient. Switching to an air bearing eliminated this problem.

The force balance was carefully calibrated and instrumented with position sensors to measure lift and thrust forces. In order to simulate the mechanism flying in an air stream at low speeds, an existing wind tunnel was converted into into an open flow tunnel capable of achieving air speeds as low as 5 meters per second. An evolving test matrix was created and used in a comprehensive testing process. Data acquired from the mechanism encoder, force balance position transducers and high video were analyzed.

When measuring the aerodynamic forces produced in the experiments, it was found that thrust was constantly generated, while lift was periodic in nature following a sinusoidal trend. It was found that lift is predominantly generated on the downstroke, with negative lift being generated on the upstroke. Using a high speed video camera, the shape of the flexible wing was found as well as the velocities of the wing at various points in the cycle. The wing positions of highest velocity generally had the highest 
magnitudes of lift. It was also shown that the relative wind over the wing increased due to the flexible nature of the wing, thus potentially enhancing lift.

It was found that a more flexible wing generated higher velocities. Wing 1 generally traveled at a higher velocity when flapping than did Wing 2 . Since lift is proportional to the square of velocity, the lift should theoretically be greater. However, the forces generated by Wing 1 were very small when compared to Wing 2 . This led to the conclusion that although there are benefits to having a flexible wing, there is some limit where an overly flexible wing generates less lift than its slightly more rigid (but still flexible) counterpart. The main reason believed to cause this was the lack of structural support during changes in stroke. It was shown that the flexible wing buckled a phenomenon which although may have some positive effects, appear to be a hindrance when extreme.

Also from the data, it can be seen that the best test case situation was the $5 \mathrm{~m} / \mathrm{s}, 4$ $\mathrm{Hz}, 7.5^{\circ}$ AoA case. It has already been shown that $4 \mathrm{~Hz}$ is a frequency at which some natural flyers flap. The increased flow stream had positive effects as well, helping provide additional lift, as did the positive angle of attack. Results showed that increasing the angle of attack was helpful only to a point. When the angle of attack was too high flow separation occurred. This caused turbulent boundary layers to form and adversely effect lift and thrust generation.

It was found that phase lag also played an important role in flapping wing flight. Wing 1 experienced greater phase lag than did the stiffer Wing 2. For Wing 1 it was found that the phase lag at the center of the upstroke was approximately $58^{\circ}$ while the phase lag at the end of the downstroke was an average of $35.5^{\circ}$. Through the images 
acquired from the high speed video camera, it was found that when the wing's root was at the center of the upstroke, the lagging tip caused the wing's leading spar to buckle. This loss of structural stability was most likely the cause of Wing 1's poor performance in generating aerodynamic loads.

Stiffening the wing proved to have beneficial effects in reducing phase lag. Wing 2 had an average of $23.5^{\circ}$ phase lag at the center of the upstroke and $27.6^{\circ}$ at the end of the downstroke. A parallel can be drawn between this flexing nature of the leading edge of the wing and the ability of a flexible wing being able to correct for such natural phenomena such as gusts or collision with a stationary object. The wings were capable of changing their physical structure along the leading edge and still produce lift and thrust; this is a major advantage of flexible wings over rigid ones.

\subsection{Contributions to Research Area}

This research was done primarily as a learning effort to better understand the role of wing flexibility in flapping wing flight. The work done has contributed to the area of flapping wing UAV research for vehicles with membrane wings. The studying of two wings, various flapping frequencies and air flows will help future researchers in perhaps eventually building a flapping wing UAV with flexible membrane wings. The research done in this thesis was done on a very low budget, approximately 500 dollars plus the cost of machining time.

The prototype which was built produced $0.3 \mathrm{lbs}$ of lift in its best case and $0.05 \mathrm{lbs}$ of net thrust, overcoming its own drag. The mechanism was a wind tunnel model which weighed approximately $1.8 \mathrm{lbs}$. With a higher budget it may be able to decrease the 
weight further. For example, if the weight was cut in half, and the lift was increased by a factor of 5 based on continued research (new wings and testing scenarios) it would be possible to build a mechanism capable of supporting its own weight and possibly flying.

Perhaps most importantly this research has planted the seeds to allow Georgia Tech to gain a better understanding of flapping wing flight. The modified open air wind tunnel facility, existing mechanism as well as force balance test bed lay the ground work for future experiments in this area giving the Georgia Tech Research Institute a 1 to 2 year head start.

\subsection{Future Work}

There is still considerable research must be done to fully understand the problem at hand. Starting at a smaller level there is so much more which can be done to improve on and better understand the device built in this research effort.

One of the most noticeable things was the motor was under powered. There was a trade off between cost, motor torque and weight. An obvious answer would be to use a motor with more torque. It would also be possible to implement a feedback control system to help keep the speed of the flap constant. Perhaps it is better to implement a feedback control algorithm which varies the speed of the wings in mid-flap. These are things which would be better determined through additional testing.

Another interesting feature would be to introduce variable pitch control in the device. The device built in this research was capable of producing passive pitching motions which were functions of wing phase during the flap. Additionally, the aerodynamics of flapping wing flight is not well understood and an extremely difficult 
problem to tackle. Additional work needs to be done on theoretical modeling using CFD codes, and trying to match these results with PIV flow visualization techniques to observe airflow patterns as the wing flaps. FEA analysis as well as using laser vibrometers on the wings would lead to better understanding wing deformation and loads seen at various points along the structural members.

Finally additional wings should be fabricated and tested. The wings used in this research all consisted of the same materials: carbon fiber structures with fiberglass membranes. Additional wings of various different materials or perhaps even wings which follow different structure patterns should be built and tested.

These are just some recommendations which will help understand the dynamics behind flapping wing flight, with the goal of eventually building an ornithopter with flexible wings capable of sustained flight. 


\section{APPENDIX A: CALIBRATION DATA}

Table A.1 below shows the spring calibration data used to estimate spring constants of the springs used to measure lift and thrust. The experiments were repeated three times to get accurate measurements and minimize error

Table A.1: Spring Constant Calibration Data

\begin{tabular}{|c|c|c|c|c|}
\hline & & Test & & \\
\hline & ce & Displacement & Force & Displacement \\
\hline g & Ib & Thrust/Drag (in) & lb & Lift (in) \\
\hline 20 & 0.044 & 4.302 & 0.450 & 3.976 \\
\hline 30 & 0.066 & 4.214 & 1.006 & 3.012 \\
\hline 50 & 0.110 & 4.145 & 1.550 & 2.261 \\
\hline 100 & 0.220 & 3.890 & 2.108 & 1.147 \\
\hline 150 & 0.331 & 3.073 & 2.650 & 0.329 \\
\hline 200 & 0.441 & 3.519 & & \\
\hline & & Test & & \\
\hline & $\mathrm{ce}$ & Displacement & Force & Displacement \\
\hline $\mathbf{g}$ & lb & Thrust/Drag (in) & lb & Lift (in) \\
\hline 20 & 0.044 & 4.451 & 0.450 & 3.941 \\
\hline 30 & 0.066 & 4.447 & 1.006 & 3.101 \\
\hline 50 & 0.110 & 4.101 & 1.550 & 2.116 \\
\hline 100 & 0.220 & 3.843 & 2.108 & 1.218 \\
\hline 150 & 0.331 & 3.473 & 2.650 & 0.307 \\
\hline 200 & 0.441 & 3.520 & & \\
\hline & & Test & & \\
\hline & $\mathrm{ce}$ & Displacement & Force & Displacement \\
\hline $\mathbf{g}$ & lb & Thrust/Drag (in) & lb & Lift (in) \\
\hline 20 & 0.044 & 4.482 & 0.450 & 3.994 \\
\hline 30 & 0.066 & 4.479 & 1.006 & 3.146 \\
\hline 50 & 0.110 & 4.267 & 1.550 & 2.270 \\
\hline 100 & 0.220 & 3.893 & 2.108 & 1.294 \\
\hline 150 & 0.331 & 3.455 & 2.650 & 0.329 \\
\hline 200 & 0.441 & 3.519 & & \\
\hline
\end{tabular}


The data from Table A.1, the values were averaged and entered into Table A.2.

Table A2: Averaged Values of Spring Calibration Data

$\begin{array}{lccc}\mathbf{l b} & \text { Avg. Thrust/Drag } & \mathbf{~ l b} & \text { Avg. Top } \\ 0.044 & 4.412 & 0.450 & 3.970 \\ 0.066 & 4.380 & 1.006 & 3.086 \\ 0.110 & 4.171 & 1.550 & 2.216 \\ 0.220 & 3.875 & 2.108 & 1.220 \\ 0.331 & 3.334 & 2.650 & 0.322 \\ 0.441 & 3.519 & & \\ & & & \\ \text { rimental k: } & -0.32 \mathrm{lb} / \mathrm{in} & & -0.60 \mathrm{lb} / \mathrm{in} \\ \text { retical k: } & 0.29 \mathrm{lb} / \mathrm{in} & & 0.56 \mathrm{lb} / \mathrm{in} \\ \text { k: } & 0.32 \mathrm{lb} / \mathrm{in} & & 0.60 \mathrm{lb} / \mathrm{in}\end{array}$

From Table A.2, the spring constants under the row "Used k" represent those which were actually used in the LabView VI to obtain a force measurement.

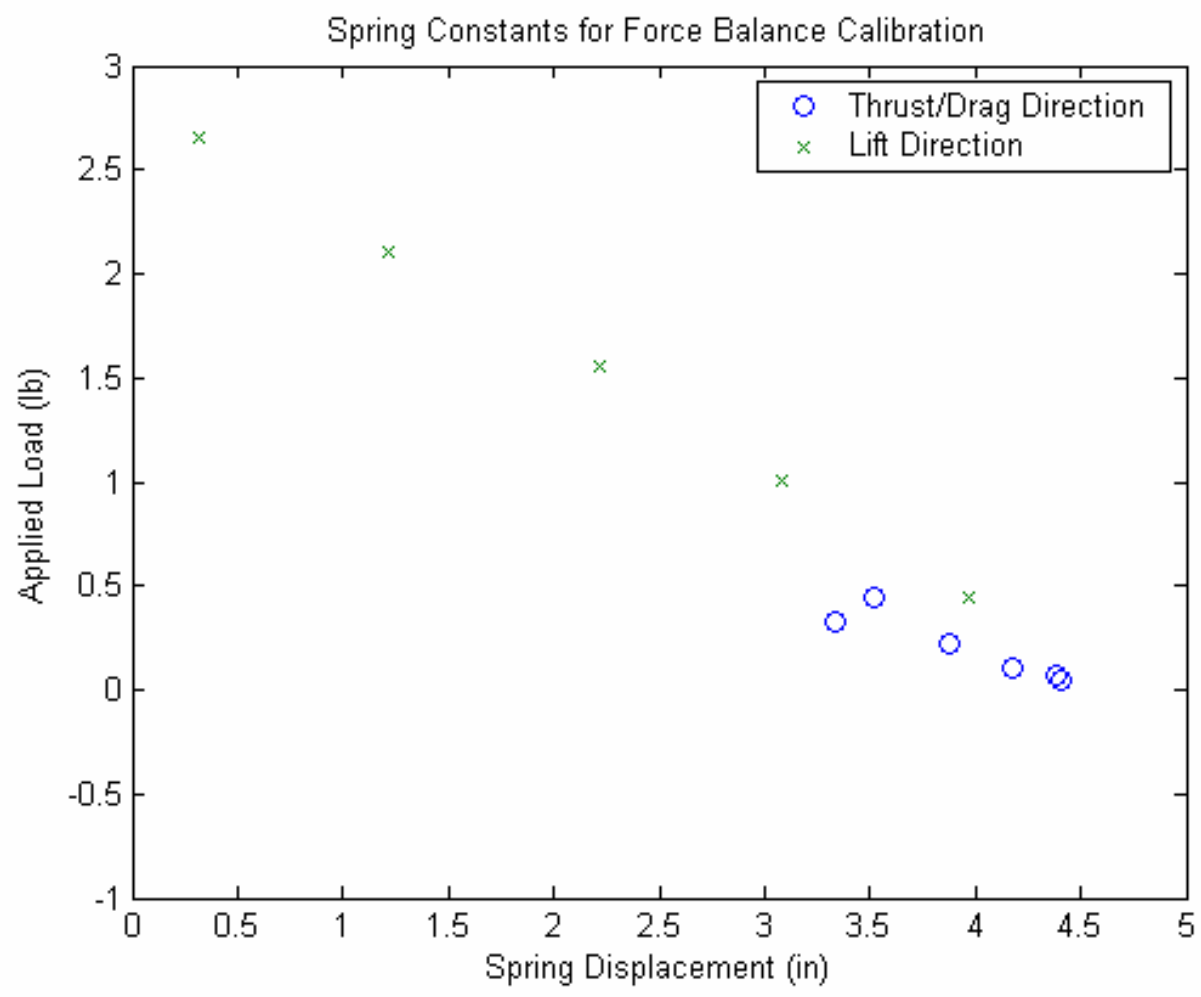

Figure A.1: Spring Constant Data for Force Balance Calibration 


\section{APPENDIX B: PLOTS}

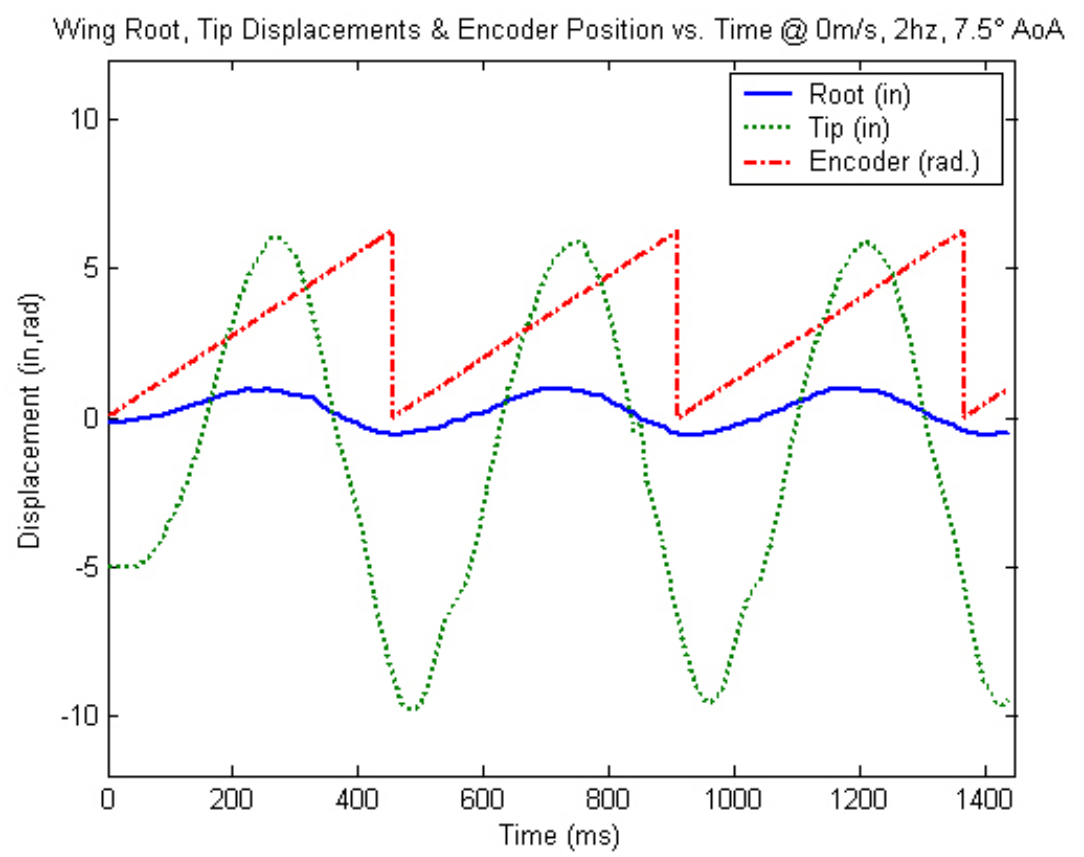

Figure B.1: Wing 1 Root, Tip \& Encoder Position vs. Time @ 0 m/s, 2 Hz, 7.5 AoA

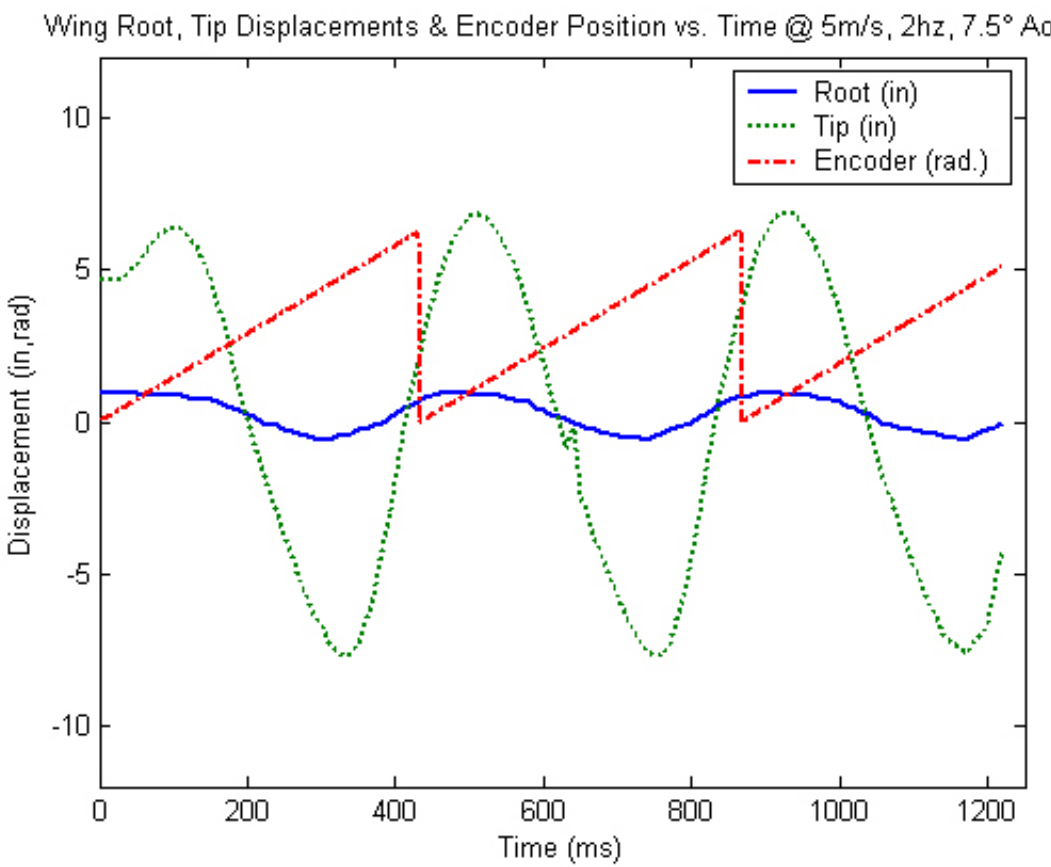

Figure B.2: Wing 1 Root, Tip \& Encoder Position vs. Time @ 5 m/s, 2 Hz, 7.5 AoA 


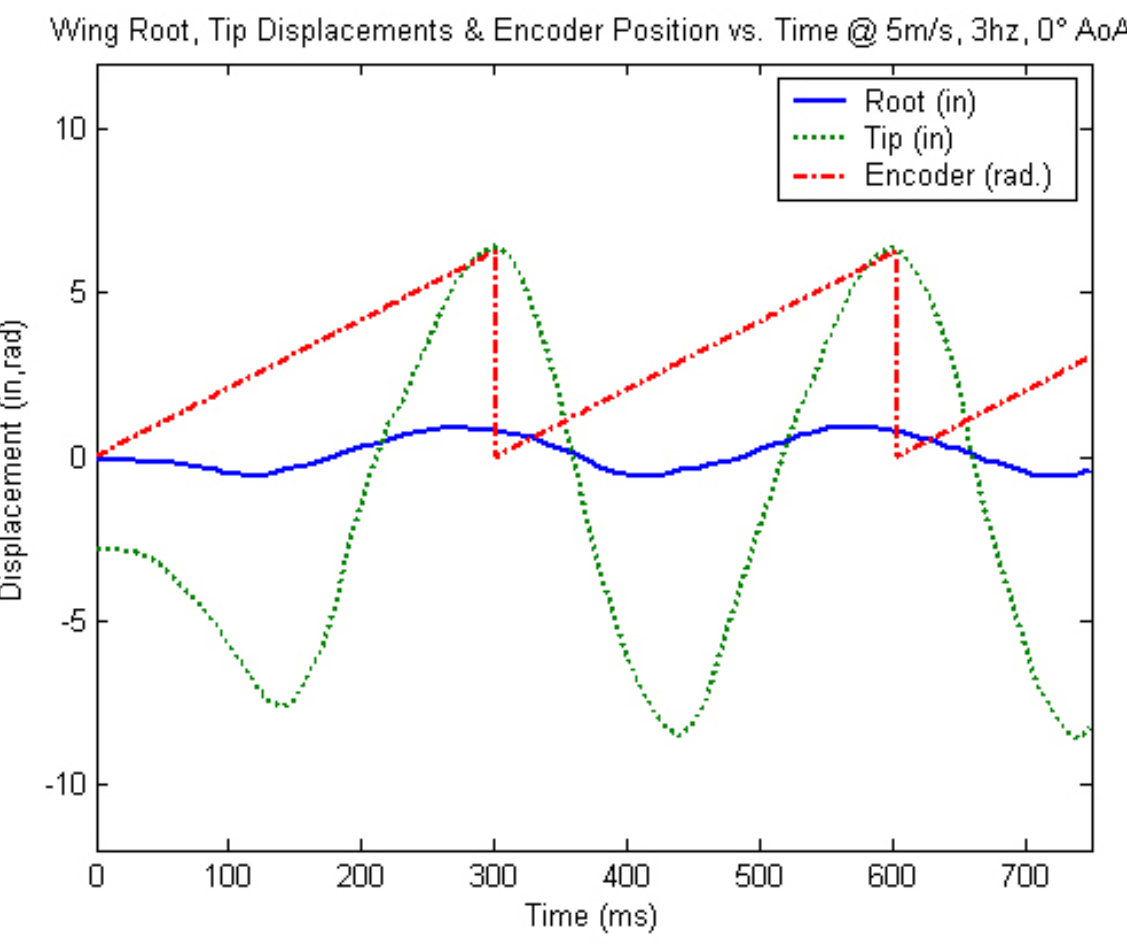

Figure B.3: Wing 1 Root, Tip \& Encoder Position vs. Time @ 5 m/s, 3 Hz, $0^{\circ}$ AoA

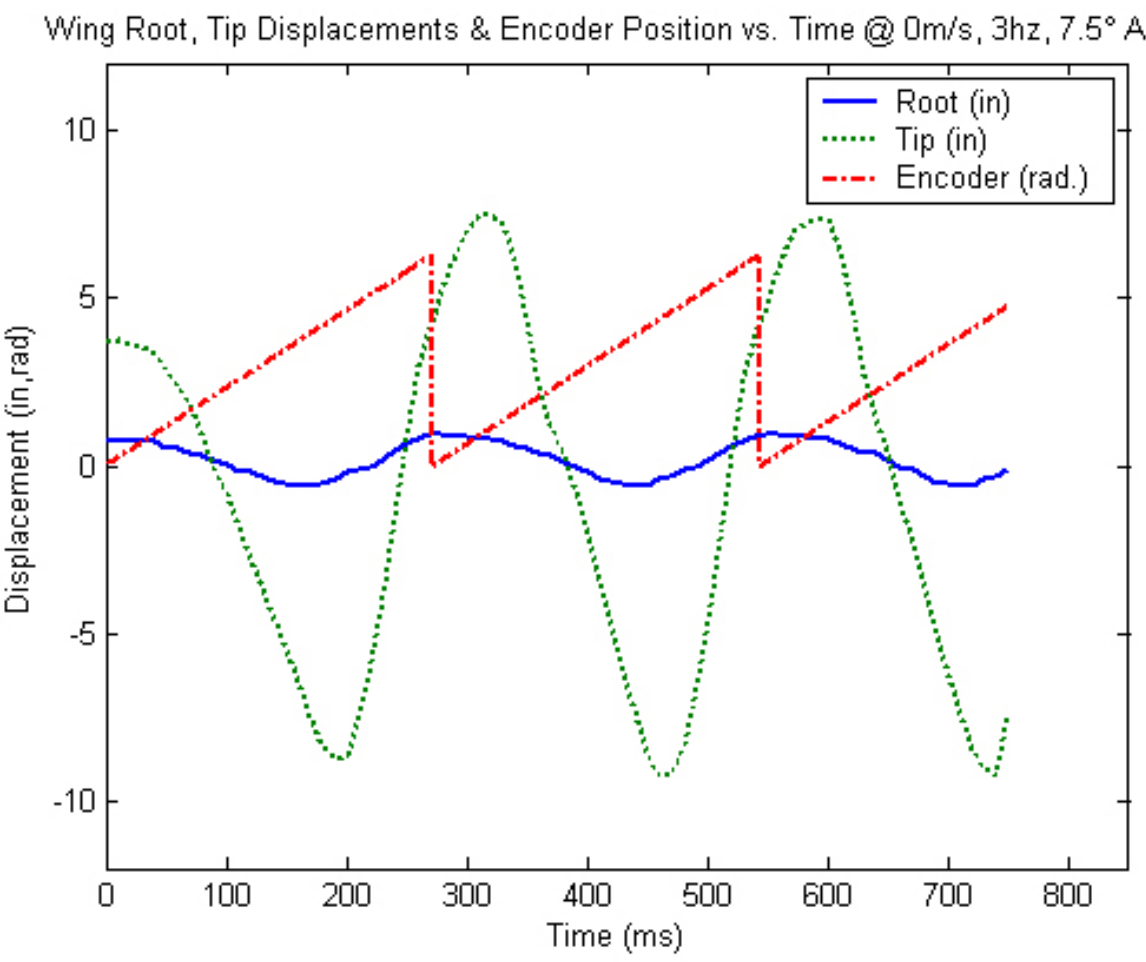

Figure B.4: Wing 1 Root, Tip \& Encoder Position vs. Time @ 0 m/s, 3 Hz, 7.5 AoA 
Wing Root, Tip Displacements \& Encoder Position vs. Time $@ 5 \mathrm{~m} / \mathrm{s}, 3 \mathrm{hz}, 7.5^{\circ} \mathrm{AoA}$

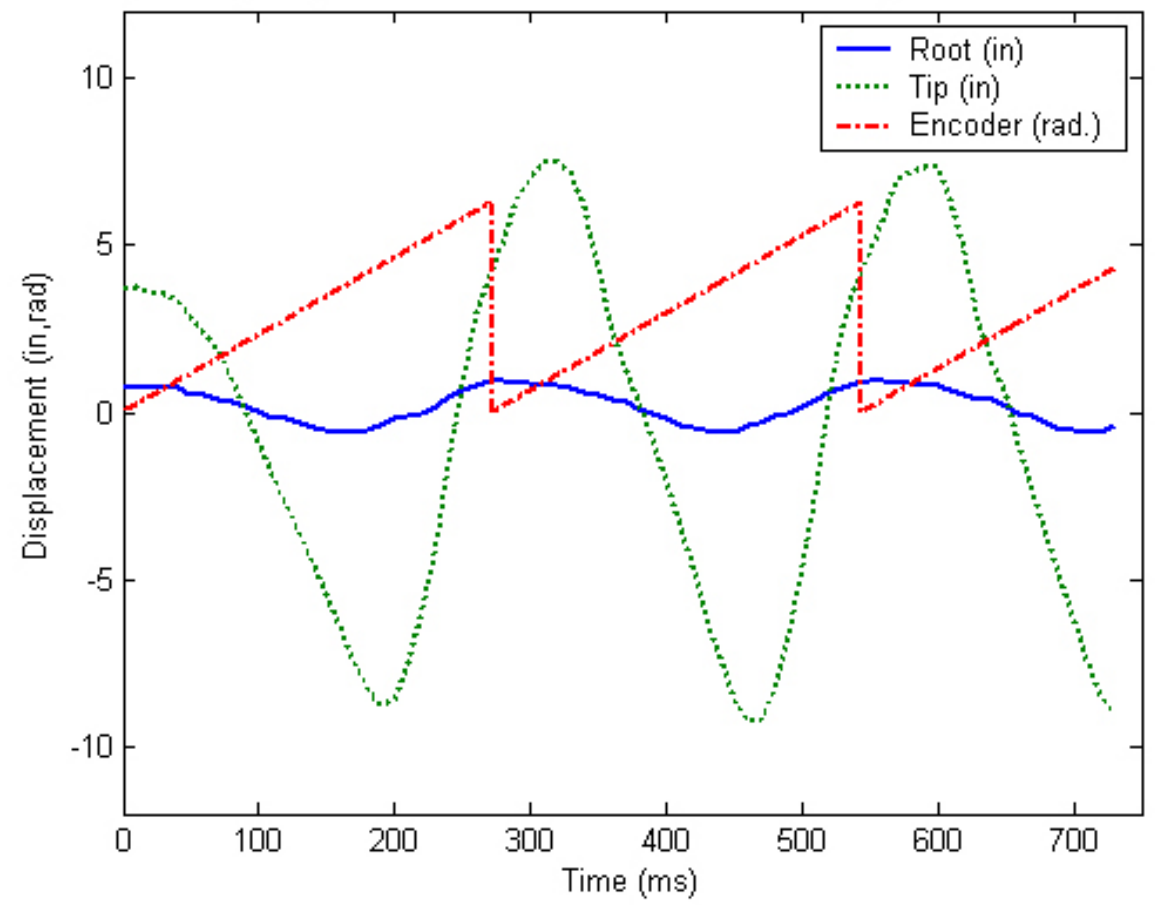

Figure B.5: Wing 1 Root, Tip \& Encoder Position vs. Time @ 5 m/s, 3 Hz, 7.5 AoA

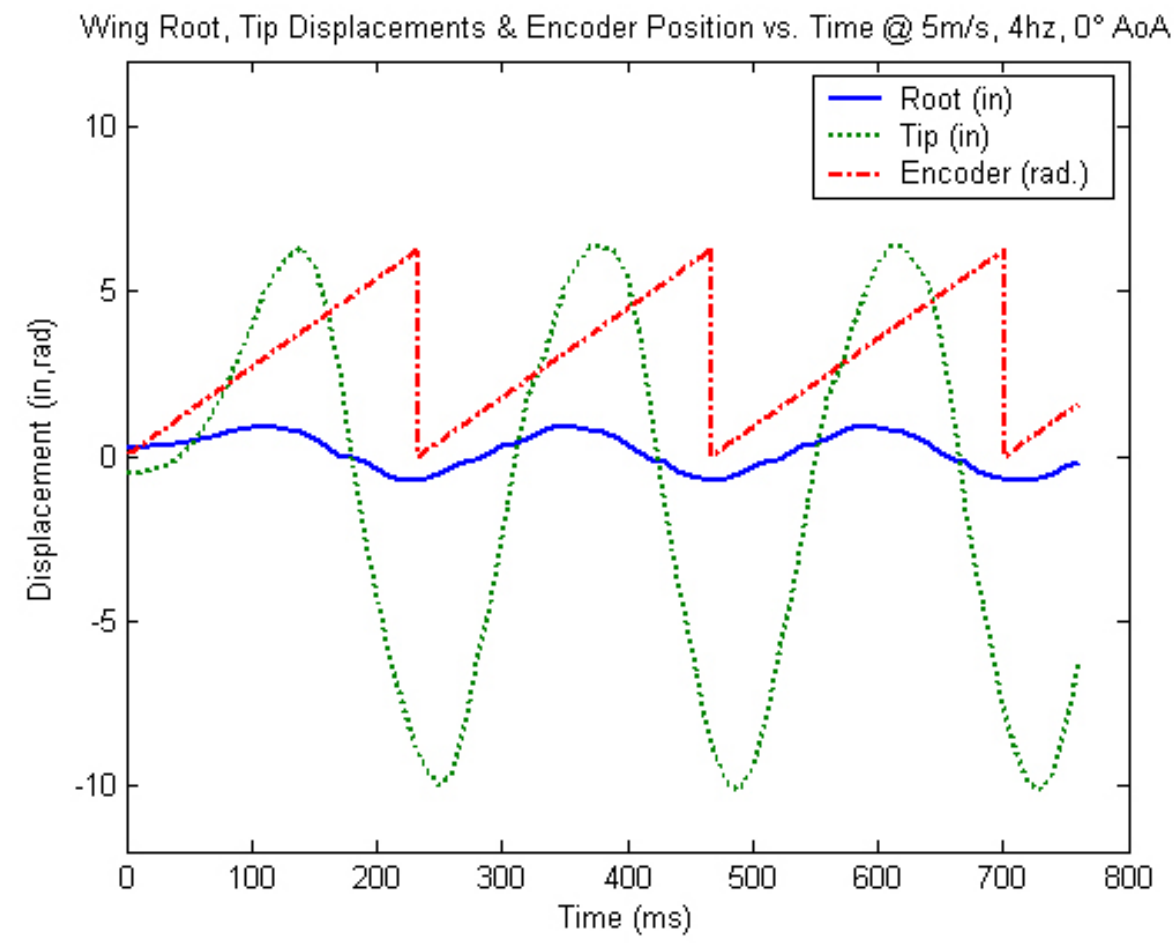

Figure B.6: Wing 1 Root, Tip \& Encoder Position vs. Time @ 5 m/s, 4 Hz, 0 AoA 


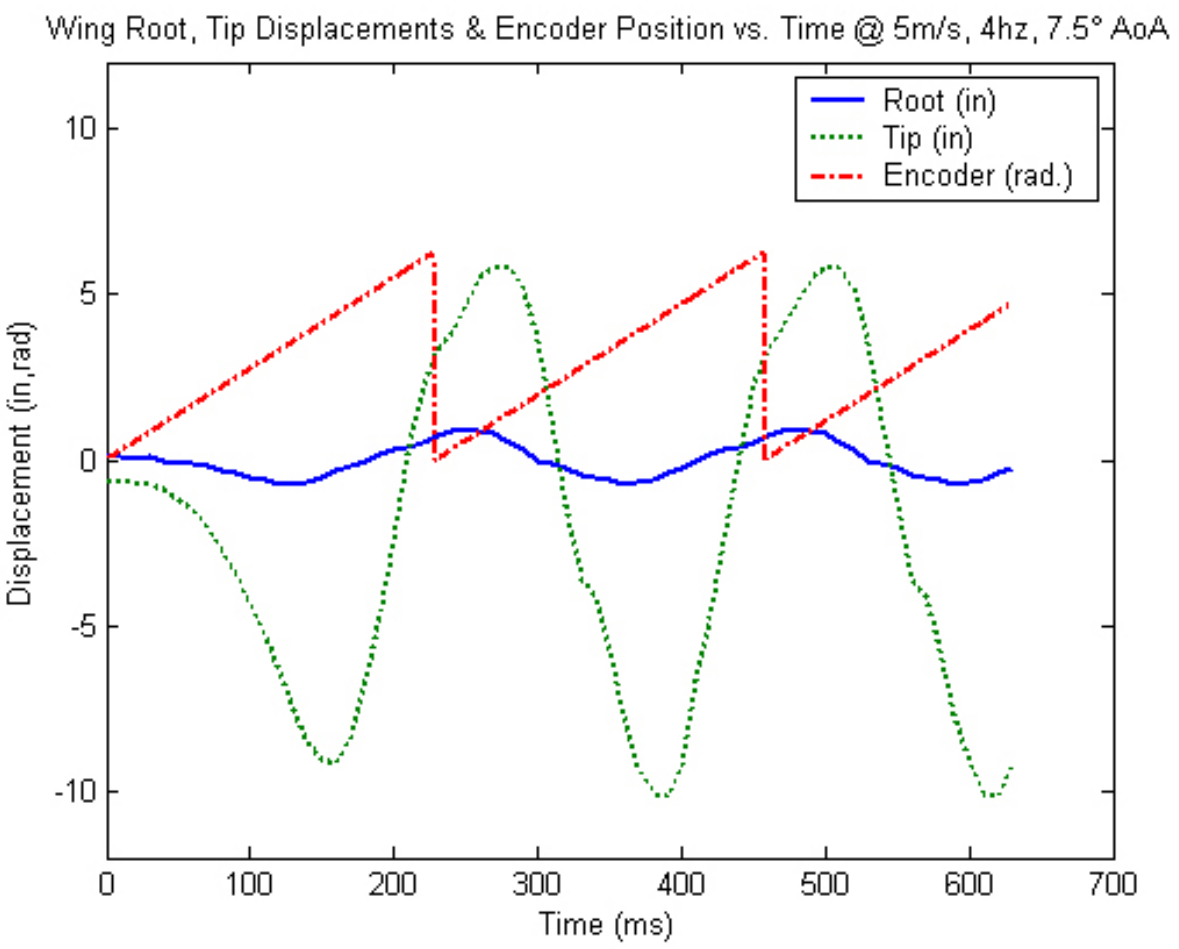

Figure B.7: Wing 1 Root, Tip \& Encoder Position vs. Time @ 5 m/s, 4 Hz, 7.5 AoA

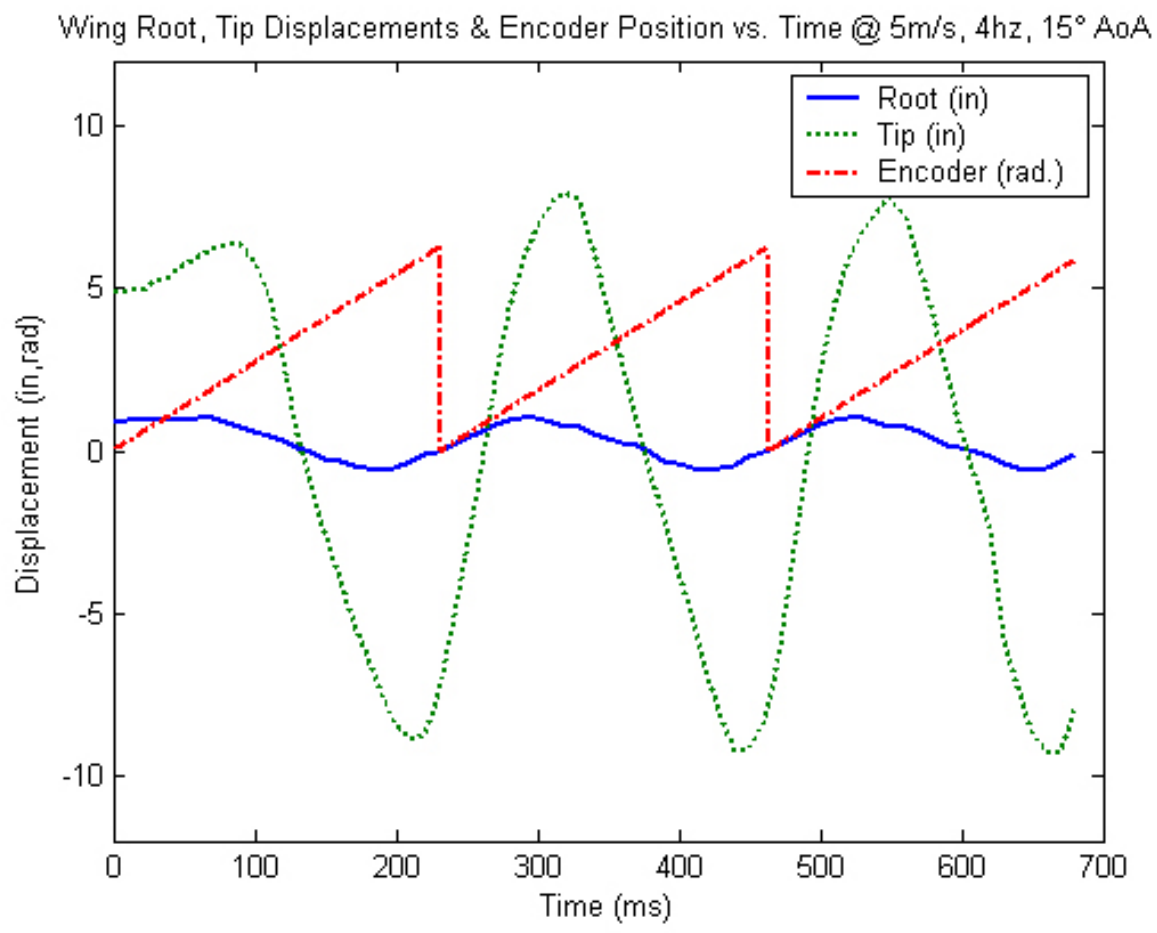

Figure B.8: Wing 1 Root, Tip \& Encoder Position vs. Time @ 5 m/s, 4 Hz, $15^{\circ}$ AoA 
Lift \& Thrust Force vs. Phase $@ 0 \mathrm{~m} / \mathrm{s} \& 5 \mathrm{~m} / \mathrm{s}, 2 \mathrm{hz}, 7.5^{\circ} \mathrm{AoA}, \mathrm{Cycle}$ Averaged over 10 Flaps

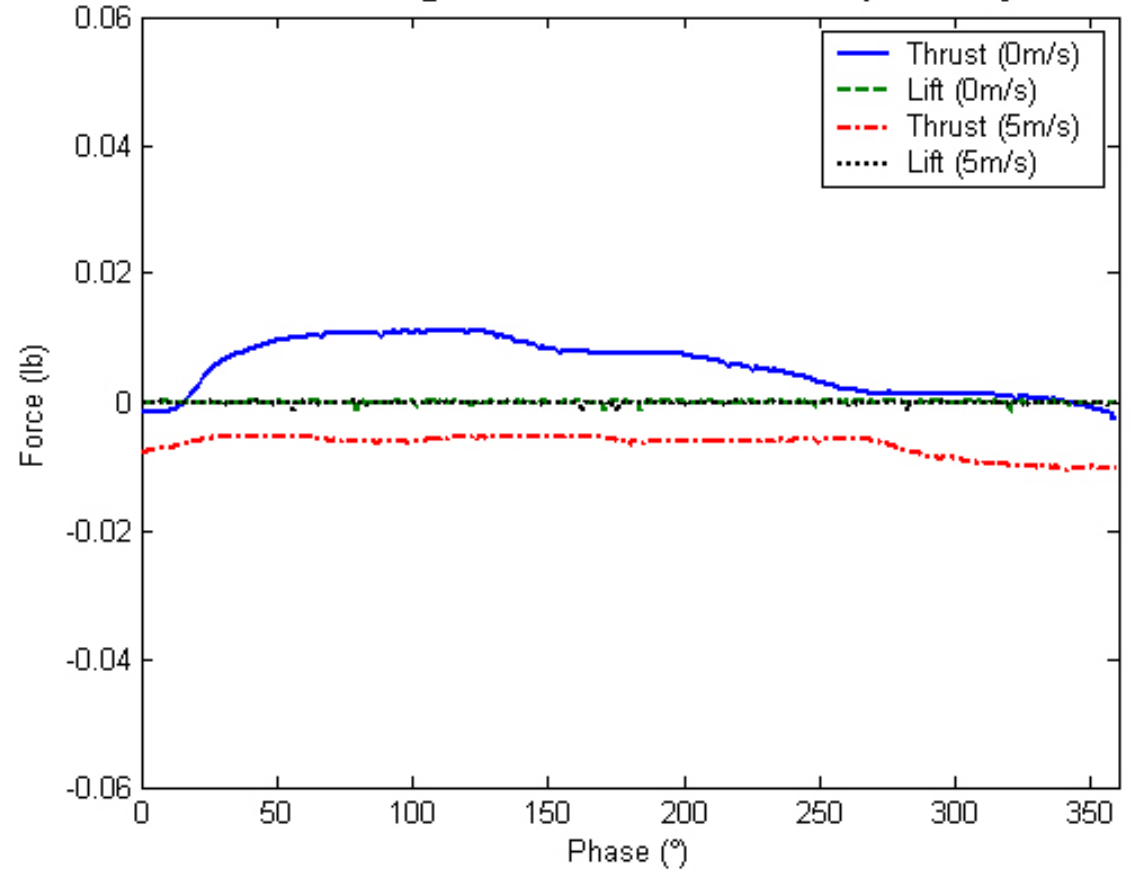

Figure B. 9: Lift \& Thrust vs. Phase @ $0 \& 5$ m/s, 2 Hz, \& 7.5 AoA

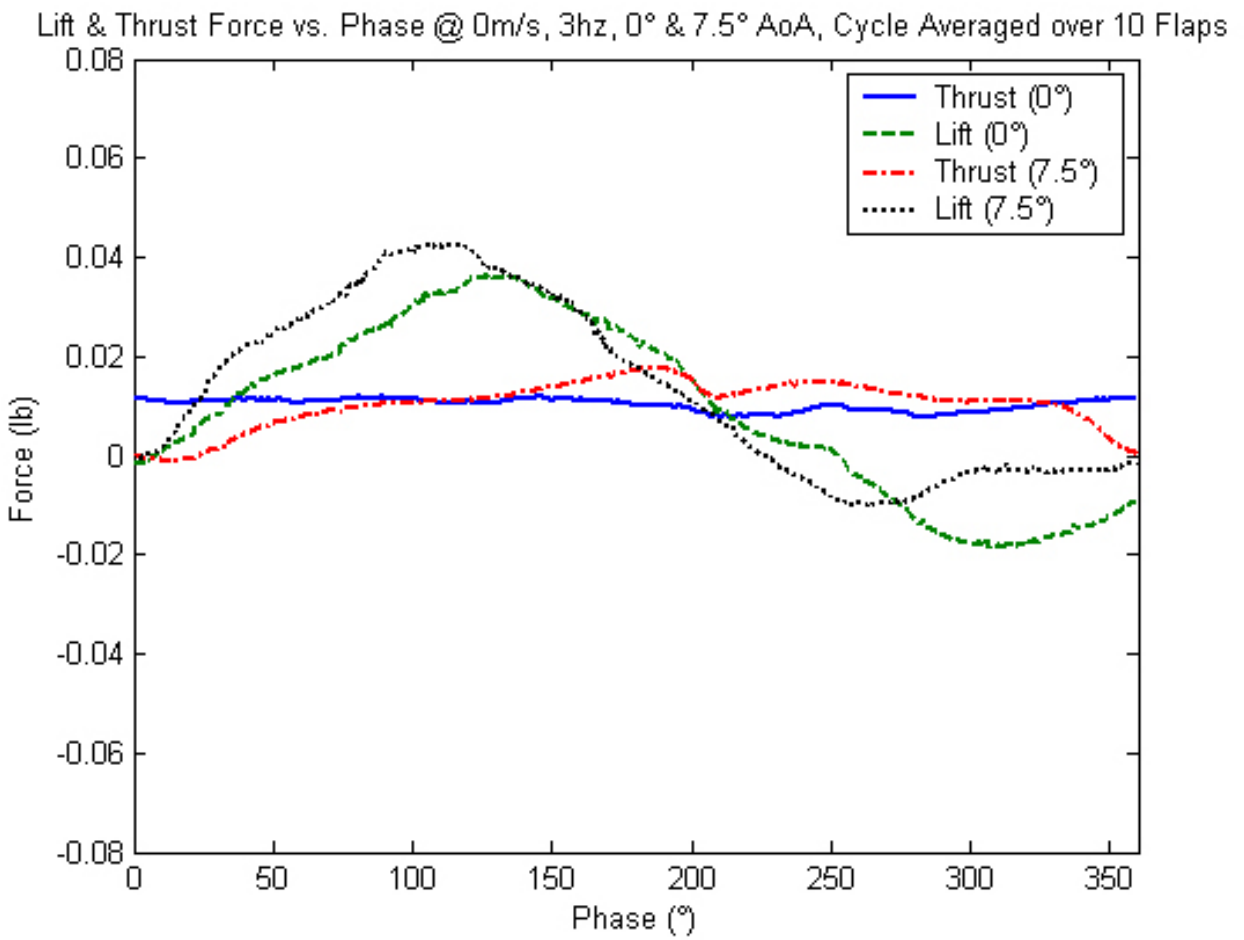

Figure B.10: Lift \& Thrust vs. Phase @ $0 \mathrm{~m} / \mathrm{s}, 3 \mathrm{~Hz}, \& 0^{\circ} \& 7.5^{\circ}$ AoA 


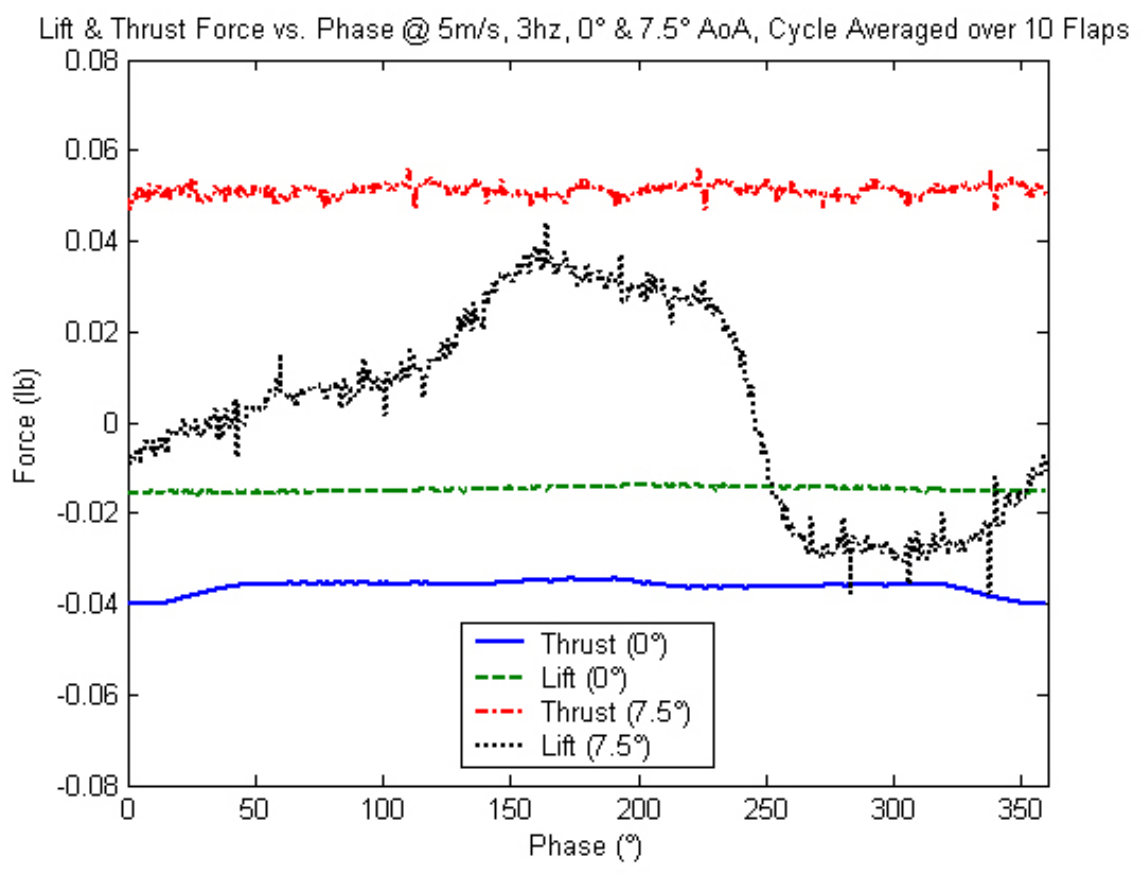

Figure B.11: Lift \& Thrust vs. Phase @ $5 \mathrm{~m} / \mathrm{s}, 3 \mathrm{~Hz}, \& 0^{\circ} \& 7.5^{\circ}$ AoA

Lift \& Thrust Force vs. Phase $@ 5 \mathrm{~m} / \mathrm{s}, 4 \mathrm{hz}, 0^{\circ} \& 7.5^{\circ} \& 15^{\circ} \mathrm{AoA}$, Cycle Averaged over 10 Flaps

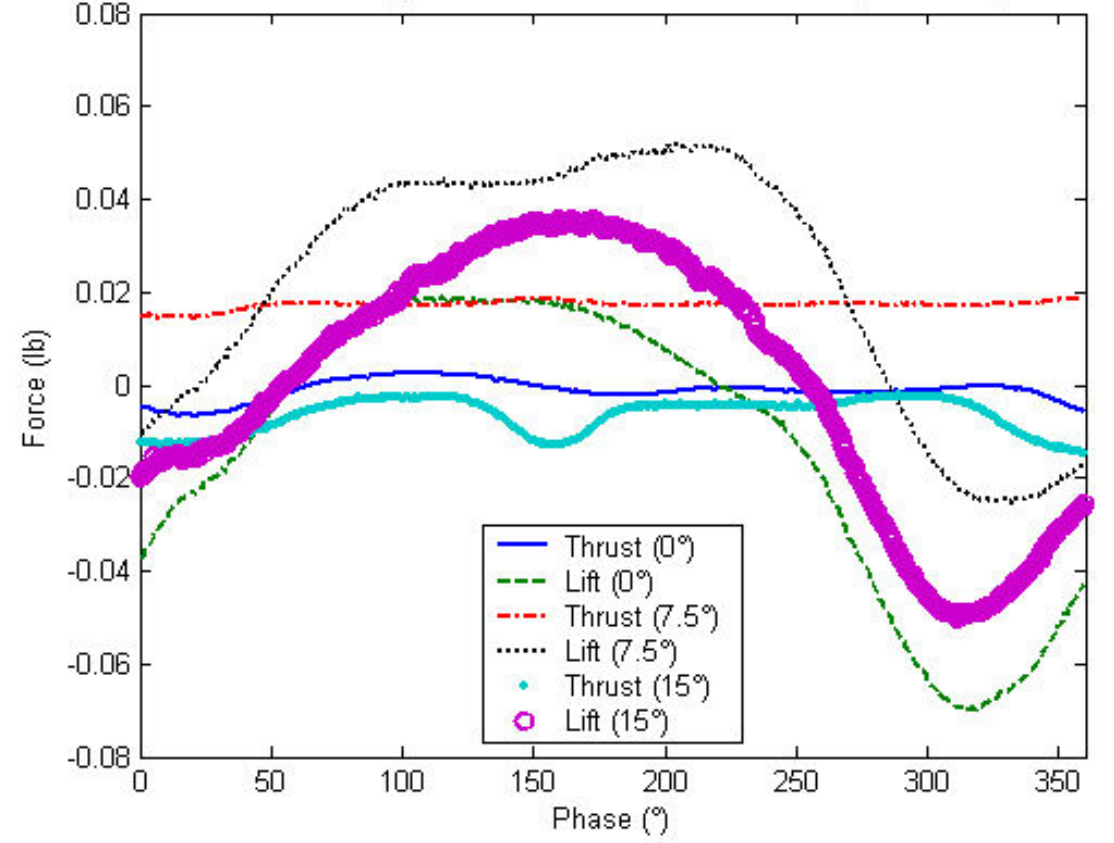

Figure B.12: Lift \& Thrust vs. Phase @ $5 \mathrm{~m} / \mathrm{s}, 4 \mathrm{~Hz}, \& 0^{\circ}, 7.5^{\circ} \& 15^{\circ} \mathrm{AoA}$ 


\section{REFERENCES}

[1] Ellington, C. P., "The Novel Aerodynamics of Insect Flight: Application to MicroAir-Vehicles," Journal of Experimental Biology, Vol. 202, No. 23, pp. 3439-3448, Dec. 1999.

[2] Ellington, Charles P., "Insects versus Birds: The Great Divide," $44^{\text {th }}$ AIAA Aerpspace Sciences Meeting and Exhibit, Reno, Nevada, Jan. 2006.

[3] Mueller, Thomas J., DeLaurier, James D., "Aerodynamics of Small Vehicles," Annu. Rev. Fluid Mech, Vol. 35, pp 89-111, 2003.

[4] Hong, Young Sun., Altman, Aaron., "An Experimental Study on Lift Force Generation Resulting from Spanwise Flow in Flapping Wings," $44^{\text {th }}$ AIAA Aerospace Sciences Meeting and Exhibit, Reno, Nevada. Sept. 2006.

[5] DeLaurier, James D., "The Development of a Full Scale Ornithopter Wing," The Aeronautical Journal of the Royal Aeronautical Society, May 1993.

[6] Pornsin-sirirak, T., Lee, S., Nassef, H., Grasmeyer, J., "MEMS Wing Technology for a Battery-Powered Ornithopter," 13th IEEE Annual International Conference on MEMS, Miyazaki, Japan, January 23-27, 2000.

[7] Viieru, Dragos., Tang, Jian., Lian, Yongsheng., Liu, Hao., Shyy, Wei., "Flapping and Flexible Wing Aerodynamics of Low Reynolds Number Flight Vehicles," $44^{\text {th }}$ AIAA Aerospace Sciences Meeting and Exhibit, Reno, Nevada. Sept. 2006.

[8] Ifju, P. G., Jenkins, A. D., Ettingers, S., Lian, Y., and Shyy, W., "Flexible-WingBased Micro Air Vehicles," 40 ${ }^{\text {th }}$ AIAA Aerospace Sciences Meeting and Exhibit, Reno, Nevada. Jan. 14-17, 2002.

[9] Ifju, Peter G., Stanford, Bret., Sytsma, Mike., "Analysis of a Flexible Wing Micro Air Vehicle," $25^{\text {th }}$ AIAA Aerodynamic Measurement Technology and Ground Testing Conference, San Francisco, California, June 5-8, 2006. 
[10] Unmanned Aerial Vehicles (UAVs) http://www.livingroom.org.au/uavblog/archives/dragon_eye_uav.php," 2003, Accessed May 2006.

[11] Naval Research Lab MITE (Micro Tactical Expendable), "http://www.designationsystems.net/dusrm/app4/mite.html," 2006, Accessed May 2006.

[12] UAV Forum, "http://www.uavforum.com/vehicles/developmental/blackwidow.htm," 2006, Accessed May 2006.

[13] Isaac, K. M., Colozza, Anthony., Rolwes, Jessica., Force Measurements on a Flapping and Pitching Wing at Low Reynolds Numbers," $44^{\text {th }}$ AIAA Aerospace Sciences Meeting and Exhibit, Reno, Nevada. Sept. 2006.

[14] McIntosh, Sean H., Agrawal, Sunil K., Khan, Zaeem., "Design of a Mechanism for Biaxial Rotation of a Wing for a Hovering Vehicle," IEEE/ASME Transactions of Mechatronics, Vol. 11, No. 2, April 2006.

[15] Pornsin-Sirirak, T. Nick., Tai, Yu-Chong., Ho, Chih-Ming., Keennon, Matt., "Microbat: A Palm-Sized Electrically Powered Ornithopter," NASA/JPL Workshop on Biomorphic Robotics, Pasadena, CA, 2001.

[16] DeLaurier, James D., Harris, Jeremy M., "A Study of Mechanical Flapping-Wing Flight," Aeronautical Journal, Oct. 1993.

[17] Liu, Tianshi., Kuykendoll, K., Rhew, R., Jones, S., "Avian Wing Geometry and Kinematics," AIAA Journal, Vol. 44, No. 5, May 2006.

[18] Nachtigall, W., Wieser, J., "Profilmessungen am Taubenflügel," Zeitschrift für Vergleichende Physiologies, Vol. 52, pp 333-346, 1966.

[19] Singh, Beerinder., Ramamasamy, Manikandan., Chopra, Inderjit., Leishman, J. Gordon., "Insect-Based Flapping Wings for Micro Hovering Air Vehicles: Experimental Investigations," American Helicopter Society International Specialists Meeting on Unmanned Rotorcraft, Arizona, Jan. 2004.

[20] Tian, Xiaodong., Iriate, Jose., Middleton, Kevin., Galvo, Ricardo., Israeli, Emily., Roemer, Abigail., Sullivan, Allyce., Song, Arnold., Swartz, Sharon., Breuer, 
Kenneth., "Direct Kinematics and Dynamics of Bat Flight," $36^{\text {th }}$ AIAA Fluid Dynamics Conference and Exhibit, San Francisco, California, June 508, 2006.

[21] Bird Identification Page, "http://www.michigan.gov/emergingdiseases/0,1607,7186-25805_25821-75725--,00.html," The State of Michigan, 2001-2005, Accessed June 2006.

[22] Vertebrate Flight, "http://www.ucmp.berkeley.edu/vertebrates/flight/bats.html," University of California, Berkeley, April 5, 2006, Accessed June 2006.

[23] Nicoud, Dean-D., Zufferey, Jean-C., “Towards Indoor Flying Robots,” IEEE/RSJ International Conference on Intelligent Robots and Systems, Lausanne, Switzerland, September 30

[24] Faulhaber Micromo, "www.micromo.com,” 2006, Accessed February 2006.

[25] Coleman, Hugh W., Steele, W. Glenn., "Experimentation and Uncertainty Analysis for Engineers, Second Edition," John Wiley and Sons, Inc, New York, 1999. 